Prepared in cooperation with the Bureau of Land Management

\title{
Multiscale Guidance and Tools for Implementing a Landscape Approach to Resource Management in the Bureau of Land Management
}

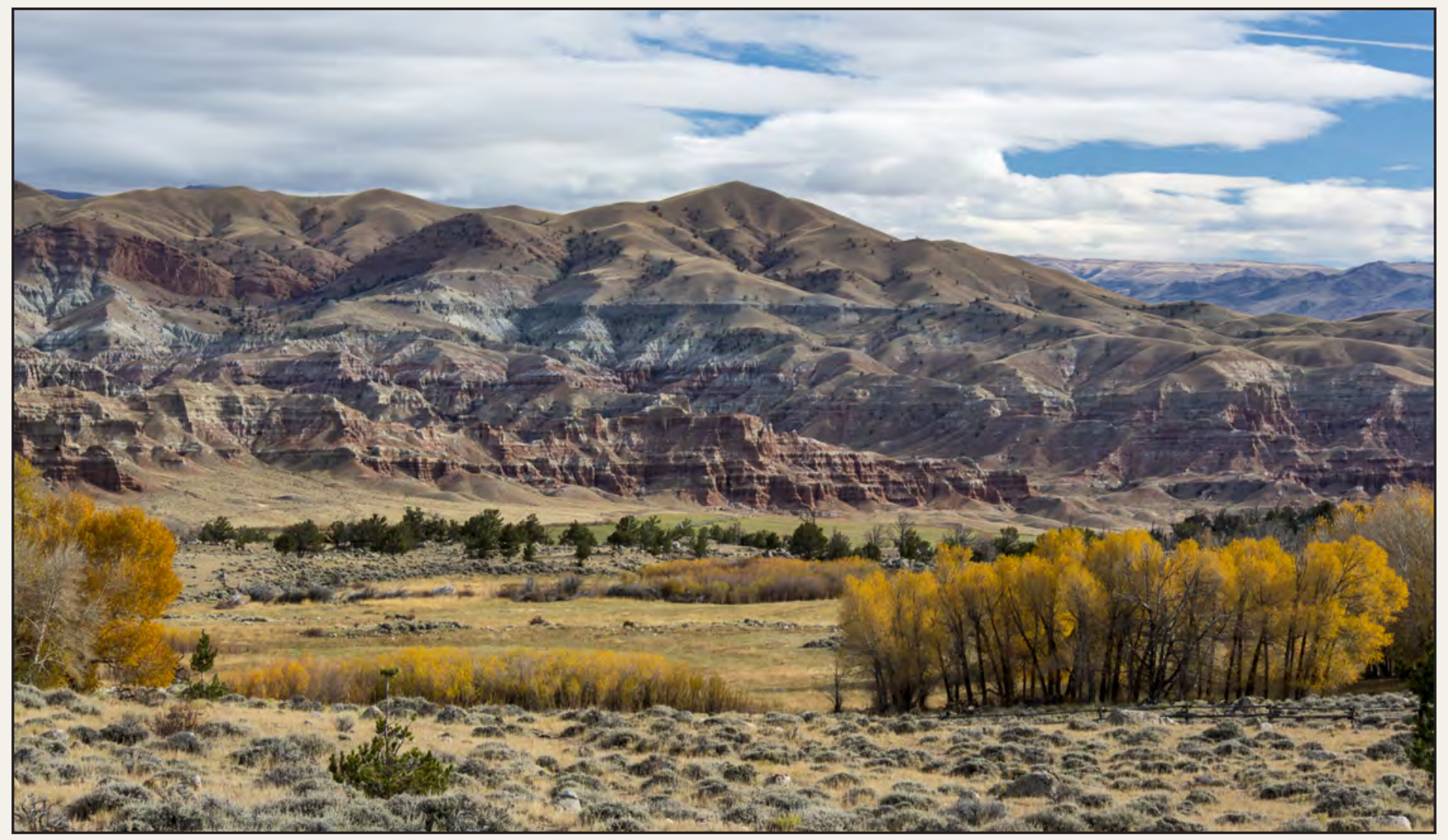

Open-File Report 2016-1207 
Cover. Dubois Badlands Wilderness Study Area, Wyoming. Photograph by Bob Wick, Bureau of Land Management. 


\section{Multiscale Guidance and Tools for Implementing a Landscape Approach to Resource Management in the Bureau of Land Management}

Edited by Sarah K. Carter, Natasha B. Carr, Kevin H. Miller, and David J.A. Wood

Chapter 1

Introduction

By Sarah K. Carter

\section{Chapter 2}

Understanding a Landscape Approach to Resource Management in the Bureau of Land Management

By Sarah K. Carter, Natasha B. Carr, Jena R. Hickey, Karla N. Rogers, and David J.A. Wood

Chapter 3

Including Broad-Scale Indicators in Multiscale Natural Resource

Montitoring and Assessment Programs in the Bureau of Land

Management

By David J.A. Wood, Sarah K. Carter, Sandra E. Litschert, and Natasha B. Carr

Chapter 4

Assessing Ecological Integrity Using Multiscale Information from Bureau of Land Management Assessment and Monitoring Programs By Sarah K. Carter, Natasha B. Carr, Curtis H. Flather, Erica Fleishman, Matthias Leu, Barry R. Noon, and David J.A. Wood

Chapter 5

A Multiscale Index of Landscape Intactness for Management of Public Lands

By Natasha B. Carr, Ian I.F. Leinwand, and David J.A. Wood

Prepared in cooperation with the Bureau of Land Management

Open-File Report 2016-1207

U.S. Department of the Interior

U.S. Geological Survey 


\section{U.S. Department of the Interior SALLY JEWELL, Secretary}

\section{U.S. Geological Survey Suzette M. Kimball, Director}

U.S. Geological Survey, Reston, Virginia: 2017

For more information on the USGS - the Federal source for science about the Earth, its natural and living resources, natural hazards, and the environment-visit http://www.usgs.gov or call 1-888-ASK-USGS.

For an overview of USGS information products, including maps, imagery, and publications, visit http://store.usgs.gov/.

Any use of trade, firm, or product names is for descriptive purposes only and does not imply endorsement by the U.S. Government.

Although this information product, for the most part, is in the public domain, it also may contain copyrighted materials as noted in the text. Permission to reproduce copyrighted items must be secured from the copyright owner.

Suggested citation:

Carter, S.K., Carr, N.B., Miller, K.H., and Wood, D.J.A., eds., 2017, Multiscale guidance and tools for implementing a landscape approach to resource management in the Bureau of Land Management: U.S. Geological Survey Open-File Report 2016-1207, 79 p., https://doi.org/10.3133/ofr20161207.

ISSN 0196-1497 (print)

ISSN 2331-1258 (online) 


\section{Contents}

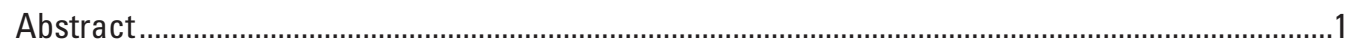

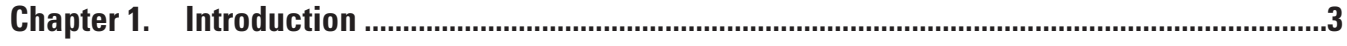

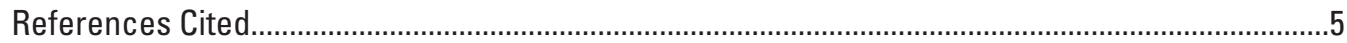

Chapter 2. Understanding a Landscape Approach to Resource Management in the Bureau of Land Management....................................................................................................

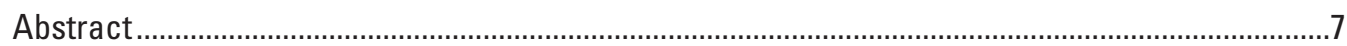

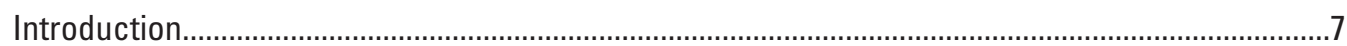

A Landscape Approach to Natural Resource Management...........................................................

Implementing a Landscape Approach to Natural Resource Management in the Bureau of Land Management .....................................................................................

Understanding Landscapes, Patterns, and Processes to Implement a Landscape Approach ...........................................................................................................

Considering Multiple Spatial Scales in Natural Resource Decisions.............................................12

Management Questions Across Spatial Scales .........................................................................13

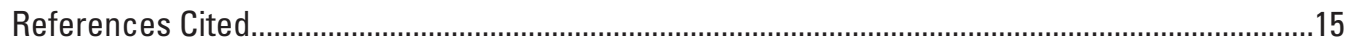

Chapter 3. Including Broad-Scale Indicators in Multiscale Natural Resource Monitoring and Assessment Programs in the Bureau of Land Management......................................19

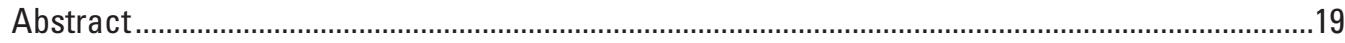

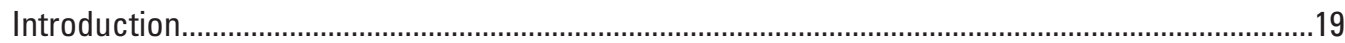

Integrating Rapid Ecoregional Assessments with the Assessment, Inventory,

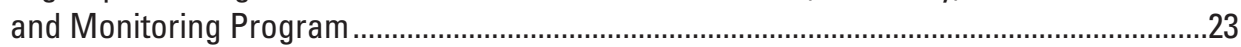

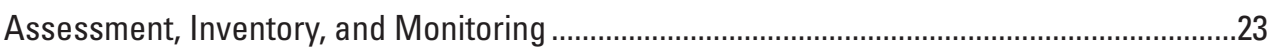

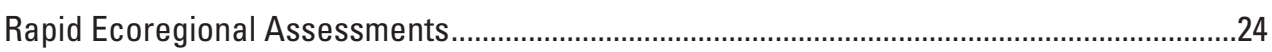

Development of Broad-Scale Indicators from Rapid Ecoregional Assessments ...........................25

A Process for Assessing Broad-Scale Indicators as part of Multiscale Monitoring Efforts..........26

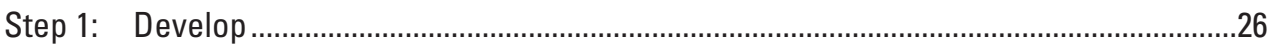

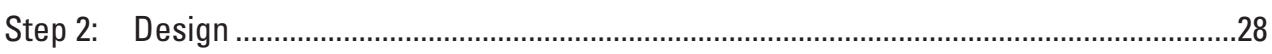

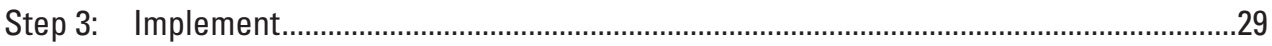

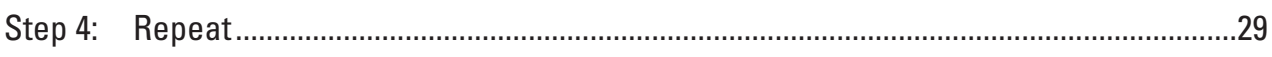

Using Broad-Scale Indicators to Inform Field Monitoring ..........................................................30

Integrating Local- and Broad-Scale Monitoring and Assessment Data to Inform Management Decisions ................................................................................

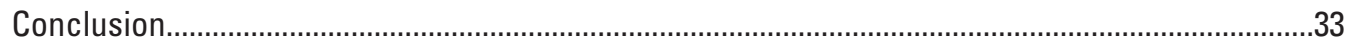

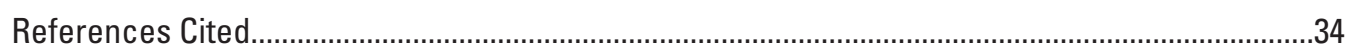

Chapter 4. Assessing Ecological Integrity Using Multiscale Information from Bureau of Land Management Assessment and Monitoring Programs .............................................39

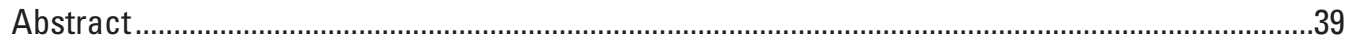

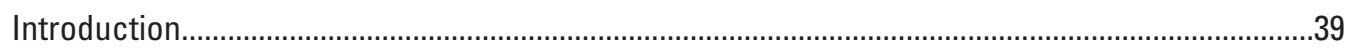

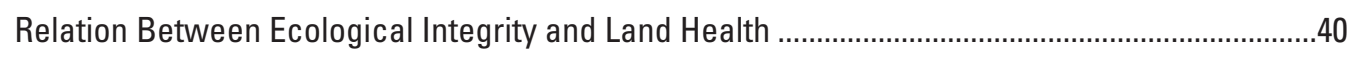

A Framework for Assessing Ecological Integrity Across Scales in Terrestrial Systems ................42 
Using the Framework to Assess Ecological Integrity on Rangelands Across the Western

United States.

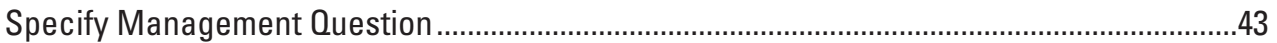

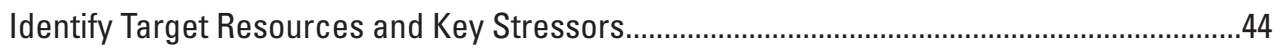

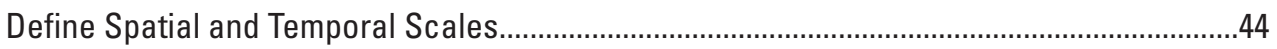

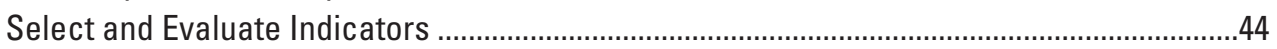

Define Natural and Acceptable Ranges

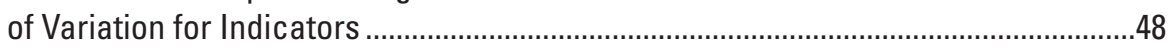

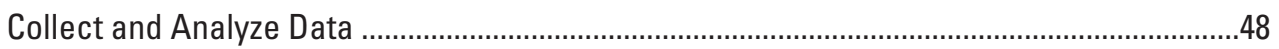

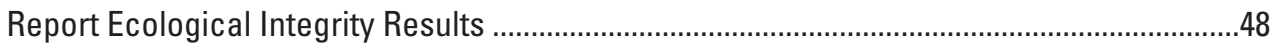

Use Assessment Results to Inform Management................................................................4

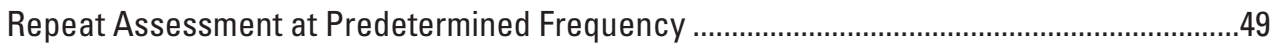

Using the Ecological Integrity Framework and Assessment Process to Facilitate Implementing

a Landscape Approach in the Bureau of Land Management.................................................49

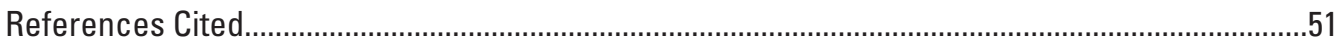

Chapter 5. A Multiscale Index of Landscape Intactness for Management of Public Lands......55

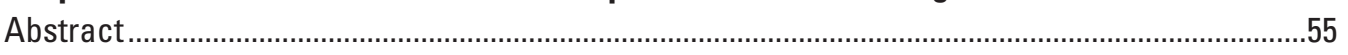

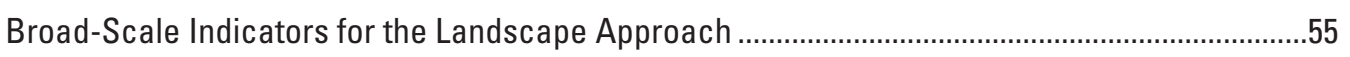

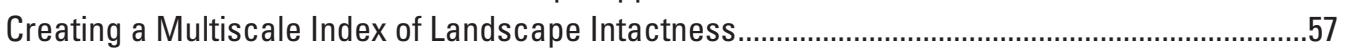

Measuring the Gradient of Anthropogenic Influence …….................................................57

Selection of Analysis Methods for Development.................................................................57

Selection of Scales of Analysis for Quantifying Development and Landscape Intactness .......58

Selection of Breakpoints for Calculating Landscape Intactness Level..................................59

Transparency and Interpretation of the Multiscale Index of Landscape Intactness..............60

Use of the Multiscale Index of Landscape Intactness to Address Management Questions .........61

1. How does landscape intactness vary across the ecoregions and ecological communities assessed for the REAs? ..........................................................................62

2. Where are the largest intact areas, and which land management agencies have primary responsibility for these areas? .................................................................64

3. How does intactness level vary by land ownership or jurisdiction? .................................64

4. What is the status of BLM lands on the basis of the multiscale index of landscape intactness, and how does this vary among field offices within an ecoregion?..........64

5. Where are the most intact areas managed by the BLM that are not protected as national conservation lands? ......................................................................................66

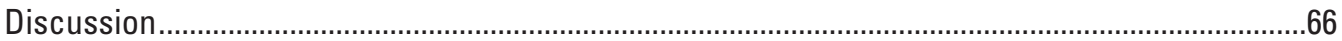

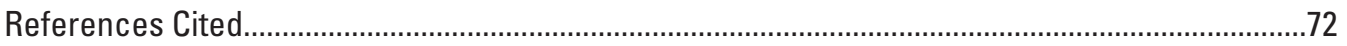

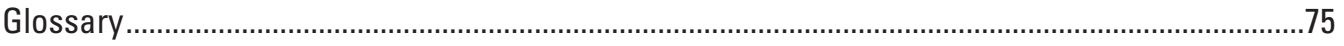

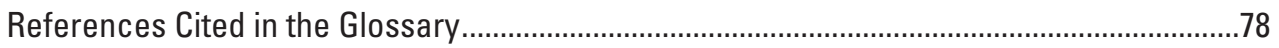

\section{Figures}

1-1. Major topics covered in subsequent chapters of this report, and their relations to implementation of a landscape approach to resource management in the Bureau of Land Management.

2-1. Key concepts and core principles of a landscape approach to resource management.

2-2. Male greater sage-grouse displaying on a lek (mating ground) near

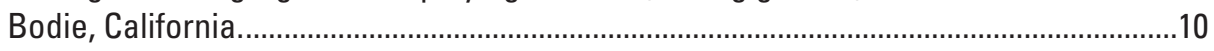

2-3. Oil and gas well-pad development in the Jonah Field near Pinedale, Wyoming.............11 
2-4. Example of a landscape hierarchy, illustrated using analyses of aspen vegetation

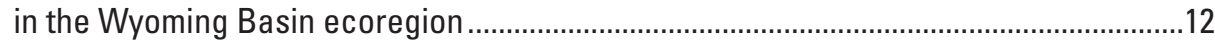

2-5. Pronghorn (Antilocapra americana) make use of a wildlife highway overpass at Trappers Point, Wyoming.....

3-1. Conceptual model of the ecosystem components monitored by the BLM Assessment, Inventory, and Monitoring program.

3-2. Example landscape condition analysis from the Mojave Basin and Range Rapid Ecoregional Assessment.

3-3. Example of indicators for sagebrush steppe for the Wyoming Basin Rapid Ecoregional Assessment

3-4. Steps in assessing broad-scale indicators of natural resource status and condition as part of a multiscale monitoring program.

3-5. Grassland conceptual model for the Northwestern Plains ecoregion

3-6. Potential ways in which broad-scale assessments may inform field monitoring efforts at each stage in the assessment process.

4-1. Conceptual framework for quantifying ecological integrity, with example ecological attributes for each level in the hierarchy and component of integrity.

4-2. Steps for assessing ecological integrity, which are consistent with the broader AIM process

4-3. Conceptual model highlighting the major ecological drivers and anthropogenic stressors affecting shortgrass prairies in the Southern Great Plains ecoregion

4-4. Bureau of Land Management Rapid Ecoregional Assessments that are in progress or have been completed across the western conterminous United States . .46

5-1. Examples of the cumulative direct and indirect ecological effects of development as a function of the surface disturbance footprint resulting from development .............56

5-2. Terrestrial development index score and the associated surface disturbance footprint from development for two landscapes in Wyoming

5-3. The terrestrial development index at two analysis scales .61

5-4. The level of landscape intactness as derived from terrestrial development index classes at two scales (2.5 and 20 -kilometer radius moving window).

5-5. Overview of the process model used to create the multiscale index of landscape intactness.

5-6. Landscape intactness for the western U.S. Intactness levels were derived from terrestrial development index classes using a 2.5- and 20.0-kilometer radius moving window

5-7. Multiscale index of landscape intactness and associated terrestrial development index for two landscapes in New Mexico

5-8. Levels of landscape intactness by ecoregion, assessed as a part of the Rapid Ecoregional Assessment program for the western U.S. Intactness levels were derived from the terrestrial development index for 2.5- and 20.0-kilometer radius moving windows

5-9. Size of patches with the highest and very high levels of landscape intactness for the western United States.

5-10. Size classes of patches on federal lands with the highest or very high landscape intactness levels, summarized by agency

5-11. Levels of landscape intactness by land ownership or jurisdiction for the entire western United States

5-12. Levels of landscape Intactness for lands managed by the Bureau of Land Management. 
5-13. Levels of landscape intactness for lands managed by the Bureau of Land Management in Wyoming.....

5-14. Levels of landscape intactness for lands that fall within the jurisdiction of the Bureau of Land Management field office boundaries in the Wyoming Basin Ecoregion. .70

5-15. Lands managed by the Bureau of Land Management with the highest levels of landscape intactness that are not protected as national conservation lands. .71

\section{Box Figures}

1-1. Vegetation Condition Class in the Middle Rockies Rapid Ecoregional Assessment boundary, Dillon field office, and Centennial watershed

1-2. Percent area in each Vegetation Condition Class within the Middle Rockies Rapid Ecoregional Assessment boundary, Dillon field office, and Centennial Watershed ...........23

2-1. $\quad A$ and $C$, Current (2015) and $B$ and $D$, future (2025-2030) landscape condition for the San Luis Valley-Taos Plateau Landscape Assessment

2-2. Evaluation of current and projected future landscape condition of grasslands and shrublands in the San Luis Valley-Taos Plateau ecoregion.

\section{Tables}

2-1. Bureau of Land Management administrative units, management decisions, and ecological processes and patterns across a range of spatial extents

3-1. Potential core, supplemental, and derived broad-scale indicators of natural resource status and condition

4-1. Proposed indicators, the spatial extent at which they are assessed (local or regional), and example reference conditions for quantifying the compositional, structural, and functional components of ecological integrity on rangelands across the western United States

4-2. One model for presenting results of an ecological integrity assessment for rangelands across the western United States

5-1. Data sources used to quantify the surface disturbance footprint from development........58

5-2. Buffer sizes for creating the surface disturbance footprint from development for linear and point features

5-3. Landscape intactness of Bureau of Land Management lands derived from two analysis scales across the western U.S.

5-4. Hierarchy of datasets included in the multiscale index of landscape intactness...........64 


\section{Contributing Authors and Editors}

Natasha B. Carr

U.S. Geological Survey, Fort Collins Science Center, Fort Collins, Colo.

Sarah K. Carter

U.S. Geological Survey, Fort Collins Science Center, Fort Collins, Colo.

Curtis H. Flather

U.S. Department of Agriculture Forest Service, Rocky Mountain Research Station, Fort Collins, Colo.

Erica Fleishman

University of California - Davis, John Muir Institute of the Environment, Davis, Calif.

(currently: Colorado State University, Center for Environmental Management of Military Lands and Department of Fish, Wildlife, and Conservation Biology, Fort Collins, Colo.)

Jena R. Hickey

Wyoming Cooperative Fish and Wildlife Research Unit, Department of Zoology and Physiology, University of Wyoming, Laramie, Wyo., in cooperation with U.S. Geological Survey, Fort Collins Science Center, Fort Collins, Colo. (currently: International Gorilla Conservation Programme, Musanze, Rwanda)

Ian I.F. Leinwand

Cherokee Nation Technologies, on contract to U.S. Geological Survey, Fort Collins Science

Center, Fort Collins, Colo.

Matthias Leu

College of William and Mary, Biology Department, Williamsburg, Va.

Sandra (Sam) E. Litschert

Quantum Spatial, on contract to Bureau of Land Management, National Operations Center, Denver, Colo.

Kevin H. Miller

Bureau of Land Management, National Operations Center, Denver, Colo.

Barry R. Noon

Department of Fish, Wildlife and Conservation Biology, Colorado State University, Fort Collins, Colo.

Karla N. Rogers

Bureau of Land Management, National Operations Center, Denver, Colo.

Leroy J. Walston

Argonne National Laboratory, Argonne, III.

David J.A. Wood

Bureau of Land Management, National Operations Center, Denver, Colo., and Montana State Office, Billings, Mont. (currently: U.S. Geological Survey, Northern Rocky Mountain Science Center, Bozeman, Mont.) 


\section{Acknowledgments}

We are grateful to numerous reviewers for providing valuable insights and suggestions on an earlier draft of the report. Reviewers from the U.S. Geological Survey included Pat Anderson, Tim Assal, Greg Auble, Dan Manier, and Mark Vandever from the Fort Collins Science Center; Sue Phillips, David Pilliod, and Doug Schinneman from the Forest and Rangeland Ecosystem Science Center; and Todd Esque from the Western Ecological Research Center. Reviewers from the Bureau of Land Management included Tim Bottomley, Chris Cole, Melissa Dickard, Emily Kachergis, Sherm Karl, Elroy Masters, Ron McCormick, Robert Means, Stephanie Miller, Kit Muller, Anthony Titolo, John Wilson, and Chris Woodward. Additional reviewers included Sean Finn from the Great Northern Landscape Conservation Cooperative, Jason Taylor from the National Park Service, and Leroy Walston from Argonne National Laboratory. We also thank Lucy Burris (U.S. Geological Survey Fort Collins Science Center) for assistance with preparing maps and figures. 


\section{Conversion Factors}

Inch/Pound to International System of Units

\begin{tabular}{lll}
\hline Multiply & By & To obtain \\
\hline foot (ft) & Length & meter (m) \\
mile (mi) & 0.3048 & kilometer (km) \\
& 1.609 & hectare (ha) \\
\hline
\end{tabular}

\section{Abbreviations}

$\begin{array}{ll}\text { AIM } & \text { Assessment, Inventory, and Monitoring (a Bureau of Land Management program) } \\ \text { BLM } & \text { Bureau of Land Management } \\ \text { LANDFIRE } & \text { Landscape Fire and Resource Management Planning Tools Project } \\ \text { NEPA } & \text { National Environmental Policy Act of } 1969 \\ \text { REA } & \text { Rapid Ecoregional Assessment } \\ \text { RMP } & \text { Resource Management Plan } \\ \text { SEZ } & \text { Solar Energy Zone } \\ \text { TDI } & \text { Terrestrial development index } \\ \text { USDA } & \text { U.S. Department of Agriculture } \\ \text { USGS } & \text { U.S. Geological Survey }\end{array}$





\title{
Multiscale Guidance and Tools for Implementing a Landscape Approach to Resource Management in the Bureau of Land Management
}

\author{
Edited by Sarah K. Carter, Natasha B. Carr, Kevin H. Miller, and David J.A. Wood
}

\section{Abstract}

The Bureau of Land Management (BLM) is implementing a landscape approach to resource management (hereafter, landscape approach) to more effectively work with partners and understand the effects of management decisions. A landscape approach is a set of concepts and principles used to guide resource management when multiple stakeholders are involved and goals include diverse and sustainable social, environmental, and economic outcomes. Core principles of a landscape approach include seeking meaningful participation of diverse stakeholders, considering diverse resource values in multifunctional landscapes, acknowledging the tradeoffs needed to meet diverse objectives in the context of sustainable resource management, and addressing the complexity of social and ecological processes by embracing interdisciplinarity and considering multiple and broad spatial and temporal perspectives.

In chapter 1, we outline the overall goal of this report: to provide a conceptual foundation and framework for implementing a landscape approach to resource management in the BLM, focusing on the role of multiscale natural resource monitoring and assessment information. In chapter 2, we describe a landscape approach to resource management. BLM actions taken to implement a landscape approach include a major effort to compile broad-scale data on natural resource status and condition across much of the west. These broadscale data now provide a regional context for interpreting monitoring data collected at individual sites and informing decisions made for local projects. We also illustrate the utility of using multiscale data to understand potential effects of different resource management decisions, define relevant terms in landscape ecology, and identify spatial scales at which planning and management decisions may be evaluated.

In chapter 3, we describe how the BLM Rapid Ecoregional Assessment program and Assessment, Inventory and Monitoring program may be integrated to provide the multiscale monitoring data needed to inform a landscape approach. We propose six core, broad-scale indicators of natural resource status and condition: the amount, spatial distribution, patch size and connectivity of ecosystems and wildlife habitats, and the pattern of existing development across the landscape. Additional supplemental broad-scale indicators may include fire return intervals, distributions of invasive species, and vulnerability of ecosystems to a changing climate. Landscape intactness is an additional derived indicator that is calculated from one or more of the core and supplemental broad-scale indicators. We then outline a process for assessing broad-scale indicators that is consistent with the overall BLM Assessment, Inventory, and Monitoring process, facilitating development of a multiscale natural resource monitoring program. Finally, we describe how broad-scale indicators of natural resource status and condition may guide field monitoring implemented through the BLM Assessment, Inventory and Monitoring program and help address complex management questions.

In chapter 4, we consider the specific question of assessing the ecological integrity of rangelands across the western United States. We first define ecological integrity and its relation to land health. We then suggest that a combination of six local-scale indicators collected through field sampling at individual sites and five complementary broad-scale indicators together provide information on the composition, structure, and function of rangelands. The terrestrial monitoring indicators collected at the level of individual field sites are the amount of bare ground, vegetation composition (including invasive plants and plants of management concern), vegetation height, and the proportion of the soil surface in large intercanopy gaps. The broad-scale indicators are vegetation amount, distribution, patch size, connectivity, and productivity, along with the pattern of terrestrial development. Our suggested approach to quantifying ecological integrity focuses specifically on informing management of public lands for multiple resource uses, and illustrates how existing data collected through BLM monitoring and assessment programs may be used together to provide multiscale information on land condition across broad extents. 


\section{Multiscale Guidance and Tools for Implementing a Landscape Approach in the Bureau of Land Management}

In chapter 5 , we develop a method for quantifying landscape intactness and apply this method to the western United States. Our multiscale index of landscape intactness is designed to be defensible, decomposable, and easy to understand. The foundation of the multiscale index of landscape intactness is the surface disturbance footprint of anthropogenic development, including energy and urban development, roads and railroads, cultivated croplands, surface mines and quarries, and energy transmission lines and pipelines. The index represents a gradient of anthropogenic influence as represented by development summarized at two spatial scales of analysis: 2.5 and 20 kilometers. We provide several example applications of the index, illustrating how these data may inform natural resource decisions at the spatial extent of BLM field and district offices, states, ecoregions, and the western United States. We find that 19.2 percent of lands managed by the BLM across the 17 western states of the conterminous United States had the highest landscape intactness. The largest intact areas occur on public lands at high elevations or in the Great Basin.

We believe the frameworks, processes, and analyses provided in this report will improve the ability of the BLM to identify and evaluate potential direct and indirect effects of management actions (such as habitat restoration and renewable energy development), and assist the BLM in further implementing a landscape approach to resource management. 


\title{
Chapter 1. Introduction
}

\author{
By Sarah K. Carter
}

The Bureau of Land Management (BLM) manages 246 million acres (100 million hectares) of public lands across the United States (Bureau of Land Management, 2015c), with a goal of accommodating multiple uses and achieving sustained yield while protecting the scientific, scenic, historic, ecological, environmental, air and atmospheric, water resource, and archeological values of the lands (Federal Land Policy and Management Act of 1976 [43 USC §1701]). Effective management of multiple-use lands requires strategies to balance different resource objectives and key pieces of information to inform those strategies.

The purpose of this report is to describe a landscape approach to natural resource management (hereafter, landscape approach), a strategy that may be used to help achieve multiple and potentially conflicting resource objectives across broad landscapes (chapter 2). Implementing a landscape approach requires, among other things, monitoring the status and condition of natural resources across broad landscapes and understanding the potential effects of management decisions across multiple spatial scales. In subsequent chapters, we present data, methods, and analyses to inform implementation of a landscape approach by the BLM (chapters 3-5) (fig. 1-1).

The report seeks to provide a conceptual foundation and framework for BLM implementation of a landscape approach to resource management. Our focus is on the role of multiscale natural resource monitoring and assessment information, and on how such information may be used to help managers and stakeholders better understand the status and condition of lands managed by the BLM, the potential effects of different management decisions on those lands, and the tradeoffs involved in managing lands to provide multiple services to the American public. The processes we describe (for example, for quantifying broad-scale indicators and assessing ecological integrity) are purposefully consistent with the overall BLM Assessment, Inventory, and Monitoring (AIM) process (Taylor and others, 2014). As such, the report highlights key opportunities for integrating local- and broad-scale monitoring efforts within the agency's existing monitoring framework and facilitating the use of multiscale natural resource assessments to inform BLM planning and management actions.
Throughout the report, we focus on ecological objectives of public land management by the BLM, with the knowledge that tools and analyses for achieving social and economic objectives are also crucial for effective management of multiple-use lands. The report presents terrestrial systems and examples, but many of the principles and methods described are also applicable to and useful for management of aquatic systems.

Although the report describes the application of approaches and analyses to management of public lands by the BLM, the information presented may be useful to other agencies and organizations that manage public lands and protected areas to meet multiple resource goals. Potential audiences include the U.S. Department of Agriculture Forest Service, U.S. Fish and Wildlife Service, National Park Service, State fish and wildlife agencies, local governments, and nongovernmental organizations.

The Department of the Interior has recently developed a strategy for improving mitigation policies and practices (Clements and others, 2014). The BLM is working to promote effective science integration in all BLM decisions and actions (Bureau of Land Management, 2015a). The BLM is also implementing a major new planning initiative, Planning 2.0, as part of their implementation of a landscape approach (Bureau of Land Management, 2015b). The information in this report supports objectives of all three efforts by providing scientific information, data, and analyses to help resource managers shift from project-level management toward landscape-level, science-based management that more effectively avoids, minimizes, and compensates for adverse effects of development on natural resources. The report also provides a potential framework for the resource assessments that are foundational to Planning 2.0, facilitating assessment of the significance and cumulative effects of potential planning and management actions at spatial extents from field offices to ecoregions. These resource assessments may help identify management priorities in light of widespread management challenges such as continuing development, more frequent and intense wildfires, and a changing climate. 


\section{Multiscale Guidance and Tools for Implementing a Landscape Approach to Resource Management in the Bureau of Land Management}

Chapter 2. Understanding a landscape approach to resource management in the Bureau of Land Management

- Describe a landscape approach to resource management.

- Summarize initial efforts by the Bureau of Land Management (BLM) to implement a landscape approach.

- Explain the importance of scale in understanding effects of a management actions on natural resources.

- Illustrate the utility of multiscale information for answering BLM resource management questions.

A landscape approach to resource management is a widely used strategy for achieving multiple resource objectives across landscapes.

Chapter 3. Including broad-scale indicators in multiscale natural resource monitoring and assessment programs in the Bureau of Land Management

- Describe BLM assessment and monitoring programs.

- Propose core, supplemental, and derived broad-scale indicators of natural resource status and condition.

- Present a process for assessing broad-scale indicators as part of a comprehensive monitoring program.

- Outline the utility of broad-scale indicators for informing field monitoring efforts and answering BLM management questions.

A participatory, accessible monitoring program that provides multiscale natural resource information is key to implementing a landscape approach.

\section{Chapter 4. Assessing ecological integrity using multiscale information form Bureau of Land Management} assessment and monitoring programs.

- Describe ecological integrity and its relation to land health.

- Present a framework and process for quantifying ecological integrity in terrestrial systems.

- Outline how existing BLM assessment and monitoring data may be used to quantify ecological integrity on rangelands across the western United States.

Multiscale monitoring and assessments allow managers to assess ecological integrity and identify tradeoffs inherent in multiple-use management, another core component of a landscape approach.

\section{Chapter 5. A multiscale index of landscape intactness for management of public lands}

- Present a method for quantifying landscape intactness in terrestrial systems.

- Quantify landscape intactness across the western United States.

- Illustrate the utility of a multiscale index of landscape intactness for informing BLM management questions.

A multiscale index of landscape intactness allows managers to focus on broad-scale threats to target resources, another core component of a landscape approach.

Figure 1-1. Major topics covered in subsequent chapters of this report, and their relations to implementation of a landscape approach to resource management in the Bureau of Land Management. 


\section{References Cited}

Bureau of Land Management, 2015a, Advancing science in the BLM: An implementation strategy: Bureau of Land Management, accessed June 2, 2015, at http://www.blm.gov/ style/medialib/blm/wo/blm_library/BLM_pubs.Par.38337. File.dat/BLMAdvSciImpStratFINAL032515.pdf.

Bureau of Land Management, 2015b, Planning 2.0: Improving the way we plan together: accessed April 14, 2015, at http:// www.blm.gov/wo/st/en/prog/planning/planning_overview/ planning_2_0.html.

Bureau of Land Management, 2015c, Public land statistics: Bureau of Land Management, accessed February 21, 2016, at http://www.blm.gov/public_land_statistics/pls14/pls2014.pdf.
Clement, J.P., Belin, A.d'A., Bean, M.J., Boling, T.A., and Lyons, J.R., 2014, A strategy for improving the mitigation policies and practices of the Department of the Interior: Washington, D.C., Energy and Climate Change Task Force, accessed October 12, 2016, at https://www.doi.gov/sites/ files/migrated/news/upload/Mitigation-Report-to-theSecretary_FINAL_04_08_14.pdf.

Taylor, Jason, Kachergis, Emily, Toevs, Gordon, Karl, Jason, Bobo, Matthew, Karl, Michael, Miller, Scott, and Spurrier, Carol, 2014, AIM-Monitoring: A component of the BLM Assessment, Inventory, and Monitoring Strategy: Denver, Colo., U.S. Department of the Interior, Bureau of Land Management, National Operations Center: accessed June 18, 2015, at http://www.blm.gov/style/medialib/blm/ wo/blm_library/tech_notes.Par.24137.File.dat/TN_445.pdf. 



\title{
Chapter 2. Understanding a Landscape Approach to Resource Management in the Bureau of Land Management
}

\author{
By Sarah K. Carter, Natasha B. Carr, Jena R. Hickey, Karla N. Rogers, and David J.A. Wood
}

\section{Abstract}

The Bureau of Land Management (BLM) has adopted a landscape approach to natural resource management (hereafter, landscape approach) on lands the agency manages. A landscape approach is a set of concepts and principles that guide resource management when multiple stakeholders are involved and goals include diverse and sustainable social, environmental, and economic outcomes. Core principles of a landscape approach include meaningful participation of diverse stakeholders, considering diverse resource values in multifunctional landscapes, acknowledging tradeoffs needed to meet diverse resource objectives, and addressing the complexity of the social and ecological processes involved by embracing interdisciplinarity and considering multiple and broad spatial and temporal perspectives. When considering the potential effects of actions such as habitat restoration and renewable energy development, data gathered at both local and broad scales help managers to evaluate direct and indirect effects of the action, including the potential significance of effects on regional plant or wildlife populations. The initial emphasis of the BLM in implementing a landscape approach has been on developing a coordinated nationwide field monitoring effort, filling in data gaps at the broad scale in its biophysical programs, and using the resulting information to inform regional planning and management efforts. Two priority areas for future work are developing data and approaches to integrate socioeconomic, recreational, cultural, visual, and historic resource values into BLM planning for large areas, and fostering greater collaboration with stakeholders across broader extents.

\section{Introduction}

In the United States, 640 million acres (259 million hectares) of public lands ( 28 percent of the Nation's total area) are managed by the Federal Government (Gorte and others, 2012). The Bureau of Land Management (BLM) manages 246 million acres (100 million hectares), which is more land than any other Federal agency (Bureau of Land Management, 2015f). Lands managed by the BLM harbor key timber and energy reserves, products used on a subsistence and commercial basis, places for recreating and experiencing natural scenery, sanctuaries of culture and traditional customs, habitat for rare and game species, and many other resources. Central to the mission of the BLM is managing public lands for multiple uses and sustained yield while protecting the scientific, scenic, historic, ecological, environmental, air, atmospheric, archeological, and water resources and values of the lands (The Federal Land Policy and Management Act of 1976 [43 USC §1701]).

Managing lands for multiple uses is not unique to the BLM. The U.S. Department of Agriculture Forest Service also operates under an explicit, multiple-use mandate (MultipleUse Sustained-Yield Act of 1960 [16 USC §528]). In addition, nearly all other land management agencies and organizations face the challenge of balancing different land uses and values. Most protected areas and public lands have been and will continue to be affected by people (Radeloff and others, 2010; Theobald, 2013) and are managed by agencies and organizations whose missions involve balancing conservation with recreation, education, historical preservation and other uses (for example, National Park Service Organic Act of 1916 [16 USC §1]; U.S. Department of Defense, 2011).

\section{Landscapes are large areas encompassing an interacting mosaic of ecosystems and human systems that are characterized by a set of common management concerns (Clement and others, 2014).}

Effective management of multiple-use lands requires strategies that consider resource patterns and uses across broad scales to inform management in the face of changing demographics, a changing climate, and other challenges (U.S. Department of the Interior, 2014). In this chapter, we describe one such strategya landscape approach to natural resource management (sensu Sayer, 2009; Sayer and others, 2013; Freeman and others, 2015; hereafter, landscape approach) as presented in the published literature. We focus on the importance of a multiscale perspective in natural resource monitoring, planning, and management activities. We define relevant terms in landscape ecology and identify spatial scales at which different planning and management decisions may be evaluated. We then consider the types of management questions that may be asked at different spatial scales, provide examples of the utility of multiscale information for answering these questions, and outline the initial efforts of the BLM to implement a landscape approach. 


\section{A Landscape Approach to Natural Resource Management}

The mission of the BLM is to sustain the health, diversity, and productivity of public lands for the use and enjoyment of present and future generations. Sustaining the health and diversity of public lands includes consideration of the upland, riparian, wetland, and aquatic components of watersheds; diverse ecological processes; water quality; and habitat for species of conservation concern (43 CFR 4180.1). Sustaining productivity of public lands may include sustaining productive rangelands that provide forage for wildlife and domestic livestock, sustaining forests that provide harvestable timber, and sustaining production of renewable and nonrenewable energy. A landscape approach is a set of concepts and principles used to guide resource management when multiple stakeholders are involved and goals include diverse and sustainable social, environmental, and economic outcomes within and across landscapes (Sayer, 2009; Sayer and others, 2013, Freeman and others, 2015).

Resource management decisions occur in the context of dynamic landscapes, diverse constituencies, and significant uncertainties about future environmental and social conditions (Sayer, 2009; Sayer and others, 2013). Seeking broad participation, understanding multifunctionality, acknowledging complexity, embracing interdisciplinarity, and striving to achieve sustainability are concepts critical to addressing such challenges, and are the foundation of a landscape approach (fig. 2-1). Core principles of a landscape approach that embody these concepts include seeking meaningful participation of diverse stakeholders, collecting and considering information at multiple and broad spatial and temporal scales to better understand complex social and ecological processes in multifunctional landscapes, and using adaptive management (Sayer and others, 2013; Freeman and others, 2015; fig. 2-1). When a landscape approach is used, stakeholders work collaboratively to set goals, implement actions, and monitor outcomes to assess whether goals are being met (Sayer, 2009; Sayer and others, 2013).

Using a landscape approach requires explicitly acknowledging diverse values and perspectives of stakeholders and the need to balance tradeoffs among different and often conflicting land uses (Sayer and others, 2013; Freeman and others, 2015). Energy development and wildlife conservation are examples of land uses that often conflict but are essential to meeting multiple-use objectives on lands managed by the BLM (Skillen, 2009; Sawyer and others, 2009a; Copeland and others, 2014). Considering multiple spatial and temporal scales is necessary to understand the complex, interacting, and multiscale nature of social and ecological drivers and processes (Lindenmayer and others, 2008; Sayer and others, 2013). A landscape approach also focuses on managing for system resilience by assessing threats and vulnerabilities to key resources, including cumulative effects across time and space (Lindenmayer and others, 2008; Sayer and others, 2013; Reed and others, 2014). Participatory monitoring programs in which the resulting data are understandable and accessible to all stakeholders foster inclusiveness, transparency, and a collective interest in measuring progress (Sayer and others, 2013).

Successfully implementing a landscape approach also requires a strong, long-term commitment to a participatory, interdisciplinary, and adaptive process to address the complexity of the problem and increase the likelihood of achieving diverse objectives across the landscape (Freeman and others, 2015). Beginning by addressing simpler issues of concern to multiple stakeholders helps build momentum and trust in the process (Sayer and others, 2013). Building stakeholder capacity helps to ensure adequate, effective and continued participation (Sayer and others, 2013; Reed and others, 2016). A fair, transparent, and inclusive process for making decisions in which the responsibilities of all stakeholders are clear is crucial for resolving conflicts (Sayer and others, 2013). Strong leadership and governance policies, effective facilitation, and adequate human and financial resources are critical for success (Sayer and others, 2015, Sunderland and others, 2015). Exploring scenarios associated with different objectives and actions helps stakeholders understand potential tradeoffs (Polasky and others, 2008) and identify solutions with the broadest support (Sayer, 2009). A commitment to monitoring specific metrics agreed upon by the group may identify to what extent progress is being made toward achieving objectives and inform adaptive management actions (Sayer and others, 2015, Reed and others, 2016).

In practice, a landscape approach may be implemented as a continuum ranging from simply adopting a broad spatial perspective, to an intermediate level that considers only one or a few resource objectives, to the more comprehensive, integrated landscape approach that we describe here (Freeman and others, 2015). As one moves along the continuum toward a more integrated (and complex) approach, greater levels of commitment to the underlying concepts of participation and interdisciplinarity are required. Correspondingly stronger commitments are also needed to adaptive management processes that address the complexity of the problems and increase the likelihood of achieving diverse and sustainable resource objectives and uses (Freeman and others, 2015).

\section{Implementing a Landscape Approach to Natural Resource Management in the Bureau of Land Management}

Many principles of a landscape approach have been used in management of all Federal lands for decades. For example, the National Environmental Policy Act (NEPA) of 1969 (42 U.S.C. §4321) established a process for making decisions 


\section{Core principles of a landscape} approach to resource management:

Meaningful involvement of diverse stakeholders

- Involve multiple, diverse stakeholders

- Work to strengthen stakeholder capacity

- Clearly identify rights and responsibilities of stakeholders

- Establish a negotiated and transparent process for making decisions

- Find immediate ways forward and build stakeholder trust by focusing first on issues of common concern to all stakeholders

\section{Accessible, multiscale information on multiple resources}

- Explicitly acknowledge the tradeoffs among resource values and uses that are required to achieve resource goals in multifunctional landscapes

- Consider multiple spatial and temporal scales, reflecting the complexity of ecological and management systems and processes

- Develop a participatory, accessible monitoring program

- Focus on system resilience, including threats to and vulnerabilities of key resources

\section{Continual learning and adaptive management}

- Use adaptive management

Figure 2-1. Key concepts (in outer ring) and core principles (in colored ovals and rectangles) of a landscape approach to resource management (Sayer and others, 2013; Freeman and others, 2015). This report focuses on the four principles listed under the heading, "Accessible, multiscale information on multiple resources."

regarding development on Federal lands and defined clear participatory rights and responsibilities of the public and other stakeholders in the process. Goals of NEPA include preventing and eliminating damage to the environment while stimulating human health and welfare (42 U.S.C. §4321, Section 101). NEPA requires Federal agencies to inform other affected agencies and the public of the environmental effects of and alternatives to major Federal actions significantly affecting the environment. Federal agencies must consider and provide multiple opportunities for public input throughout this process (Bureau of Land Management, 2008). The NEPA process is an important mechanism for achieving open and transparent decisions in the Federal Government (for example, Smith, 2007; Skillen, 2009), but it is also a common source of conflict and lawsuits for the BLM and other Federal agencies (Canter and Clark, 1997; Skillen, 2009).
The BLM also has decades of experience in engaging stakeholders, generating and managing information, and integrating resource management decisions across social, economic, and renewable and non-renewable resource programs. These activities have typically occurred at the spatial extents where resource decisions are often made in the agency (for example, the boundaries of resource management plans or field offices, or smaller areas within these boundaries). With the advent of increasingly complex and widespread challenges such as managing wildfires across extensive sagebrush landscapes and addressing the effects of climate change, there is a need to manage systems across even broader spatial extents. Such challenges have prompted the BLM to build on prior broad-scale planning and management efforts (Bracke and McCaffrey, 2010) and formally adopt a landscape approach (Bureau of Land Management, 2014c). The result has been a 
renewed focus on providing the best available tools, science, and information to implement the multiple-use and sustainedyield mandate of the BLM. The BLM has also implemented new initiatives to inform, integrate, and enhance management across different resource management programs (for example, visual, cultural, and natural resources) and across spatial and temporal scales (Bureau of Land Management, 2014a).

A broad spatial perspective is inherent to a landscape approach (Lindenmayer and others, 2008; Reed and others, 2014). However, collecting data, developing partnerships, and sharing information all become more difficult at larger spatial extents such as district offices, states, ecoregions, or across international borders (for example, O'Donnell and others, 2014). Accordingly, the initial emphasis of the BLM in implementing a landscape approach has been on addressing data gaps at broad spatial scales in its biophysical programs through (1) conducting Rapid Ecoregional Assessments to synthesize the best available geospatial data on resource status and condition at the spatial extent of ecoregions (Bureau of Land Management, 2016); (2) implementing management priorities across broad scales through the Healthy Lands Initiative (Bureau of Land Management, 2011); (3) piloting and developing a coordinated, nationwide Assessment, Inventory, and Monitoring (AIM) program (Toevs and others, 2011); and (4) emphasizing the use of science to inform planning and management decisions (Bureau of Land Management, 2014c, 2015b).

Gathering and sharing multiscale monitoring and assessment information and working to develop strong partnerships across broader areas and with diverse stakeholders have helped the BLM to better evaluate tradeoffs inherent in natural resource decisions. Two early examples of such efforts were the Northwest Forest Plan (U.S. Department of Agriculture Forest Service and Bureau of Land Management, 1994) and the Interior Columbia Basin Ecosystem Management Project (U.S. Department of Agriculture Forest Service and Bureau of Land Management, 2000). Both efforts had a strong partnership between science and management, and the information and processes developed in both projects strongly influenced current efforts within the BLM to implement a landscape approach.

More recent efforts by the BLM to bring together the information and stakeholders needed to effectively plan and implement management actions across broad spatial extents include a multiagency conservation plan addressing future renewable energy development across seven counties in California (California Energy Commission and others, 2014), a multiagency land use planning effort across ten western states to support conservation of the greater sage-grouse (Centrocercus urophasianus, fig. 2-2) (Bureau of Land Management, 2015c), an integrated activity plan developed for the 9-million ha (23-million acre) National Petroleum Reserve-Alaska (Bureau of Land Management, 2015d), a resource management plan developed for western Oregon (Bureau of Land Management, 2015g), and a coordinated resource management plan addressing future solar

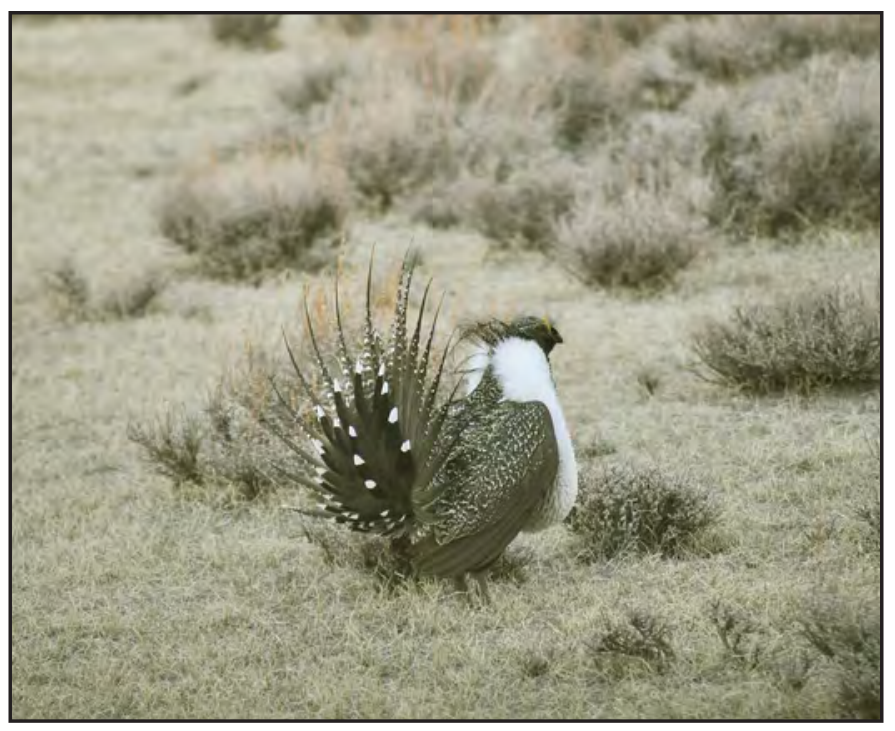

Figure 2-2. Male greater sage-grouse displaying on a lek (mating ground) near Bodie, California (Photograph by Jeannie Stafford, U.S. Fish and Wildlife Service).

energy development across six southwestern states (Bureau of Land Management, 2012). An example of a next step in implementing a landscape approach is the regional mitigation strategy for solar energy development in southeast Nevada (Bureau of Land Management, 2014b), which identifies specific strategies for implementing decisions reached by using a landscape approach.

Two priority areas for future work have emerged following these initial efforts by the BLM to implement a landscape approach (see Bureau of Land Management, 2015e). The first is development of approaches and datasets to further integration of socioeconomic, recreational, cultural, visual, and historic resource services and values into BLM planning efforts conducted at broad scales. The primary broad-scale assessment and monitoring efforts of BLM (AIM westwide landscape monitoring, Rapid Ecoregional Assessments) have focused on resource management questions related to wildlife, vegetation, and biological communities. However, the Northwest Forest Plan and the ecosystem assessment for the Interior Columbia Basin Ecosystem Management Project included broad-scale assessments of socioeconomic conditions, and the Northwest Forest Plan continues to monitor socioeconomic and tribal issues as part of plan implementation (U.S. Department of Agriculture Forest Service and Bureau of Land Management, 1994, 2000). More recently, broad-scale data on cultural resources were used in developing the San Luis Valley_-Taos Plateau Landscape Assessment and Solar Regional Mitigation Strategy (Westcott, 2014), providing a starting point for more explicit consideration of the human dimensions of resource management in the future. Information is at the heart of understanding the tradeoffs involved in managing landscapes for diverse resource values and uses. Accordingly, having accessible, timely, multiscale resource data for all BLM programs is critical for moving forward in implementing a landscape approach. 
A second priority area is to foster greater coordination and collaboration with stakeholders across broader spatial extents. Partnerships facilitate development of a shared vision for the landscape, collection of consistent monitoring data across land ownerships, and efficiencies in conducting resource assessments across regions. Many successful partnerships between the BLM and diverse stakeholders exist at local levels. An important focus for the future is to support and integrate these partnerships into a larger network that can help the BLM to identify and achieve regional and national resource objectives. There are examples of effective land planning and management partnerships between Federal agencies (Northwest Forest Plan [U.S. Department of Agriculture Forest Service and Bureau of Land Management, 1994]), Federal and State agencies (Western Governors' Association Crucial Habitat Assessment Tool [State Wildlife Agencies of the Western United States, 2014]), and Federal and State agencies and other organizations (Landscape Conservation Cooperatives). A core goal of the new BLM planning framework, Planning 2.0, is to enhance opportunities for planning across broad landscapes using a collaborative process that strongly values involvement by and contributions from stakeholders (Bureau of Land Management, 2015e).

\section{Understanding Landscapes, Patterns, and Processes to Implement a Landscape Approach}

A key aspect of implementing a landscape approach is considering the effects of potential actions, such as habitat restoration and renewable energy development, across broad landscapes (Jones and others, 2015). Landscapes have been defined in a number of ways, often focusing primarily on ecological processes (Freeman and others, 2015). The Department of the Interior definition explicitly considers the human element of landscapes: large areas encompassing an interacting mosaic of ecosystems and human systems that are characterized by a set of common management concerns (Clement and others, 2014). Landscapes are mosaics in many senses of the word: mosaics of vegetation types, mosaics of land ownerships, and mosaics of land uses, to name a few. These mosaics are characterized by different landscape patterns and processes. For example, vegetation patches may be large or small, abundant or few in number, and clumped or widely scattered. Land ownership patterns may be characterized by many small parcels or few large ones. Roads may be clustered in specific areas or evenly dispersed across the landscape following environmental patterns or gridlines. Maintaining landscape patterns that include large, structurally complex and connected patches of native vegetation is essential for maintaining biodiversity in production landscapes (Fischer and others, 2006).
Landscape patterns affect ecological processes across the landscape. Road networks foster the spread of invasive species. The presence of invasive plants and the size, type, and proximity of vegetation patches affect wildfire frequency, intensity, and extent. The size and proximity of habitat patches and surrounding patterns of land use affect the extent to which populations of habitat specialist species are functionally connected.

Landscape patterns also affect human use patterns across the landscape. The location and characteristics of lands suited for particular types of recreation determine where, when, and with what intensity those recreational activities will occur. The location and amount of energy and mineral resources shape energy development patterns. Managing for the persistence of key ecological processes (such as wildfire), conducting management to mimic natural disturbance processes that are now greatly altered (through prescribed fire, for example), and controlling processes resulting from anthropogenic disturbance (such as the spread of invasive species) are priority conservation actions in multiple-use landscapes (Fischer and others, 2006).

Our perception of landscape patterns and processes, and the ways in which they both affect and are affected by each other, is influenced by the spatial and temporal scales at which we examine them. For example, a single gas well pad has a small surface disturbance footprint. However, that well pad together with many other well pads compose a large oil field (often developed over multiple years), which affects resource quality and quantity over much of a landscape (fig. 2-3). A wildfire may kill individual plants and animals within its perimeter but play an important role in maintaining the broader ecological community that supports these same species over the long term. Considering multiple spatial and temporal scales helps planners, managers, and policy makers better understand and quantify the potential effects of proposed management actions by providing perspectives on both short- and long-term effects and both local and regional context (Jones and others, 2015).

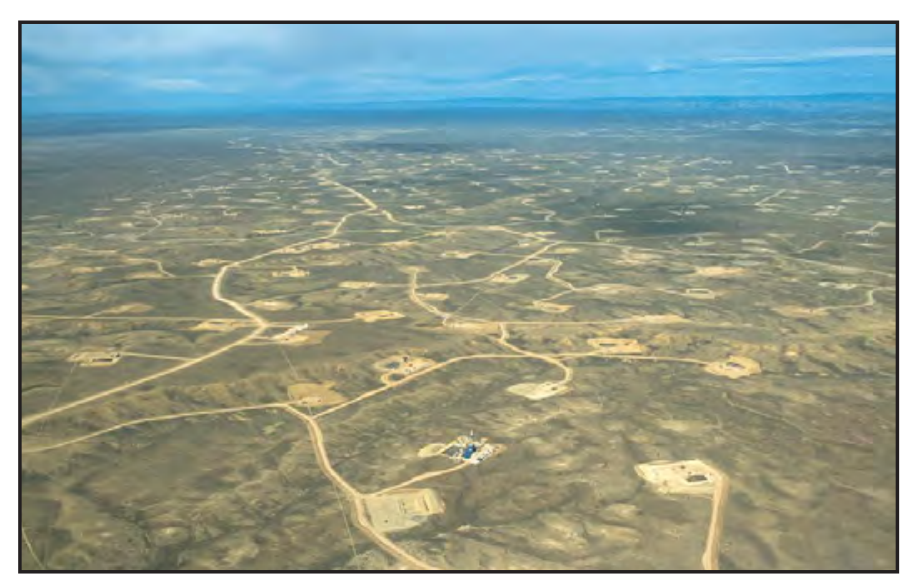

Figure 2-3. Oil and gas well-pad development in the Jonah Field near Pinedale, Wyoming (Photograph by Peter Aengst, The Wilderness Society). 


\section{Considering Multiple Spatial Scales in Natural Resource Decisions}

When evaluating the potential effects of natural resource decisions and actions, it is helpful to consider a hierarchy of spatial scales from the local level up to and including landscapes and regions (Lindenmayer and others, 2008; Wiens, 2009). Each level in the hierarchy provides different information for assessing the potential effect of a resource decision. For example, when considering the value of an individual vegetation patch for wildlife, the local scale provides specific information on the health and composition of habitat within the patch itself (fig. 2-4). A broader perspective, at the level of watersheds or landscapes, provides information on the context in which the patch occurs, such as the land cover type and land ownership of the habitat surrounding the patch or the location of adjacent populations. A regional perspective provides information on the role that the patch plays in maintaining regional connectivity of plant or wildlife populations. In general, the finest spatial scale provides information on the specific effects of a resource management action or decision on vegetation composition and structure within a patch. An intermediate scale provides information on the direct and indirect effects of a decision on the amount and configuration of habitat across a landscape and the potential to affect adjacent populations. The broadest spatial scale indicates how a decision may affect species or habitat connectivity across a region.

There are no predefined rules for determining the exact size or number of spatial scales at which to consider the potential effects of a resource decision. Relevant scales will vary by project type and characteristics of the resources likely to be affected (for example, ecological, economic, recreational, or visual resources). When wildlife species of conservation concern are involved, the body size, movement patterns, and dispersal distances of the species may inform scale selection (Jackson and Fahrig, 2012). For example,

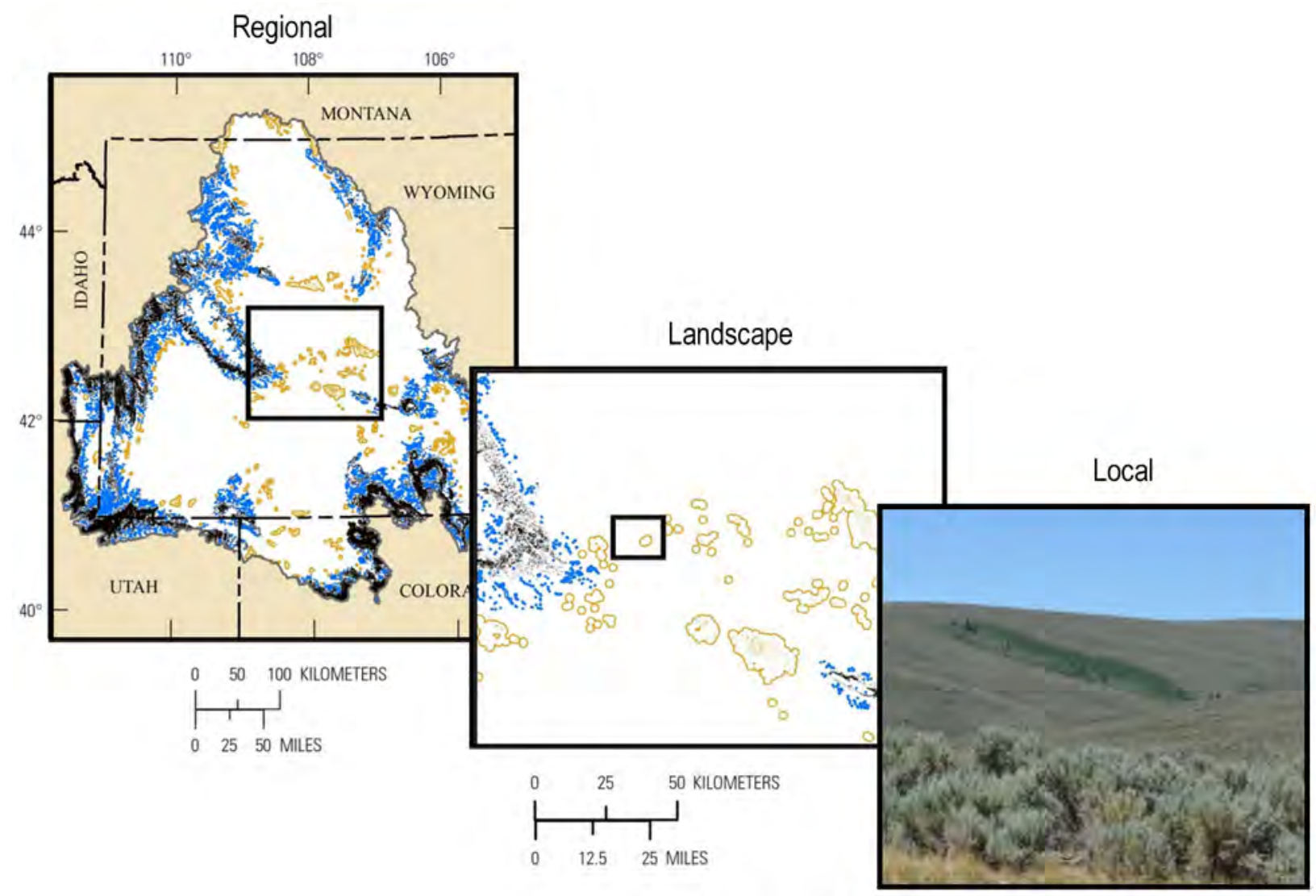

Figure 2-4. Example of a landscape hierarchy, illustrated using analyses of aspen vegetation in the Wyoming Basin ecoregion (modified from Carr and Melcher, 2015). Considering multiple levels in the landscape hierarchy is helpful for understanding details within the individual site along with the landscape and regional importance of the site. The regional level illustrates structural connectivity of aspen across the Wyoming Basin ecoregion, with black, blue, and orange colors indicating aspen patch complexes that are connected at distances of $0.3,1.3$, and 6.5 kilometers, respectively. At the landscape level, it is possible to identify specific aspen patches in the landscape that may be important stepping stones for dispersing wildlife species. At the local level (often an individual patch or forest stand), field samples provide important details about vegetation composition and stand structure. At the local level, the contribution of a patch to structural connectivity of aspen across the landscape and region might not be apparent. (Photograph by Natasha B. Carr, U.S. Geological Survey). 
mule deer (Odocoileus hemionus) and other ungulates in the Intermountain West often complete seasonal migrations of 50-100 km, requiring consideration of broad spatial scales and seasonal habitats to fully understand effects of potential development on populations (Sawyer and others 2009a, 2009b). In this case, the finest spatial extent to consider may be the size of a typical habitat patch (for example, a foraging or reproduction area), an intermediate extent might be the average size of an individual home range, and the broadest extent might include the full geographic range of the species.

The specific boundaries used in evaluating potential effects of a management decision will depend on the action being considered, the resources and species potentially affected, and any measures being considered to minimize or mitigate negative effects to each. Ecological boundaries such as ecoregions or watersheds are likely to be most relevant for species. Geographic boundaries such as counties or states may be appropriate for considering management constraints (for example, county permitting processes and State endangered species regulations). Agency administrative boundaries such as field offices and districts may be relevant for management actions corresponding to agency funding or planning processes. Often a combination of ecological, geographic, and administrative boundaries is useful for accommodating ecological, regulatory, and management considerations.

\section{Management Questions Across Spatial Scales}

The resource management questions of BLM span local to national extents (table 2-1). Consequently, data collected across a range of spatial extents may be useful for addressing those questions. For example, at the broadest scale, the BLM is responsible for reporting on the condition and trend in condition of rangelands managed by the BLM across the Nation (Public
Rangelands Improvement Act of 1978, Public Law 95-514). This is a major goal of the westwide landscape monitoring effort of the BLM (Toevs and others, 2011). Field sampling conducted at individual rangeland sites that are selected in a consistent and statistically valid manner allows inference to be made across rangelands managed by the BLM nationwide. The BLM also is working to use data collected at individual rangeland sites in conjunction with remotely sensed data collected across broad spatial extents to answer additional management questions (Toevs and others, 2011; see chapter 4).

At the scale of ecoregions, BLM planners and managers may use information on the status, condition, and distribution of natural resources and of key stressors acting on those resources to, for example, map where development is concentrated and identify where large, relatively undeveloped areas occur (see chapter 5). Information on patterns of existing development may be used to help guide future development activities and minimize negative effects on large, relatively undeveloped areas. Patterns of existing and projected future development also may be used together with other natural resource information in a systematic conservation planning framework to help prioritize areas for conservation or restoration activities (Margules and Pressey, 2000). Remotely sensed data that are appropriate for use at an ecoregional or broader scale also increasingly have a spatial resolution (for example, 30- x 30-m cells) and level of discrimination between different land use and land cover types that are suitable for informing decisions made at smaller extents such as field offices or watersheds.

At the spatial extent of a field or district office, an important management question may be to determine whether planning and management actions are effective in meeting objectives identified in resource management plans (RMPs) (Toevs and others, 2011). RMPs guide management decisions and actions on public lands within the RMP boundary (often a BLM field office) such as the balance between developed and conserved habitats. Monitoring conducted at the scale

Table 2-1. Bureau of Land Management administrative units, management decisions, and ecological processes and patterns across a range of spatial extents. Note that local, intermediate (often a watershed or landscape), and regional extents represent a continuum, with many management decisions and ecological processes being relevant across more than one spatial extent (modified from Carr and Melcher, 2015).

\begin{tabular}{|c|c|c|c|}
\hline & \multicolumn{3}{|c|}{ Spatial extent } \\
\hline & Local & Intermediate & Regional \\
\hline
\end{tabular}


of the RMP boundary is the best tool for assessing the extent to which RMPs are effective tools in producing the desired resource outcomes (Toevs and others, 2011).

Many decisions within the BLM are made in response to proposed actions at a specific site. The effects of these proposed actions often encompass multiple scales: anticipated site effects (often direct physical disturbance) and indirect and cumulative effects at broader spatial and temporal scales. For example, accurate assessment of the potential effects of the proposed installation of a single wind turbine often requires a broad spatial perspective (Jones and others, 2015). Specific questions to be investigated will include the area over which the structure is visible; the distance over which noise, dust, or vibrations will travel; the likely locations of associated activities such as road construction; and the sensitivity, spatial distribution, and population structure of wildlife species of conservation concern that are present perennially or seasonally in the area. Decisions that may affect resources over a large area or long time period, often with requirements for offsite mitigation of negative effects on resources within the project boundary, may require the broadest spatial and temporal perspectives. However, all projects can benefit from multiscale assessment and planning. Broad-scale data (such as Rapid Ecoregional Assessments) and plans (such as RMPs, Bureau of Land Management, 2004) provide important context for making specific decisions at all scales, including individual sites or projects.

Energy development occurring within the range of the greater sage-grouse (fig. 2-3) provides another illustration of the potential effects of development that may extend beyond the footprint of a proposed well pad or wind turbine. Greater sage-grouse require large, connected areas of sagebrush for lekking, nesting, and overwintering (Connelly and others, 2011). Females typically avoid nesting within 950 meters of the infrastructure of natural gas fields (Holloran and others, 2010), and wind turbines can decrease nesting survival to a distance of 30 kilometers or more (Lebeau and others, 2014). In addition, greater sage-grouse avoid paved roads (Fedy and others, 2014), and even lightly traveled roads (1-12 vehicles per day) may lead to reduced rates of nest initiation (Lyon and Anderson, 2003). Thus, potential indirect and cumulative effects of an individual well pad or wind turbine may affect breeding behavior and reproductive success at locations and scales that extend well beyond the individual site.

Considering potential effects of proposed development actions at multiple spatial scales may also improve the effectiveness of proposed mitigation actions. A proposed road that will cross an important wildlife corridor may be designed to minimize adverse localized effects by incorporating wildlife overpasses or underpasses to allow animal movement to continue (Sawyer and others, 2012; fig. 2-5). Integrating broader scale information enables application of compensatory mitigation elsewhere in the landscape where it may be most effective in offsetting negative effects on natural resources (Bureau of Land Management, 2014a, 2015g). To compensate for the effects of the proposed road on wildlife movement in the landscape, other wildlife corridors that contribute to regional connectivity of the population could be protected. Mitigation actions that compensate for negative effects of development at multiple scales help to achieve more effective and defensible resource management (Clement and others, 2014).

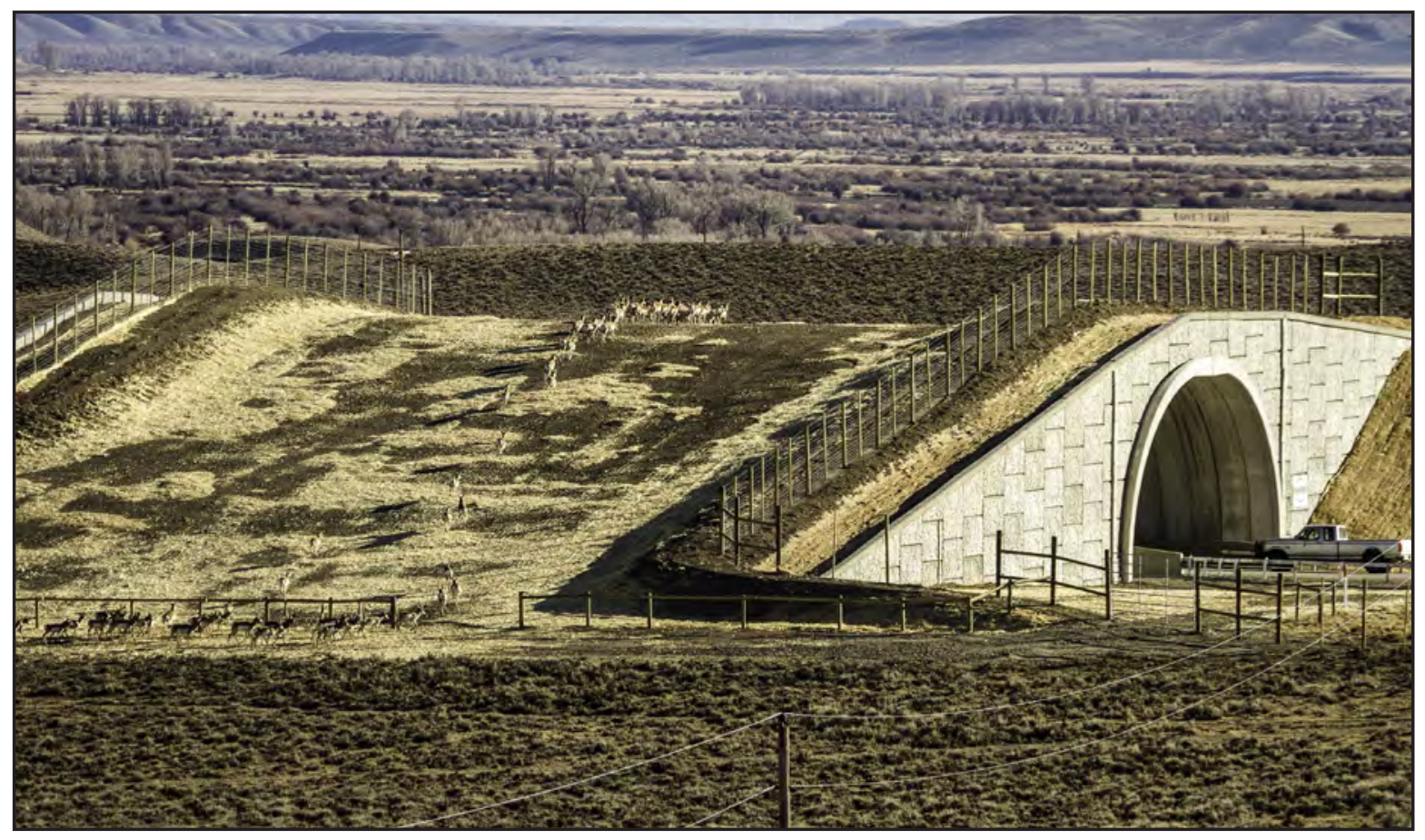

Figure 2-5. Pronghorn (Antilocapra americana) make use of a wildlife highway overpass at Trappers Point, Wyoming (Photograph by Jeff Burrell, Wildlife Conservation Society). 
Implementing a landscape approach involves considering, assessing, and monitoring multiple resource values and uses, and understanding the implications of management decisions on those resources, across spatial and temporal scales. Using multiscale information in managing natural resources is not a new concept. However, expanding from evaluating effects of proposed actions at the scale of individual sites to considering effects at multiple spatial and temporal scales and on multiple natural resources is still a developing science (Haines and others, 2014; Jones and others, 2015). Unanticipated ecological and policy interactions may be evident only when examined at a variety of scales (Smith and others, 2011, Sunderland and others, 2015). Considering cultural, visual, and other human dimensions resources, some without defined tools for multiscale analyses, adds additional complexity. Although there are clear challenges in implementing a landscape approach (Sayer and others, 2015), assessing and monitoring changes in welldefined indicators of key ecological patterns and processes in response to different management decisions at different spatial and temporal scales are needed to inform and adapt future management actions.

\section{References Cited}

Bracke, Marsha, and McCaffery, Maggie, 2010, Lessons learned report-Ecoregional assessment processes: U.S. Institute for Environmental Conflict Resolution and EnviroIssues, Inc., accessed February 21, 2016, at http:/www.blm.gov/ style/medialib/blm/wo/Communications_Directorate/ public_affairs/landscape_approach/documents1.Par.51236. File.dat/20101110_EcoregionalAssessment_Lessons_ Learned_Report_FINAL_v2.pdf.

Bureau of Land Management, 2004, Bureau of Land Management national sage-grouse habitat conservation strategy: Bureau of Land Management, accessed July 31, 2015, at http://www.blm.gov/style/medialib/blm/wo/Planning_and_ Renewable_Resources/fish_wildlife_and.Par.9151.File.dat/ Sage-Grouse_Strategy.pdf.

Bureau of Land Management, 2008, Bureau of Land Management National Environmental Policy Act Program: Bureau of Land Management, accessed June 15, 2015, at http:/www.blm.gov/style/medialib/blm/wo/Information Resources_Management/policy/blm_handbook.Par.24487. File.dat/h1790-1-2008-1.pdf.

Bureau of Land Management, 2011, The Bureau of Land Management Healthy Lands Initiative, accessed January 12, 2017, at https://www.blm.gov/about/how-we-manage/ shared-conservation-strategies.
Bureau of Land Management, 2012, Approved resource management plan amendments/record of decision (ROD) for solar energy development in six southwestern states: Bureau of Land Management, accessed September 25, 2015, at http:// solareis.anl.gov/documents/docs/Solar_PEIS_ROD.pdf.

Bureau of Land Management, 2014a, Draft regional mitigation manual section (MS)-1794: Bureau of Land Management, accessed January 10, 2017, at http://www.blm.gov/pgdata/etc/ medialib/blm/wo/Information_Resources_Management/policy/ im_attachments/2013.Par.57631.File.dat/IM2013-142_att1.pdf.

Bureau of Land Management, 2014b, Solar regional mitigation strategy for the Dry Lake Solar Energy Zone: Bureau of Land Management, Southern Nevada District Office, Technical Note 444, accessed September 25, 2015, at https:/www.blm.gov/style/medialib/blm/wo/blm_library/ tech_notes.Par.29872.File.dat/TN_444.pdf.

Bureau of Land Management, 2014c, The BLM's landscape approach for managing public lands: Bureau of Land Management, accessed April 14, 2015, at http:/www.blm.gov/ wo/st/en/prog/more/Landscape_Approach.html.

Bureau of Land Management, 2015a, Advancing science in the BLM: An implementation strategy: Bureau of Land Management, accessed June 2, 2015, at http://www.blm.gov/ style/medialib/blm/wo/blm_library/BLM_pubs.Par.38337. File.dat/BLMAdvSciImpStratFINAL032515.pdf.

Bureau of Land Management, 2015b, Implementing mitigation at the landscape-scale: Department of the Interior Manual 600 DM 6: Bureau of Land Management, accessed December 7, 2015, at https:/www.doi.gov/sites/doi.gov/files/ uploads/TRS\%20and\%20Chapter\%20FINAL.pdf.

Bureau of Land Management, 2015c, Land use planning to support conservation of greater sage-grouse and sagebrush: Bureau of Land Management, accessed September 25, 2015, at http://www.blm.gov/wo/st/en/prog/more/ sagegrouse.html.

Bureau of Land Management, 2015d, National Petroleum Reserve-Alaska Integrated Activity Plan/Environmental Impact Statement: Bureau of Land Management, accessed September 25, 2015, at https://eplanning.blm.gov/ epl-front-office/eplanning/planAndProjectSite.do?method Name $=$ dispatchToPatternPage\&currentPageId=14702.

Bureau of Land Management, 2015e, Planning 2.0: Improving the way we plan together: Bureau of Land Management, accessed April 14, 2015, at http://www.blm.gov/wo/st/en/ prog/planning/planning_overview/planning_2_0.html.

Bureau of Land Management, 2015f, Public land statistics: Bureau of Land Management, accessed February 21, 2016, at http://www.blm.gov/public_land_statistics/pls14/pls2014.pdf. 
Bureau of Land Management, 2015g, Western Oregon draft Resource Management Plan/Environmental Impact Statement: Bureau of Land Management, accessed September 25, 2015, at http://www.blm.gov/or/plans/ rmpswesternoregon/deis.php.

Bureau of Land Management, 2016, Rapid Ecoregional Assessments: Bureau of Land Management, accessed March 7, 2016, at http:/www.blm.gov/wo/st/en/prog/more/ Landscape_Approach/reas.html.

California Energy Commission, California Department of Fish and Wildlife, Bureau of Land Management, and U.S. Fish and Wildlife Service, 2014, Draft Desert Renewable Energy Conservation Plan (DRECP) and Environmental Impact Report/Environmental Impact Statement: California Energy Commission, California Department of Fish and Wildlife, Bureau of Land Management, and U.S. Fish and Wildlife Service, accessed September 25, 2015, at http://www.drecp.org/draftdrecp/.

Carr, N.B., and Melcher, C.P., eds., 2015, Wyoming Basin Rapid Ecoregional Assessment: U.S. Geological Survey Open-File Report 2015-1155, 896 p., accessed December 8, 2016, at http://dx.doi.org/10.3133/ ofr20151155.

Clement, J.P., Belin, A.d'A., Bean, M.J., Boling, T.A., and Lyons, J.R., 2014, A strategy for improving the mitigation policies and practices of the Department of the Interior: Washington, D.C., Energy and Climate Change Task Force, accessed October 12, 2016, at https:/www.doi.gov/sites/ doi.gov/files/migrated/news/upload/Mitigation-Report-tothe-Secretary_FINAL_04_08_14.pdf.

Connelly, J.W., Rinkes, E.T., and Braun, C.E., 2011, Characteristics of greater sage-grouse habitats: A landscape species at micro- and macroscales, in Knick, S.T., and Connelly, J.W. eds., Greater sage-grouse - Ecology and conservation of a landscape species and its habitats: Studies in Avian Biology, v. 38, p. 69-83.

Copeland, H.E., Sawyer, Hall, Monteith, K.L., Naugle, D.E., Pocewicz, Amy, Graf, Nicholas, and Kauffman, M.J., 2014, Conserving migratory mule deer through the umbrella of sage-grouse: Ecosphere, v. 5, no. 9, p. 1-16, accessed October 12, 2016, http://dx.doi.org/10.1890/ES14-00186.1.

Fedy, B.C., Doherty, K.E., Aldridge, C.L., O’Donnell, Micheal, Beck, J.L., Bedrosian, Bryan, Gummer, David, Holloran, M.J., Johnson, G.D., Kaczor, N.W., Kirol, C.P., Mandich, C.A., Marshall, David, McKee, Gwyn, Olson, Chad, Pratt, A.C., Swanson, C.C., and Walker, B.L., 2014, Habitat prioritization across large landscapes, multiple seasons, and novel areas-An example using greater sagegrouse in Wyoming: Wildlife Monographs, v. 190, p. 1-39.
Fischer, Joern, Lindenmayer, D.B., and Manning, A.D., 2006, Biodiversity, ecosystem function, and resilience-Ten guiding principles for commodity production landscapes: Frontiers in Ecology and the Environment, v. 4, p. 80-86.

Freeman, O.E., Duguma, L.A., and Minang, P.A., 2015, Operationalizing the integrated landscape approach in practice: Ecology and Society, v. 20, no. 1, accessed October 12, 2016, at http://www.ecologyandsociety.org/vol20/iss1/art24/.

Gorte, R.W., Vincent, C.H., Hanson, L.A., and Rosenblum, M.R., 2012, Federal land ownership: Overview and data: Washington, D.C., Congressional Research Service, accessed June 22, 2015, at https://fas.org/sgp/crs/misc/ R42346.pdf.

Haines, S.S., Diffendorer, J.E., Balistrieri, Laurie, Berger, Byron, Cook, Troy, DeAngelis, Don, Doremus, Holly, Gautier, D.L., Gallegos, Tanya, Gerritsen, Margot, Graffy, Elisabeth, Hawkins, Sarah, Johnson, K.M., Macknick, Jordan, McMahon, Peter, Modde, Tim, Pierce, Brenda, Schuenemeyer, J.H., Semmens, Darius, Simon, Benjamin, Taylor, Jason, and Walton-Day, Katie, 2014, A framework for quantitative assessment of impacts related to energy and mineral resource development: Natural Resources Research, v. 23 , p. 3-17.

Holloran, M.J., Kaiser, R.C., and Hubert, W.A., 2010, Yearling greater sage-grouse response to energy development in Wyoming: Journal of Wildlife Management, v. 74, p. 65-72.

Jackson, H.B., and Fahrig, Lenore, 2012, What size is a biologically relevant landscape?: Landscape Ecology, v. 27, p. 929-941.

Jones, N.F., Pejchar, Liba, and Kiesecker, J.M., 2015, The energy footprint: How oil, natural gas, and wind energy affect land for biodiversity and the flow of ecosystem services: Bioscience, v. 65, p. 290-301.

Lebeau, C.W., Beck, J.L., Johnson, G.D., and Holloran, M.J., 2014, Short-term impacts of wind energy development on greater sage-grouse fitness: Journal of Wildlife Management, v. 78, p. 522-530.

Lindenmayer, David, Hobbs, J.R., Montague-Drake, Rebecca, Alexandra, Jason, Bennett, Andrew, Burgman, Mark, Cale, Peter, Calhoun, Aram, Cramer, Viki, Cullen, Peter, Driscoll, Don, Fahrig, Lenore, Fischer, Joern, Franklin, Jerry, Haila, Yrjo, Hunter, Malcolm, Gibbons, Philip, Lake, Sam, Luck, Gary, MacGregor, Chris, McIntyre, Sue, Mac Nally, Ralph, Manning, Adrian, Miller, James, Mooney, Hal, Noss, Reed, Possingham, H.P., Saunders, Denis, Schmiegelow, Fiona, Scott, Michael, Simberloff, Dan, Sisk, Tom, Tabor, Gary, Walker, Brian, Wiens, John, Woinarski, John, and Zavaleta, Erika, 2008, A checklist for ecological management of landscapes for conservation: Ecology Letters, v. 11, p. 78-91. 
Lyon, A.G., and Anderson, S.H., 2003, Potential gas development impacts on sage grouse nest initiation and movement: Wildlife Society Bulletin, v. 31, p. 486-491.

Margules, C.R., and Pressey, R.L., 2000, Systematic conservation planning: Nature, v. 405 , p. $243-253$.

O'Donnell, M.S, Assal, T.J., Anderson, P.J., and Bowen, Z.H., 2014, Geospatial considerations for a multiorganizational, landscape-scale program: Journal of Map and Geography Libraries, v. 10, p. 62-99.

Polasky, Stephen, Nelson, Erik, Camm, Jeff, Csuti, Blair, Fackler, Paul, Lonsdorf, Eric, Montgomery, Claire, White, Denis, Arthur, Jeff, Garber-Yonts, Brian, Haight, Robert, Kagan, Jimmy, Starfield, Anthony, and Tobalske, Claudine, 2008, Where to put things? Spatial land management to sustain biodiversity and economic returns: Biological Conservation, v. 141, p. 1505-1524.

Radeloff, V.C., Stewart, S.I., Hawbaker, T.J., Gimmi, Urs, Pidgeon, A.M., Flather, C.H., Hammer, R.B., and Helmers, D.P., 2010, Housing growth in and near United States protected areas limits their conservation value: Proceedings of the National Academy of Sciences of the United States of America, v. 107, p. 940-945.

Reed, James, Deakin, Liz, and Sunderland, Terry, 2014, What are 'Integrated Landscape Approaches' and how effectively have they been implemented in the tropics: a systematic map protocol: Environmental Evidence, v. 4, p. 1-7.

Reed, James, Van Vianen, Josh, Deakin, E.L., Barlow, Jos, and Sunderland, Terry, 2016, Integrated landscape approaches to managing social and environmental issues in the tropics: learning from the past to guide the future: Global Change Biology, v. 22, p. 2540-2554.

Sawyer, Hall, Kauffman, M.J., Nielson, R.M., and Horne, J.S., 2009a, Identifying and prioritizing ungulate migration routes for landscape-level conservation: Ecological Applications, v. 19, p. 2016-2025.

Sawyer, Hall, Kauffman, M.J., Nielson, R.M., and Horne, J.S., $2009 \mathrm{~b}$, Influence of well pad activity on the winter habitat selection patterns of mule deer: Journal of Wildlife Management, v. 73, p. 1052-1061.

Sawyer, Hall, Lebeau, Chad, and Hart, Thomas, 2012, Mitigating roadway impacts to migratory mule deer-a case study with underpasses and continuous fencing: Wildlife Society Bulletin, v. 36, p. 492-498.

Sayer, Jeffrey, 2009, Reconciling conservation and development: Are landscapes the answer?: Biotropica, v. 41, p. 649-652.
Sayer, Jeffrey, Margules, Chris, Boedhihartono, A.K., Dale, Allan, Sunderland, Terry, Supriatna, Jatna, and Saryanthi, Ria, 2015, Landscape approaches: what are the pre-conditions for success?: Sustainability Science, v. 10, p. 345-355.

Sayer, Jeffrey, Sunderland, Terry, Ghazoul, Jabouary, Pfund, Jean-Laurent, Sheil, Douglas, Meijaard, Erik, Venter, Michelle, Boedhihartono, A.K., Day, Michael, Garcia, Claude, van Oosten, Cora, and Buck, L.E., 2013, Ten principles for a landscape approach to reconciling agriculture, conservation, and other competing land uses: Proceedings of the National Academy of Sciences of the United States of America, v. 110, p. 8349-8356.

Skillen, J.R., 2009, The Nation's largest landlord: the Bureau of Land Management in the American West: Lawrence, Kans., University Press of Kansas, 297 p.

Smith, M.D., 2007, A review of recent NEPA alternatives analysis case law: Environmental Impact Assessment Review, v. 27, p. 126-144.

Smith, A.C., Fahrig, Lenore, and Francis, C.M., 2011, Landscape size affects the relative importance of habitat amount, habitat fragmentation, and matrix quality on forest birds: Ecography, v. 34, p. 103-113.

State Wildlife Agencies of the Western United States, 2014, West-wide crucial habitat data set. Western Association of Fish and Wildlife Agencies Crucial Habitat Assessment Tool-Mapping fish and wildlife across the west: State Wildlife Agencies of the Western United States, accessed September 29, 2015, at http://www.wafwachat.org/map.

Sunderland, Terry, Baudron, Frédéric, Ickowitz, Amy, Padoch, Christine, Ros-Tonen, Mirjam, Sandbrook, Chris, Vira, Bhaskar, Chambers, Josephine, Deakin, Elizabeth, Foli, Samson, Jeary, Katy, Parrotta, J.A., Powell, Bronwen, Reed, James, Ayeri Ogalleh, Sarah, Neufeldt, Henry, and Serban, Anca, 2015, Response options across the landscape, in Bhaskar Vira, Wildburger, Christoph, and Mansourian, Stephanie, eds., Forests, trees and landscapes for food security and nutrition: Vienna, Austria, International Union of Forest Research Organizations World Series, v. 33, p. 113-127.

Theobald, D.M., 2013, A general model to quantify ecological integrity for landscape assessments and US application: Landscape Ecology, v. 28, p. 1859-1874.

Toevs, G.R., Taylor, J.J., Spurrier, C.S., MacKinnon, W.C., and Bobo, M.R., 2011, Bureau of Land Management Assessment, Inventory, and Monitoring Strategy: For integrated renewable resources management: Bureau of Land Management, National Operations Center, accessed June 15, 2015, at http://www.blm.gov/style/medialib/blm/wo/Information Resources_Management/policy/ib_attachments/2012. Par.53766.File.dat/IB2012-080_att1.pdf. 
U.S. Department of Agriculture Forest Service and Bureau of Land Management, 1994, Record of decision for amendments to Forest Service and Bureau of Land Management planning documents within the range of the northern spotted owl: U.S. Department of Agriculture Forest Service and Bureau of Land Management, accessed February 21, 2016, at http:/www.reo.gov/library/reports/newroda.pdf.

U.S. Department of Agriculture Forest Service and Bureau of Land Management, 2000, Interior Columbia Basin Final Environmental Impact Statement: U.S. Department of Agriculture Forest Service and Bureau of Land Management, accessed February 21,2016 , at http://www.icbemp.gov/html/icbhome.html.

U.S. Department of Defense, 2011, Instruction 4715.03: Natural Resources Conservation Program, U.S. Department of Defense, accessed June 22, 2015, at http://www.dtic.mil/ whs/directives/corres/pdf/471503p.pdf.
U.S. Department of the Interior, 2014, Strategic plan for fiscal years 2014-2018: Washington, D.C., U.S. Department of the Interior, accessed June 15, 2015, at https://www.doi.gov/sites/doi.gov/files/migrated/bpp/ upload/DOI-Strategic-Plan-for-FY-2014-2018-POSTEDON-WEBSITE.pdf.

Westcott, Konnie, 2014, Cultural landscape assessment: San Luis Valley_-Taos Plateau: Colorado SEZ Solar Regional Mitigation Strategy Public Workshop, Alamosa, Colo. [Presentation], September 10, 2014, accessed June 15, 2015, at http://www.blm.gov/co/st/en/fo/slvfo/solar/solar_regional_ mitigation.html.

Wiens, J.A., 2009, Landscape ecology as a foundation for sustainable conservation: Landscape Ecology, v. 24, p. 1053-1065. 


\title{
Chapter 3. Including Broad-Scale Indicators in Multiscale Natural Resource Monitoring and Assessment Programs in the Bureau of Land Management
}

\author{
By David J.A. Wood, Sarah K. Carter, Sandra E. Litschert, and Natasha B. Carr
}

\section{Abstract}

The collection and use of multiscale monitoring data are key components of a landscape approach to natural resource management. However, broad-scale indicators of resource status and condition are not always monitored, and methods are frequently not consistent across regions and organizations. We describe key components of the Assessment, Inventory, and Monitoring Strategy of the Bureau of Land Management, including the Rapid Ecoregional Assessment program. We identify a suite of core, supplemental, and derived broadscale indicators that emerged from the Rapid Ecoregional Assessment program as the most important and feasible to quantify at the ecoregional scale: the amount and distribution of ecological communities and wildlife habitats, the patch size and connectivity of communities and habitats, the pattern and amount of development, the frequency with which ecological communities burn, the distribution of invasive species, the potential effects of climate change on communities and habitats, and landscape intactness. We outline steps for assessing broad-scale indicators within a multiscale monitoring program and suggest ways in which broad-scale indicators may inform field monitoring programs and be used in multiscale assessments. Multiagency, multiscale monitoring programs that collect data consistently across broad extents regardless of land ownership or jurisdiction are an important component of a landscape approach to resource management, and emerging regional partnerships may support these efforts.

\section{Introduction}

The Bureau of Land Management (BLM) is committed to implementing a landscape approach to resource management (hereafter landscape approach) on the public lands it manages (see chapter 2). One fundamental aspect of a landscape approach is collecting and sharing monitoring information at multiple spatial scales, including broad scales such as ecoregions (Stahl and others, 2011; Sayer and others, 2013).
Multiscale monitoring data inform all stages of natural resource management from setting resource objectives to evaluating the effectiveness of management actions (Noss, 1990; Lui and Taylor, 2002; Frost and others, 2006; Fancy and others, 2009).

Traditionally, much of the ecological monitoring conducted within the BLM has occurred at local scales commensurate with permitting activities (for example, applications for grazing or drilling permits). The boundaries of most projects and permit decisions are relatively small, occurring well within field offices or National Conservation Areas. Accordingly, available funding and capacity within the BLM have traditionally been prioritized to support making frequent, fine-scale decisions for projects and permits. The BLM is now addressing widespread threats and conservation needs through planning and management actions carried out across large areas. There is an associated need for both field-collected and broad-scale monitoring data to fully evaluate the effectiveness of these actions.

Data collected at individual field sites provide important information on, for example, vegetation composition and stand structure (see chapter 2), and the BLM has recently begun to systematically sample sites across the western United States to gather such information. However, there are challenges in relying only on fine-scale data to characterize resource status and condition across broad regions. For example, data collected at individual project and permit sites in the course of completing land management projects and issuing or renewing permits are unlikely to adequately represent the broader landscape, as field sampling sites need to be chosen in an unbiased manner to provide an accurate assessment of resources across broader extents (Gruijter and others, 2006). In many regions, the scattered pattern of public lands for which the BLM has surface management authority may also limit site access, making it difficult for the BLM to implement a standardized and efficient monitoring program that relies on only field sampling. Monitoring broadscale indicators derived from remotely sensed data also provides additional benefits, including the ability to quantify indicators that may be difficult or time consuming to measure on the ground (for example, productivity) and to easily summarize indicators across broad extents, including across jurisdictional and land ownership boundaries. 
In light of the challenges associated with field sampling and potential benefits of considering broad-scale data, the BLM has traditionally augmented its field data with broad-scale data collected by other agencies and organizations. Examples include the U.S. Geological Survey Gap Analysis Program, the U.S. Department of Agriculture National Resources Conservation Service National Resources Inventory, and the Landscape Fire and Resource Management Planning Tools (LANDFIRE, a joint program of the U.S. Departments of the Interior and Agriculture). However, using such data may at times not adequately meet the information needs of the BLM. For example, datasets designed primarily for fuels inventory and management in forested landscapes such as LANDFIRE are often inadequate for characterizing the arid shrublands and grasslands that constitute the majority of lands managed by the BLM outside of Alaska.

Many BLM resource management objectives relate to the distribution of ecological resources across large landscapes, which is typically quantified using remotely sensed datasets (Wulder and others, 2010). As remote sensing technologies improve, the availability of consistent land cover data across broad extents is increasing. There is a concomitant need to collect field data to ground truth broad-scale indicators (for example, vegetation type and productivity). The BLM is now prioritizing the systematic collection of natural resource data at both fine- and broad-scales to facilitate efficiencies in monitoring and assessment at both scales, meet its agency reporting requirements, and enable more effective and efficient decisionmaking across landscapes (Toevs and others, 2011).

\section{Broad-scale indicators provide information about the spatial pattern and distribution of species and ecological communities across landscapes.}

Agencies and organizations outside of the BLM are also implementing multiscale monitoring and assessment programs to inform conservation and management decisions. Multiscale monitoring programs have been proposed or are being implemented by the National Park Service (Fancy and others, 2009; National Park Service, 2012), by the U.S. Department of Agriculture Forest Service through their new planning rule (U.S. Department of Agriculture Forest Service, 2012) and Watershed Condition Framework (U.S. Department of Agriculture Forest Service, 2011), and by the U.S. Fish and Wildlife Service through their Strategic Habitat Conservation initiative (U.S. Fish and Wildlife Service, 2008). Natural resource management agencies at the State level (The Heinz Center, 2009; Western Governors Wildlife Council, 2013) and nongovernmental conservation organizations (World Wildlife Fund International, 2004; The Nature Conservancy, 2006) also use multiscale monitoring to inform their management actions. As these programs mature and expand their data repositories, cooperation, coordination, and data sharing can increase the information available to all entities and foster consistency and efficiencies in data collection.

Broad-scale indicators provide information about the spatial pattern and distribution of species and communities across landscapes, complementing and providing context for detailed information about the species composition of communities collected at the scale of individual sites or projects (see chapter 2). From a management perspective, understanding the status and condition of resources across an ecoregion provides context for targeted management actions (see Box 1) and can identify areas where localized, supplemental sampling of habitat condition is needed to inform local decisions.

Multiscale monitoring also captures information about ecological processes that interact across spatial scales. For example, the hydrologic function of a specific site will depend on precipitation and flow patterns that are affected by soils and vegetation both locally and across a watershed. Similarly, wildlife need individual habitat patches of adequate size and condition to provide high value forage opportunities. However, those patches also need to occur in adequate numbers and proximity across a species' range to provide the conditions needed to maintain traditional movement patterns (for example, seasonal migrations), effective population sizes, and genetic diversity.

In this chapter, we first describe key components of the BLM Assessment, Inventory, and Monitoring (AIM) Strategy, and the relation between the AIM Strategy, initial AIM monitoring efforts, and Rapid Ecoregional Assessments (REAs). We then propose core and supplemental broad-scale indicators of resource status and condition that have been developed through the REAs and found to be most appropriate and feasible to measure at the extent of ecoregions. The proposed broad-scale indicators complement terrestrial and aquatic indicators measured locally, facilitating the use of multiscale information in making resource decisions on lands managed by the BLM. Finally, we suggest ways in which broad-scale indicators may inform the development, design, and implementation of field monitoring programs and be used in multiscale natural resource assessments. 


\title{
Box 1-Using Rapid Ecoregional Assessment Data to Provide a Broader Context for the Centennial Watershed Assessment
}

\author{
By Sandra (Sam) E. Litschert
}

One of several applications for broad-scale data is to understand better how a specific area of interest relates to the surrounding landscape. For example, how does the status and condition of resources within the area of interest compare to other areas across the landscape or region? Rapid Ecoregional Assessments provide broad-scale data over one or more ecoregions that can be used to evaluate the ecological and physical contexts of smaller areas (Bureau of Land Management, 2016). Understanding the status and condition of natural resources, and the ecological processes and anthropogenic activities that may affect those resources, can help resource managers identify potential areas for restoration and mitigation actions and assess potential cumulative effects of proposed development activities.

We used resource condition data from the Middle Rockies Rapid Ecoregional Assessment (REA) (Science Applications International Corporation, 2012a) to provide information on existing threats and potential future risks to highly valued resources in the Centennial Watershed and surrounding landscape (Bureau of Land Management, 2015b). Dillon Field Office personnel selected several resources and issues of management concern to evaluate including priority terrestrial and aquatic species and assemblages, riparian communities, forest health, risk of wildfire, and conifer expansion. We analyzed data addressing each resource and issue at three different spatial extents: the Middle Rockies REA, the Dillon Field Office, and the Centennial Watershed (Box 1-fig. 1). The watershed and field office extents cover about 1 percent and 7 percent of the Middle Rockies REA area respectively. Here we present example results illustrating the relation between the Centennial Watershed and the rest of the ecoregion.

The Centennial Watershed contains corridors of high quality habitat for priority terrestrial species, including large carnivores. Vegetation Condition Class data (LANDFIRE, 2012) provide information about the condition of vegetation in these corridors, specifically the degree to which current vegetation is different from simulated historical (preEuroAmerican settlement) reference conditions (Box 1-fig. 2). Low departure indicates areas of vegetation that are generally within the historic or natural range of variation for that area (Barrett and others, 2010). Areas showing high departure indicate uncharacteristic conditions that may be a result of fire suppression, introduction of invasive weeds, insects, disease, forest harvest, or repeated grazing (Barrett and others, 2010). Proportionally, Centennial Watershed has the largest area with high departure (57 percent) compared to the Dillon Field Office (39 percent) and the Middle Rockies (43 percent) (Box 1-fig. 2). Our findings illustrate that wildlife habitat corridors within the Centennial watershed may be at high risk from shifts in vegetation condition compared to the broader ecoregion.

Broad-scale data from REAs can help to inform and provide context for resource assessments conducted for smaller areas. Broad-scale data may have limited spatial resolution and accuracy for assessing localized areas, but can indicate a need for collecting more detailed data to verify local conditions and identify factors potentially affecting resource condition locally. Using a combination of fine-scale and broad-scale data provides a more complete understanding of the status and condition of resources in the area of interest. In this case, broad-scale data identifying the location of and risks to wildlife habitat corridors helped to both identify fine-scale data collection needs and plan individual projects that will provide benefits across a broader area.

"Looking at the data at multiple scales, helped the Interdisciplinary Team put resource issues and concerns in context with larger scales and therefore helped us to develop and prioritize projects at the watershed level. Projects selected for implementation are aimed at incrementally improving conditions within the ecoregion. These datasets will also be very valuable to support and defend our decisions for the Centennial Watershed."-Pat Fosse, September 2015, Dillon Field Office, Bureau of Land Management 


\section{Box 1-Continued}

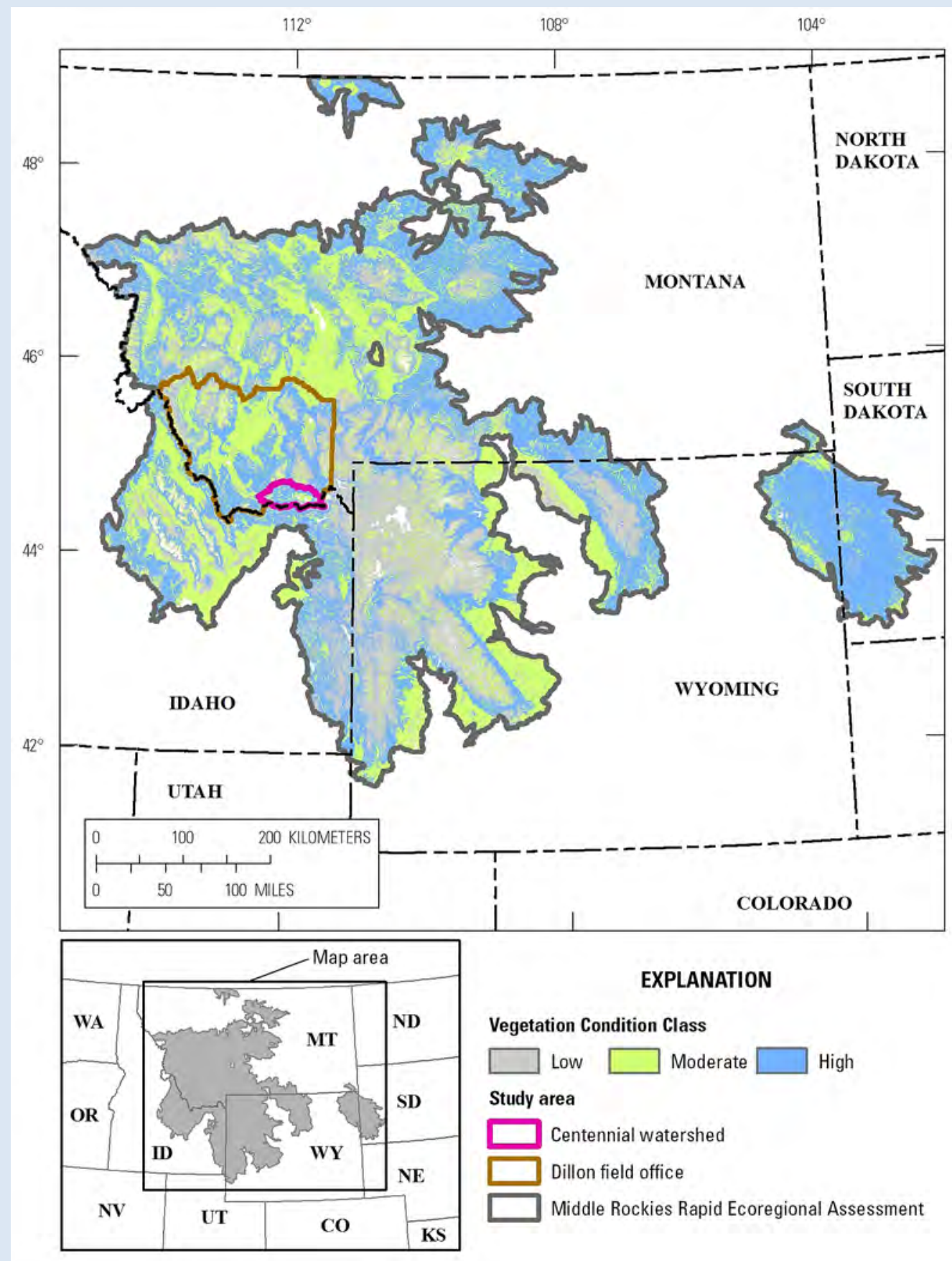

Box 1-Figure 1. Vegetation Condition Class (LANDFIRE, 2012) in the Middle Rockies Rapid Ecoregional Assessment boundary, Dillon field office, and Centennial watershed. 


\section{Box 1-Continued}

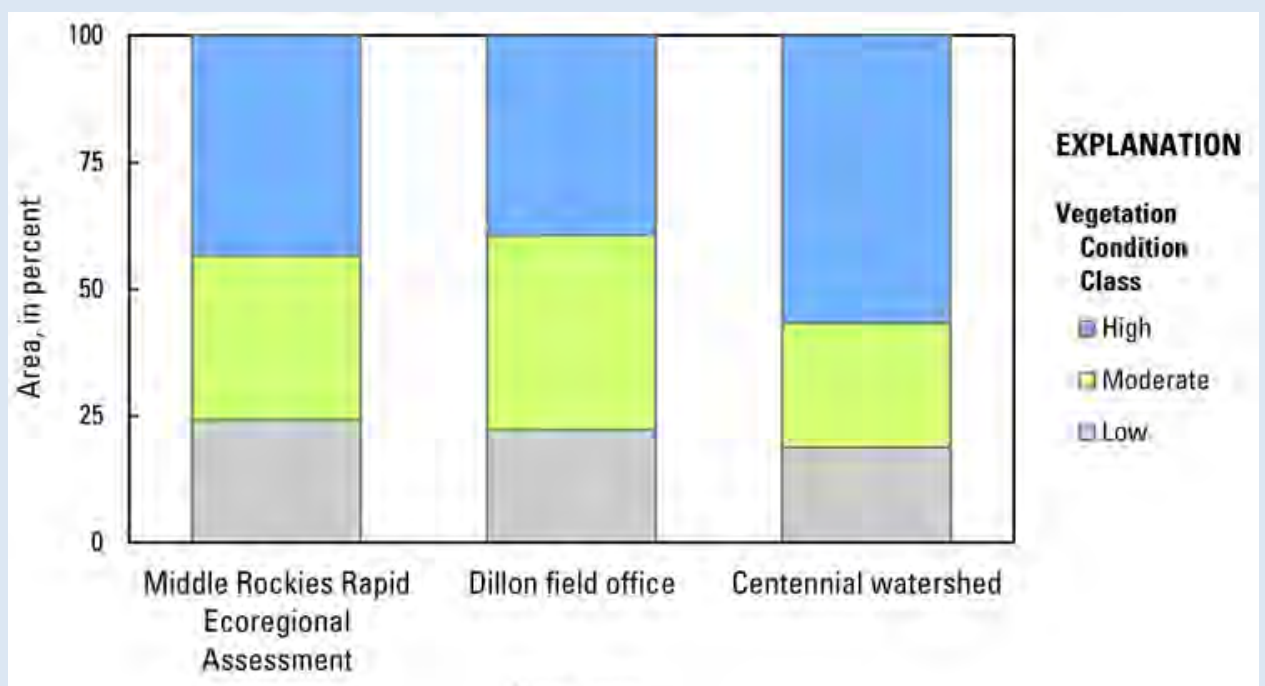

Study area

Box 1-Figure 2. Percent area in each Vegetation Condition Class (LANDFIRE, 2012) within the Middle Rockies Rapid Ecoregional Assessment boundary, Dillon field office, and Centennial Watershed.

\section{Integrating Rapid Ecoregional Assessments with the Assessment, Inventory, and Monitoring Program}

In 2011, the BLM developed an AIM Strategy in response to a program evaluation of the BLM by the U.S. Office of Management and Budget that identified gaps in monitoring of resource condition (Toevs and others, 2011, Office of Management and Budget, 2004). The AIM Strategy outlines 10 fundamental management issues spanning local to national resource concerns, including assessing the cumulative effects of management actions, the status and condition of resources across an ecoregion, and the location and abundance of priority renewable resources across all lands managed by the BLM (Toevs and others, 2011). The AIM Strategy also proposes a process for collecting and managing data to address these issues. Key components of the process are: (1) consistent collection of core indicators, (2) use of statistically valid sampling designs, (3) use of remote sensing techniques, and (4) efficient data management and acquisition. The AIM Strategy is a multiscale, coordinated, and integrated approach for new data collection, and is intended to allow the BLM to more easily address management issues that cross field office boundaries (Toevs and others, 2011).
Initial accomplishments of the AIM Strategy have been to establish scientifically valid monitoring principles (Toevs and others, 2011) and identify standardized indicators for field monitoring of terrestrial systems (MacKinnon and others, 2011). Many pilot efforts helped the BLM develop effective and efficient monitoring and assessment programs. In the Assessment, Inventory, and Monitoring section of this report, we describe two of these efforts that together provide complementary local- and broad-scale information spanning the fundamentals of the AIM Strategy: AIM monitoring and Rapid Ecoregional Assessments (REA).

\section{Assessment, Inventory, and Monitoring}

AIM monitoring describes monitoring conducted according to a standardized process originally outlined in the AIM Strategy (Toevs and others, 2011) and further defined in subsequent work (Taylor and others, 2014). The fundamental components of AIM monitoring are to use a standardized monitoring process, a core set of indicators to monitor key ecosystem components (fig. 3-1), a statistically valid sampling design, electronic data capture, and integration of field and remotely sensed data. Additional supplemental indicators may also be monitored to help answer specific management questions (for example, questions related to endangered species habitat). 


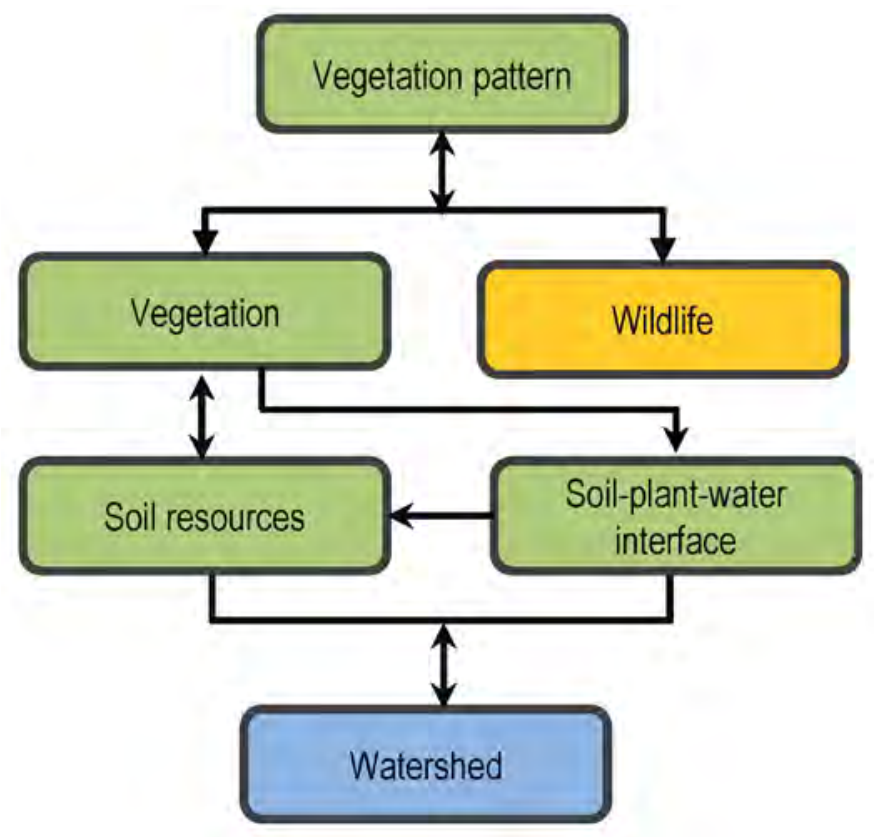

Figure 3-1. Conceptual model of the ecosystem components monitored by the BLM Assessment, Inventory, and Monitoring program (modified from Taylor and others, 2014).

To date, AIM monitoring efforts have primarily used sitebased field sampling of vegetation composition and height, amount of bare ground, and other metrics to assess the status and condition of terrestrial systems (Taylor and others, 2014). Example efforts include the westwide landscape monitoring effort, land health assessments for rangelands in Nevada, and monitoring in the National Petroleum Reserve-Alaska (Taylor and others, 2014; Karl, 2015). All of these projects use annual sampling of core and supplemental indicators to address questions about the condition of Federal lands within large geographic areas. Core indicators for streams and rivers have also been developed that will guide aquatic AIM monitoring efforts (Bureau of Land Management, 2015a). Core broad-scale indicators of natural resource status and condition have not yet been developed. Further work is also needed to identify how locally collected and broad-scale indicators may be used together to increase monitoring efficiency and enhance our understanding of resource status and condition (for example, using field sampling of vegetation to validate indices of vegetation productivity calculated using satellite imagery).

\section{Rapid Ecoregional Assessments}

The purpose of REAs is to facilitate evaluation of the cumulative effects of management decisions on regionally important species and ecosystems at broad spatial scales (Bureau of Land Management, 2016). REAs identify and map the distribution of priority ecological communities and wildlife habitats within ecoregions, including wide-ranging species such as mule deer, caribou (Rangifer tarandus), and golden eagles (Aquila chrysaetos). REAs also evaluate potential threats to natural resource values (fig. 3-2), including development, climate change, wildfire, and invasive species. Some REAs compared current resource status to estimated historical reference conditions (for example, LANDFIRE biophysical settings [LANDFIRE, 2010]) to evaluate changes in vegetation patterns that have occurred since EuroAmerican settlement. Using information from multiple REA analyses can help managers understand, for example, where development may have had the greatest effects on wildlife habitat and where relatively undeveloped areas of wildlife habitat remain. In this way REAs provide broad-scale information needed to help identify areas that may be most appropriate for future conservation, restoration, or development actions, informing a landscape approach to natural resource management (see chapter 2).

REAs consider all lands (regardless of ownership) within an ecoregion. Ecoregions span administrative boundaries and typically encompass areas much larger than those managed by individual BLM field offices. The assessment areas of completed REAs range in size from 4 to 39 million hectares (11 to 91 million acres). In the conterminous United States, REA boundaries were derived from the Environmental Protection Agency (EPA) Level III Ecoregions (Omernik, 1987). In Alaska, REAs use the Unified Ecoregions of Alaska (Nowacki and others, 2001). Examples of ecoregions include the Sonoran Desert, Seward Peninsula, and Colorado Plateau.

REAs compile existing data; no new field data are collected for these assessments. A goal of the REAs is to identify key data gaps and management questions that cannot be fully addressed because adequate data are not available across the ecoregion. Such data gaps, along with our limited understanding of many species and communities, restricted many REA modeling efforts. As new information becomes available, REA analyses can be updated. New priorities may also emerge, and REAs may be able to more fully address some management questions through new or enhanced models. To date, REAs have been completed as one-time assessments. Repeated assessments could provide a mechanism for monitoring current trends in resource status and condition.

The challenge for the BLM is to build on lessons learned through REAs and initial AIM monitoring efforts to integrate the two programs. Goals for both programs are compatible. Using a common framework (the AIM Strategy) and linking the field- and remote sensing-based approaches will facilitate implementation of a coordinated, multiscale monitoring program. Such a program would allow managers to address management questions that span local to national scales, to more fully evaluate progress towards meeting resource objectives at multiple scales, and to develop a multiscale working understanding of the landscape, all of which support implementation of a landscape approach (see chapter 2). In chapter 4, we outline one example application of how REA and AIM monitoring data could be used together to assess the ecological integrity of rangelands across the western United States. 

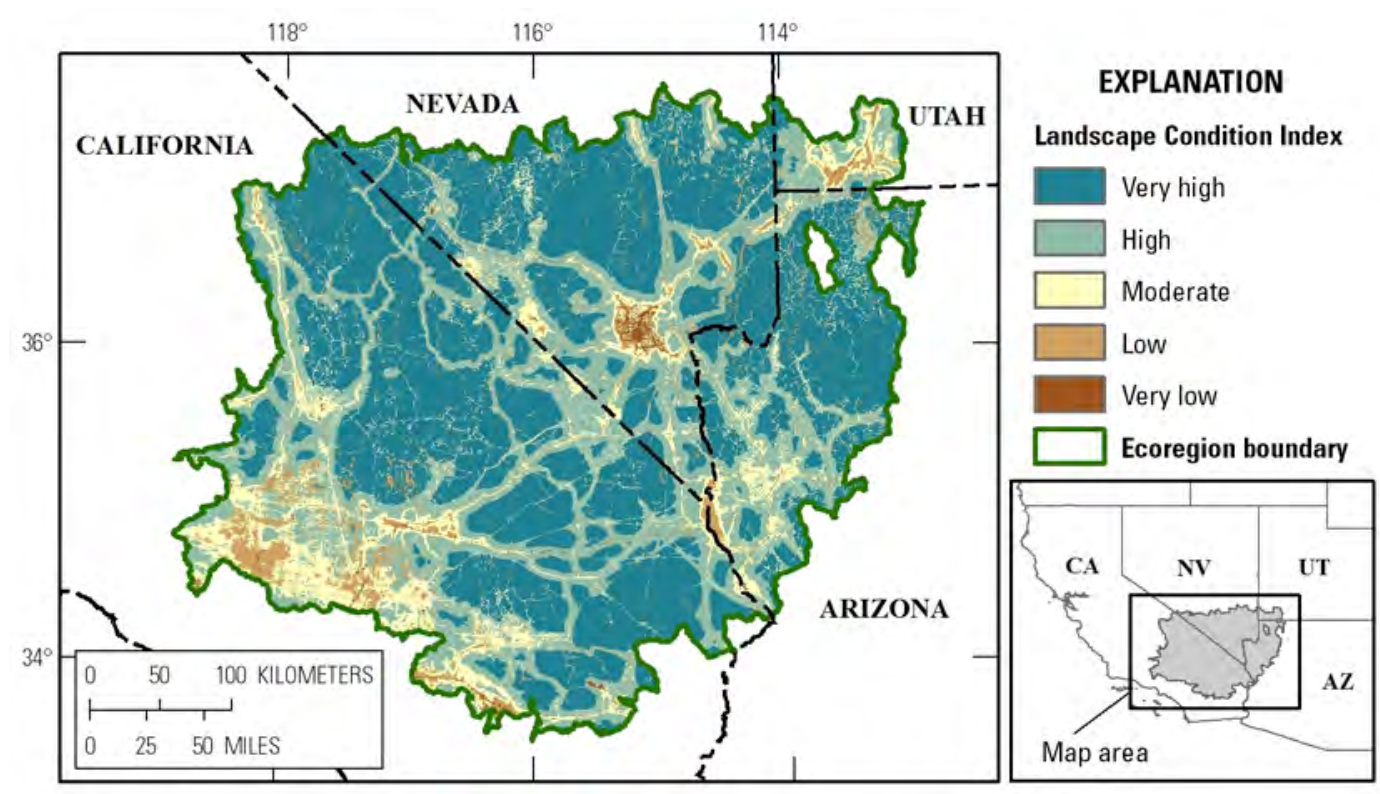

Figure 3-2. Example landscape condition analysis from the Mojave Basin and Range Rapid Ecoregional Assessment (map modified from Comer and others, 2013b).

\section{Development of Broad-Scale Indicators from Rapid Ecoregional Assessments}

The BLM has initiated or completed 15 REAs to date. The REAs were conducted using different approaches to address local information needs and to foster innovation in regional assessment approaches and analysis techniques. The following questions have emerged as priorities at the ecoregion level that are feasible to answer with currently available data.

1. What is the amount and spatial distribution of ecological communities and wildlife habitats across the ecoregion, and how have they changed over time (compared to a natural or historical reference condition)?

2. What is the size distribution of patches of ecological communities and wildlife habitats, and how has it changed over time?

3. How well connected are patches of ecological communities and wildlife habitats, and how has connectivity changed over time?

4. What is the current amount and spatial distribution of development across the ecoregion, and how do both relate to ecological communities and wildlife habitats?

5. How frequently do ecological communities burn currently, and how has this changed over time?

6. What is the current distribution of invasive species, and how does the presence of invasive species relate to the distribution of ecological communities that may be vulnerable to invasion?
7. How may a changing climate affect ecological communities and wildlife habitats in the ecoregion?

8. What is the current level of landscape intactness across the ecoregion, and how does intactness vary spatially across ecological communities and wildlife habitats?

The first two questions were addressed consistently by the majority of REAs. Most REAs also addressed connectivity and existing development, but they used a variety of analysis methods. Consequently, standardized methods for quantifying connectivity and development have yet to be identified. In chapter 5 , we review the different methods used to quantify development in REAs and propose one approach for quantifying development as part of a multiscale index of landscape intactness.

We suggest that the first four questions represent core broad-scale indicators - the amount and spatial distribution of ecological communities and wildlife habitats, the size distribution and structural connectivity of community and habitat patches, and the amount and distribution of development (table 3-1, fig. 3-3, see chapter 5). Core indicators provide the foundational information needed to address common management questions that apply to many ecosystems and landscapes. We suggest that questions 5 -7 represent a preliminary list of supplemental broad-scale indicators that may be relevant to managers in many, but not all situations (table 3-1). Supplemental indicators provide the ability (and flexibility) to address more specific management questions that may emerge for particular communities, species, or locations. The final question represents a key derived indicator, landscape intactness, that is calculated using one or more of the core and supplemental indicators across the extent of interest (see chapter 5). 
Table 3-1. Potential core, supplemental, and derived broad-scale indicators of natural resource status and condition.

\begin{tabular}{|c|c|c|c|}
\hline \multirow[t]{3}{*}{ Core } & Amount and distribution of ecological community/habitat & $\begin{array}{l}\text { LANDFIRE Existing Vegetation Type and } \\
\text { Biophysical Setting summarized under } \\
\text { the National Vegetation Classification }\end{array}$ & $\begin{array}{l}\text { All ecoregions with BLM } \\
\text { surface management }\end{array}$ \\
\hline & $\begin{array}{l}\text { Patch size (ecological community, species, or habitat) } \\
\text { Connectivity }\end{array}$ & To be developed & \\
\hline & Amount and distribution of development & See chapter 5 & \\
\hline Derived & Landscape intactness & See chapter 5 & When needed \\
\hline
\end{tabular}

In the remainder of this chapter, we provide guidance on how to assess broad-scale indicators as part of multiscale AIM monitoring projects and outline ways in which the broad-scale indicators may inform management.

\section{A Process for Assessing Broad-Scale Indicators as part of Multiscale Monitoring Efforts}

AIM monitoring projects are intended to be long term, iterative efforts in which management questions drive project design and indicators across multiple scales are used, as appropriate, to improve understanding of and adaptively manage resources across landscapes and regions (Taylor and others, 2014). The four steps of AIM monitoring are to develop, design, implement, and repeat the monitoring or assessment. Similar to the design of other monitoring programs (for example, Cooperrider and others, 1986), these steps encompass scoping to identify management concerns, evaluating scoping results to identify major resources and values of concern, key threats, and additional specialized assessment needs; defining the temporal and (or) geographic scope of the monitoring effort; and linking resources, values, and threats through conceptual models. In the four steps below, we apply the generalized AIM monitoring process to the specific task of quantifying broad-scale indicators and describe key steps in assessing broad-scale indicators as part of a multiscale monitoring project (fig. 3-4).

\section{Step 1: Develop}

Defining priority management questions will guide identification of the natural resources and environmental and anthropogenic processes (such as development, fire, and invasive species) that are of greatest management concern in the study area (fig. 3-4). Using established frameworks for characterizing anthropogenic processes improves consistency across assessments (see Salafsky and others, 2008). Careful consideration is needed of the number of species and ecological communities selected for inclusion, the number of environmental or anthropogenic drivers relevant to each, and the level of detail required to address the management questions. Otherwise assessments may become so large in scope that some topics must be treated superficially because of logistical constraints (Sutherland, 2013).

Priority management questions and objectives will drive the geographic extent of the assessment. For species, assessment extents may encompass the range of relevant populations or species (for example, Manier and others, 2013). Considering larger extents and using consistent methodologies across ecoregions may enable rangewide analyses of habitat for and potential threats to species with ranges that span ecoregional boundaries (for example, greater sage-grouse, golden eagles). Similarly, questions relating to the potential response of species and communities to a changing climate frequently are addressed at broader spatial extents than ecoregions. In REAs, analyses of potential effects of a changing climate on a species or community are often conducted across the entire bioclimatic range of the species or community but interpreted within the region of interest (for example, Comer and others, 2013a, b; Crist and others, 2014), and may include consideration of areas outside the current range of a species (for example, Inman and others, 2016). The spatial and temporal scales at which the selected processes operate along with relevant ecological and administrative boundaries help define the study area boundary and analysis units. The REAs focus on terrestrial and aquatic communities and wide-ranging wildlife species and use broad ecological boundaries.

Developing conceptual models relating priority resources to environmental and anthropogenic drivers highlights interactions between different ecosystem components and stressors and helps ensure that relevant spatial and temporal scales and indicators are considered. For example, a grassland conceptual model (fig. 3-5) may identify fire and invasive species as key drivers for which supplemental indicators should be measured. Conceptual models may often be available from prior efforts (for example, Britten and others, 2007; Chung-MacCoubrey, 2008; Gitzen and others, 2010; Miller and others, 2010; The Heinz Center, 2009). For example, the Middle Rockies and Northwestern Plains REAs used conceptual models developed by the National Park Service Rocky Mountain Network (fig. 3-5). 

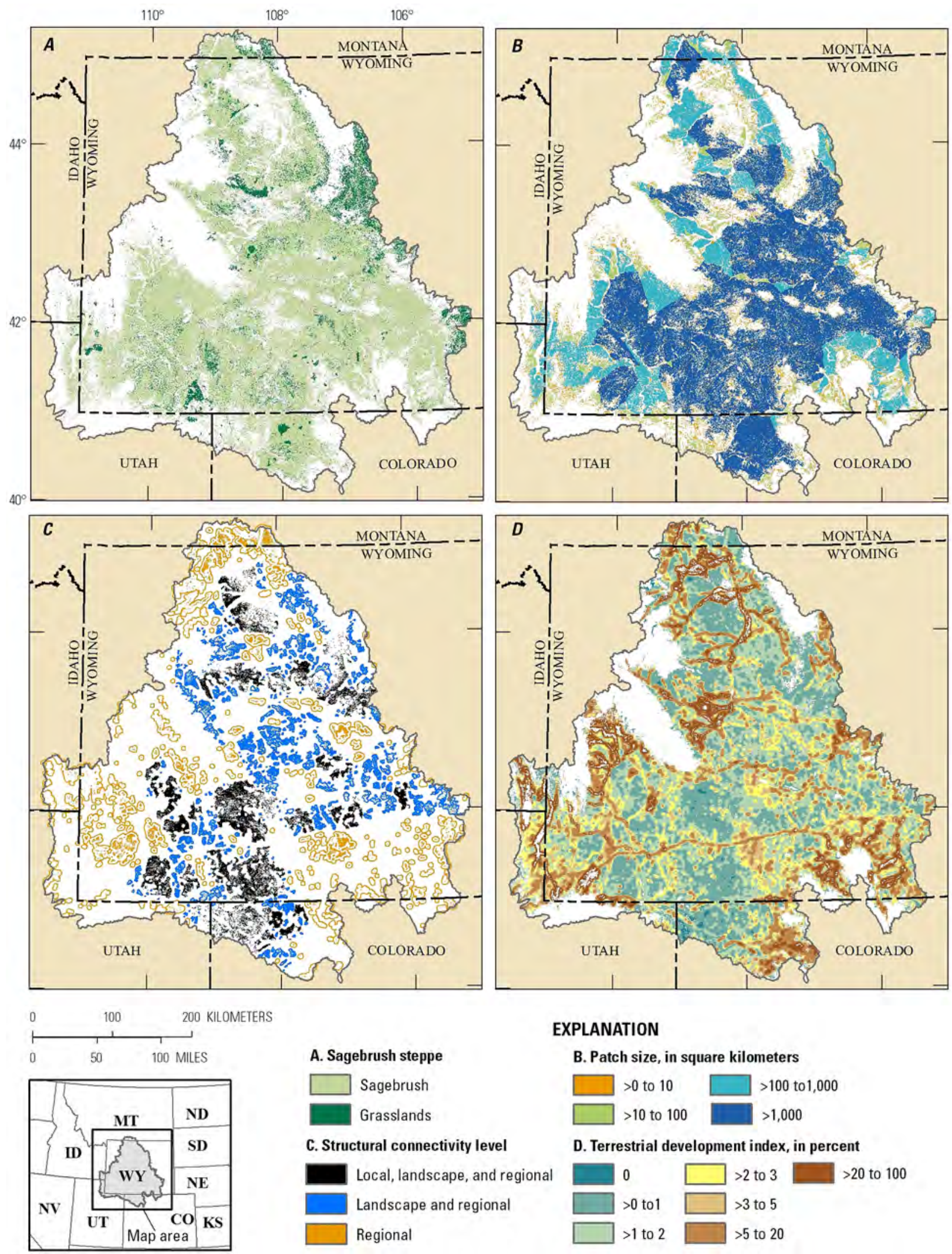

A. Sagebrush steppe

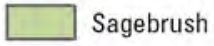

Grasslands

C. Structural connectivity level

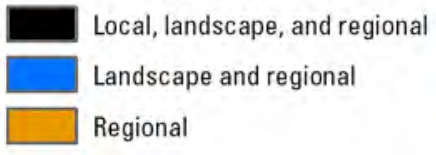

\section{EXPLANATION}

B. Patch size, in square kilometers

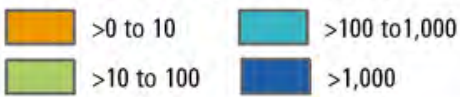

D. Terrestrial development index, in percent

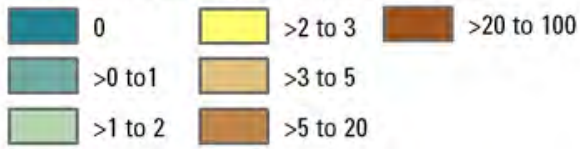

Figure 3-3. Example of indicators for sagebrush steppe for the Wyoming Basin Rapid Ecoregional Assessment. $A$, distribution of sagebrush steppe, $B$, patch size for reference conditions, $C$, structural connectivity, and $D$, development levels (modified from Carr and Melcher, 2015). 


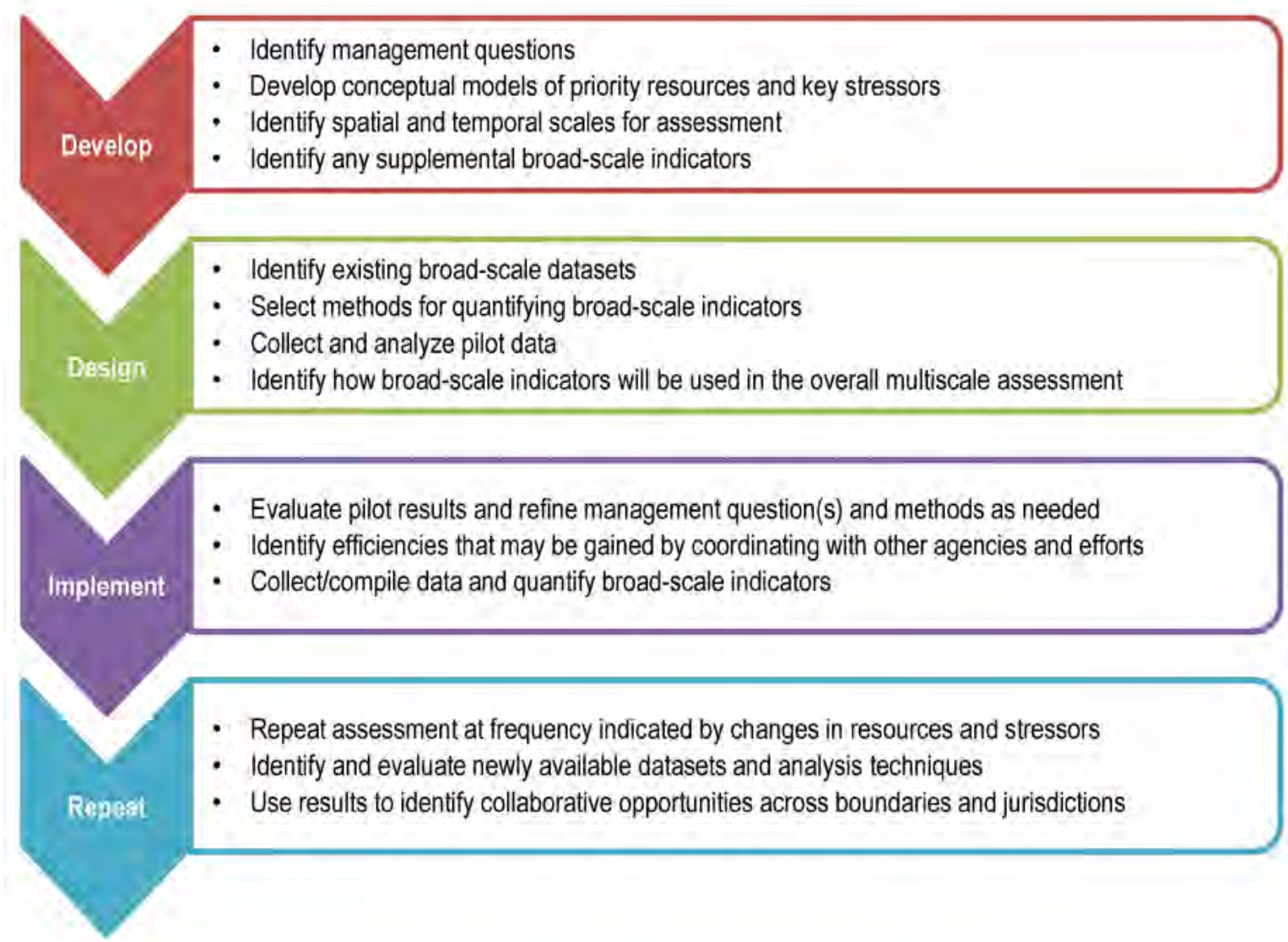

Figure 3-4. Steps in assessing broad-scale indicators of natural resource status and condition as part of a multiscale monitoring program.

\section{Step 2: Design}

When designing the assessment, the selected questions and indicators will guide identification of specific datasets and methods to be used. Existing datasets, completed assessments, and ongoing monitoring can help identify the broad-scale indicators that may be most feasible to quantify and provide information on available reference or historical conditions for evaluating resource condition. Acceptable methods for quantifying indicators may exist, or may need to be developed or adapted from the scientific literature. The development and design steps are likely to be iterative. Time, funding, and scope limitations may mean that some management questions or approaches are not feasible to address given available capacity and information.

The design of the monitoring program can be improved by explicitly considering the need, balance, and tradeoffs between collecting and compiling generalized information applicable to many species and communities compared to developing specific, detailed models for fewer high priority resources. For example, many REAs focused on broad-scale indicators of development rather than species-level indicators of the likely effects of development on individual species (for example, Carr and Melcher, 2015). For species with limited available information, generalized indicators may be helpful to managers. However, developing species-level models and approaches may improve the utility of the assessment for informing management of those species. Considering how detailed information, such as existing field data or detailed habitat models, can be used together with more generalized, broad-scale indicators to address management questions helps set expectations, identify information gaps, and guide the assessment.

Using standardized classification schemes for vegetation communities facilitates addressing management questions at different levels of detail. For example, the BLM uses macrogroups from the National Vegetation Classification Standard (Bureau of Land Management, 2013) when assessing terrestrial communities at a Level III ecoregion. The macrogroup level in the classification hierarchy provides a reasonable number of vegetation communities to inform BLM resource management plans. For specific high priority resources (such as five-needle pines in the Middle Rockies [Science Applications International Corporation, 2012a] or mesquite in the Madrean Archipelago [Crist and others, 2014]), a more detailed level in the classification such as group or alliance may be needed.

As with the development step, general frameworks for multiscale assessments (Groves, 2003; Lindenmayer and others, 2015, Noon, 2003, Unnasch and others, 2009) provide valuable information for designing multiscale programs. Many multiscale monitoring programs exist, including programs that focus on monitoring individual species (Carroll and others, 2001; Parrish and others, 2003; The Heinz Center, 2009; Stiver and others, 2015) and terrestrial systems (Diffendorfer and others, 2007; 


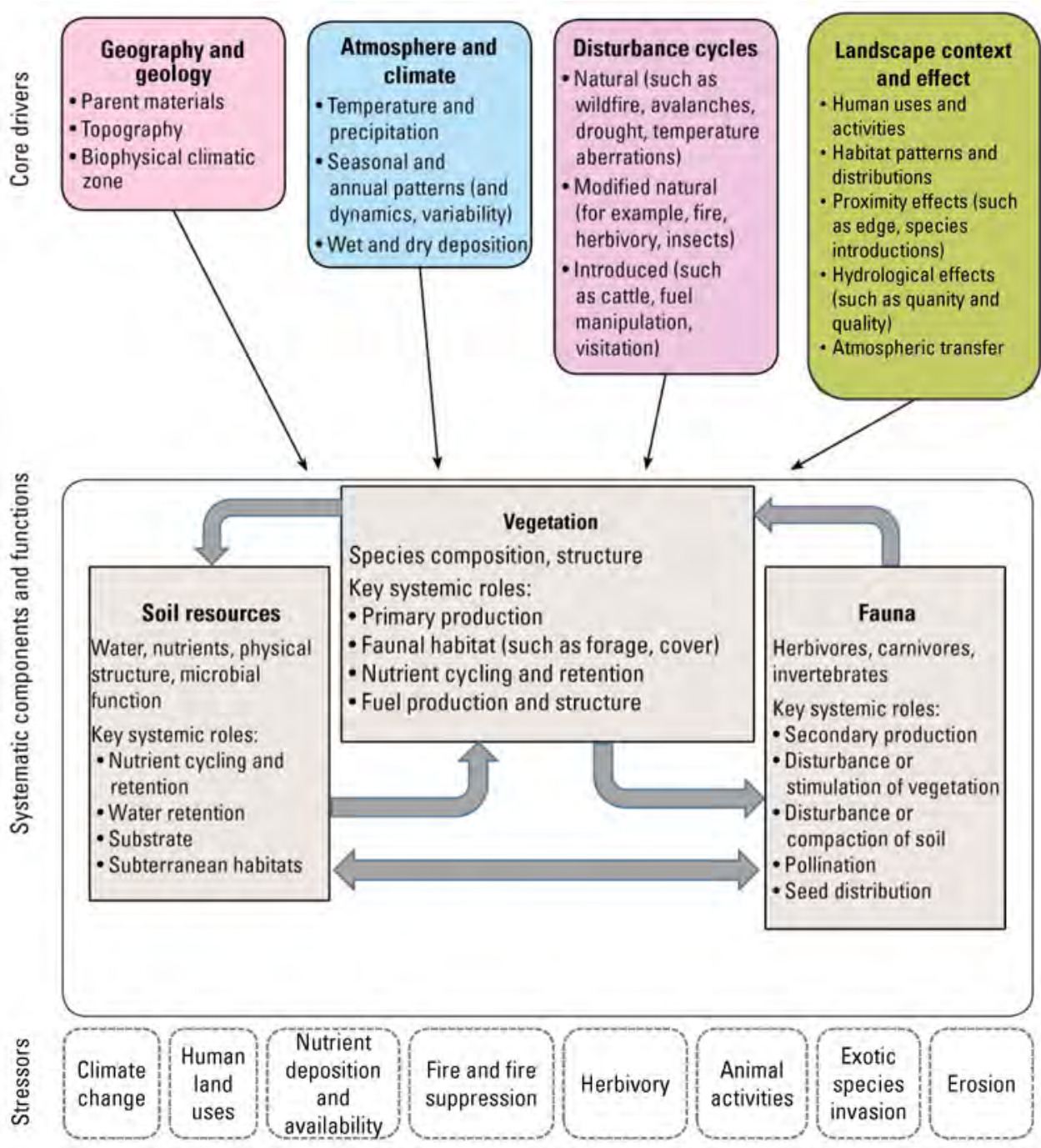

Figure 3-5. Grassland conceptual model for the Northwestern Plains ecoregion (figure modified from the Northwestern Plains Rapid Ecoregional Assessment [Science Applications International Corporation, 2012b] and originally developed for the Rocky Mountain Network Vital Signs Monitoring Plan [Britten and others, 2007]). Note that this model fits within a conceptual model for the landscape and includes submodels to provide more detail about specific processes.

Tierney and others, 2009; Wulder and others, 2010; Wilson and Bayley, 2012; Thompson and others, 2013). Communicating and cooperating during the design step with other entities that have established monitoring programs may help highlight data gaps that need to be filled, identify useful indicators and methods, promote consistency in methods, and augment the pool of available data.

\section{Step 3: Implement}

Collecting and analyzing data to implement the assessment will follow the overall AIM monitoring process. Broadscale indicators are typically collected in multijurisdictional landscapes, so there may be opportunities to leverage monitoring efforts with other agencies and organizations. Assessment of broad-scale indicators may focus on analyses of existing datasets. Conducting pilot analyses and following appropriate data quality assurance and control steps will help determine if modifications to the development or design steps are needed.

\section{Step 4: Repeat}

The speed at which a landscape is changing in terms of both resources and environmental and anthropogenic drivers, such as energy development, will inform the ideal frequency for repeating broad-scale assessments. Some components of an assessment may need to be repeated frequently (for example, calculation of development in a rapidly urbanizing landscape), while other indicators may be more durable. New techniques and datasets may also emerge that allow more accurate quantification of additional broad-scale indicators (for example, the amount and distribution of invasive species). 


\section{Using Broad-Scale Indicators to Inform Field Monitoring}

Developing, designing, and implementing a broad-scale assessment with explicit consideration of potential links to field monitoring increase the utility of broad-scale data and inform field monitoring efforts in a number of ways (fig. 3-6). Some management questions may be answered (or partially answered) using the core broad-scale indicators. With the increasing quality and resolution of remotely sensed land cover data, standardized indicators calculated across broad regions may meet more localized information needs as well. Broad-scale indicators also provide context for interpreting data collected at individual sites. For example, what appears to be unexplained variability in individual field samples may be consistent with broad environmental patterns evident from remotely sensed data collected across regions. Alternately, broad-scale indicators may provide early warning that field sampling is needed and help prioritize areas for more intensive monitoring efforts. For example, broad-scale indicators may identify where habitat conversion or loss has occurred and whether remaining habitat patches occur in close proximity within a landscape that is primarily natural or are isolated within an area that has been largely developed. Field sampling to evaluate local habitat condition can then focus on specific questions related to habitat degradation within key patches or habitat areas. Poor data availability at regional extents (for example, on invasive species) may also indicate a need to collect more data (for example, on the species and abundance of invasive plants) at field sampling locations. Understanding the amount and distribution of vegetation communities across a landscape may also be used, in part, to stratify field sampling efforts.

\section{Integrating Local- and Broad-Scale Monitoring and Assessment Data to Inform Management Decisions}

Local- and broad-scale monitoring efforts provide managers with key information needed to prioritize and target conservation, restoration, and mitigation actions within and across landscapes (for example, Pyke and others, 2015). Broad-scale assessments provide information on the current distribution of priority ecological communities and wildlife habitats, where they may have occurred in the past, and where environmental processes or human activities may threaten priority resources. Field sampling provides detailed information on the composition, structure, and function of ecosystems and habitats at a local scale. Field data are often critical for understanding the condition of the community and the specific manner and extent to which it may be affected by human activities or environmental processes. For example, information on areas of potential habitat for sage-grouse (from broad-scale indicators) that are currently in poor condition (from field sampling) may help guide habitat restoration efforts. Similarly, broad-scale assessments that map locations of sensitive species and ecosystems are a first step in determining where other desired resource uses, such as solar energy development, can best be accommodated, and how negative effects to the environment from development may be mitigated (see Box 2).

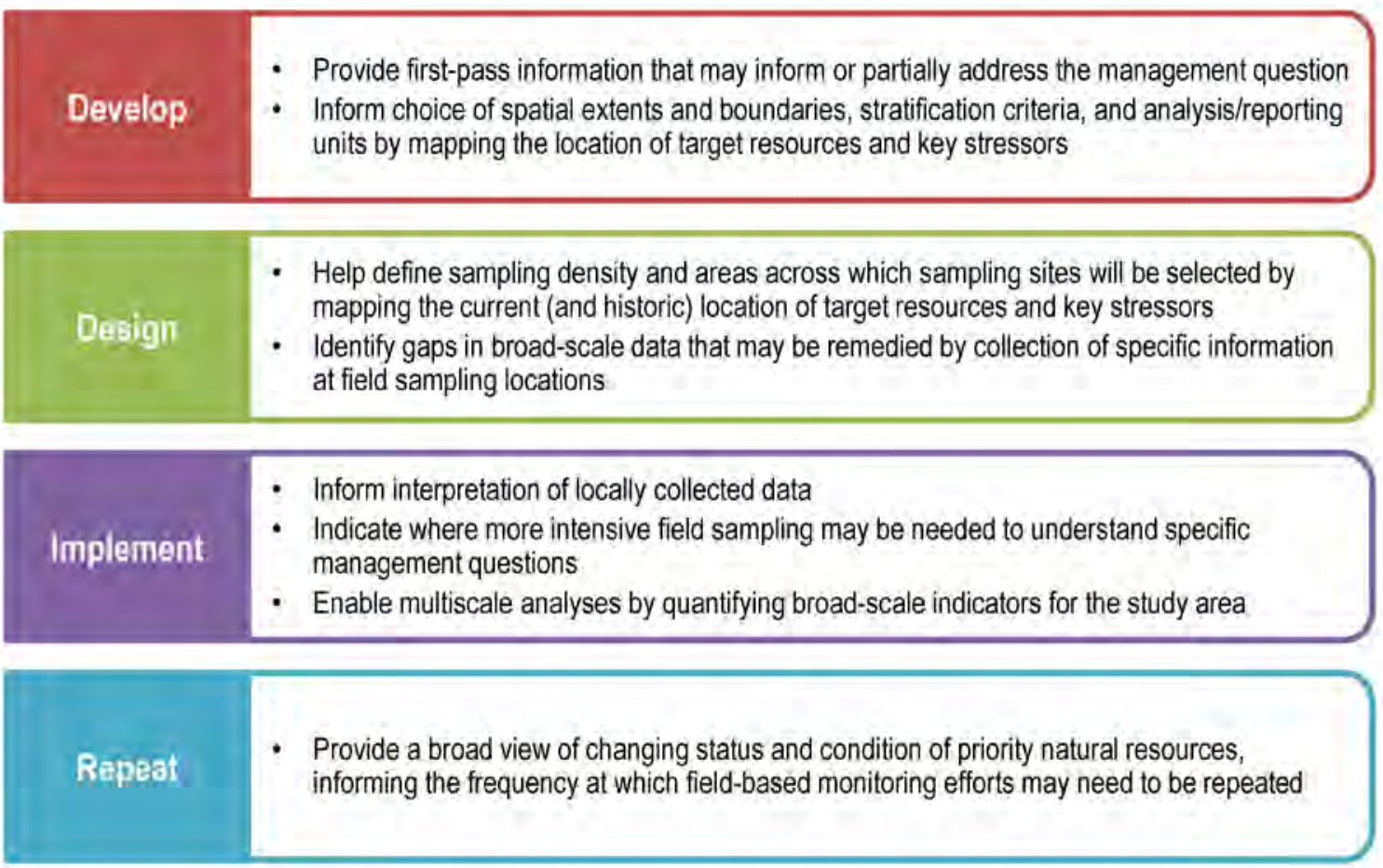

Figure 3-6. Potential ways in which broad-scale assessments may inform field monitoring efforts at each stage in the assessment process. 


\title{
Box 2-Using Rapid Ecoregional Assessment Data to Inform Regional Mitigation Planning for Solar Energy Development
}

\author{
By Leroy J. Walston
}

The Bureau of Land Management (BLM) and other Federal agencies are adopting a landscape approach to mitigation planning for management decisions affecting large areas of public lands. The BLM has outlined a process for evaluating proposed utility-scale solar developments (for example, facilities with electric capacities greater than 20 megawatts) on lands managed by the BLM (Bureau of Land Management and U.S. Department of Energy, 2012). As a result of this process, the BLM committed to preparing regional mitigation strategies for 17 Solar Energy Zones (SEZs). SEZs are locations where solar energy potential is maximized while minimizing potential negative effects of development on wildlife and other resources. Accordingly, the SEZs are priority areas for utility-scale solar energy development. The SEZs range from approximately 1,000 to 60,000 hectares in size.

The BLM follows a formal mitigation hierarchy to avoid, minimize, and compensate for the direct, indirect, and cumulative effects of all land use decisions, including solar development (Clement and others, 2014). The BLM has adopted a regional perspective in identifying potential opportunities for mitigating negative environmental effects of solar energy development by completing Solar Regional Mitigation Strategies (SRMSs) for each SEZ or group of SEZs (for example, Colorado SEZs). SRMSs provide a systematic process for identifying project-specific compensatory mitigation opportunities based on regional goals and objectives (for example, Bureau of Land Management, 2014).

The BLM uses data on the distribution of resources across broad extents to identify SRMSs in which resources may be affected by energy development and other environmental stressors, SRMSs in which anticipated resource effects may warrant mitigation, and potential locations of mitigation actions. Rapid Ecoregional Assessments (REAs) are one source of data and models used to develop SRMSs. A key broad-scale indicator for the Dry Lake SRMS (Bureau of Land Management, 2014) was landscape condition, which is a spatial characterization of the degree of naturalness across the landscape (Box 2-fig. 1).

Broad-scale indicators are used in several ways in SRMS evaluations:

1. Determining which environmental effects warrant mitigation-The compensatory mitigation recommendations in a SRMS are largely based on an understanding of the anticipated direct, indirect, and cumulative effects of solar energy development in a regional context, and the status, condition, and trend of resources across the region that may be affected by solar development. Landscape condition, in combination with data on cultural and visual resources across the region, is particularly useful in determining which unavoidable effects may warrant compensatory mitigation. Compensatory mitigation is determined on the basis of (a) the status, condition, and trend of regionally important resources, and (b) how solar energy development is expected to affect those regional trends (Box 2-fig. 2). Examples of unavoidable effects warranting regional compensatory mitigation include (but are not limited to) (a) loss or degradation of ecosystem services and vegetation, (b) loss of habitat for special status species and other wildlife, (c) effects to cultural resources, and (d) effects to visual resources.

2. Evaluating mitigation locations - Landscape condition is one indicator used to identify and evaluate candidate mitigation sites and actions recommended in SRMSs. For example, landscape condition can inform the mitigation actions (such as acquisition, preservation, or restoration) that are most suited for a particular location. In general, sites with low landscape condition (relative to the surrounding region) that have the potential to improve key resource attributes (for example, patch size and connectivity of habitat for wildlife species of conservation concern) may be suitable areas for restoration actions. Sites with relatively high landscape condition may be suitable areas for preservation actions. 


\section{Box 2-Continued}

3. Calculating a recommended compensatory mitigation fee-The SRMS recommended fee is calculated per acre and averaged across the entire SEZ. The fee considers the full range of potential mitigation actions that may be employed (for example, restoration, preservation, or acquisition). The recommended base fee is determined using a market analysis of local acquisition and restoration costs. Several adjustments to the base fee may be applied, including an adjustment that considers the current landscape condition in the SEZ. This adjustment is designed to account for any pre-existing degradation of the area that is not the responsibility of the solar energy lessee.

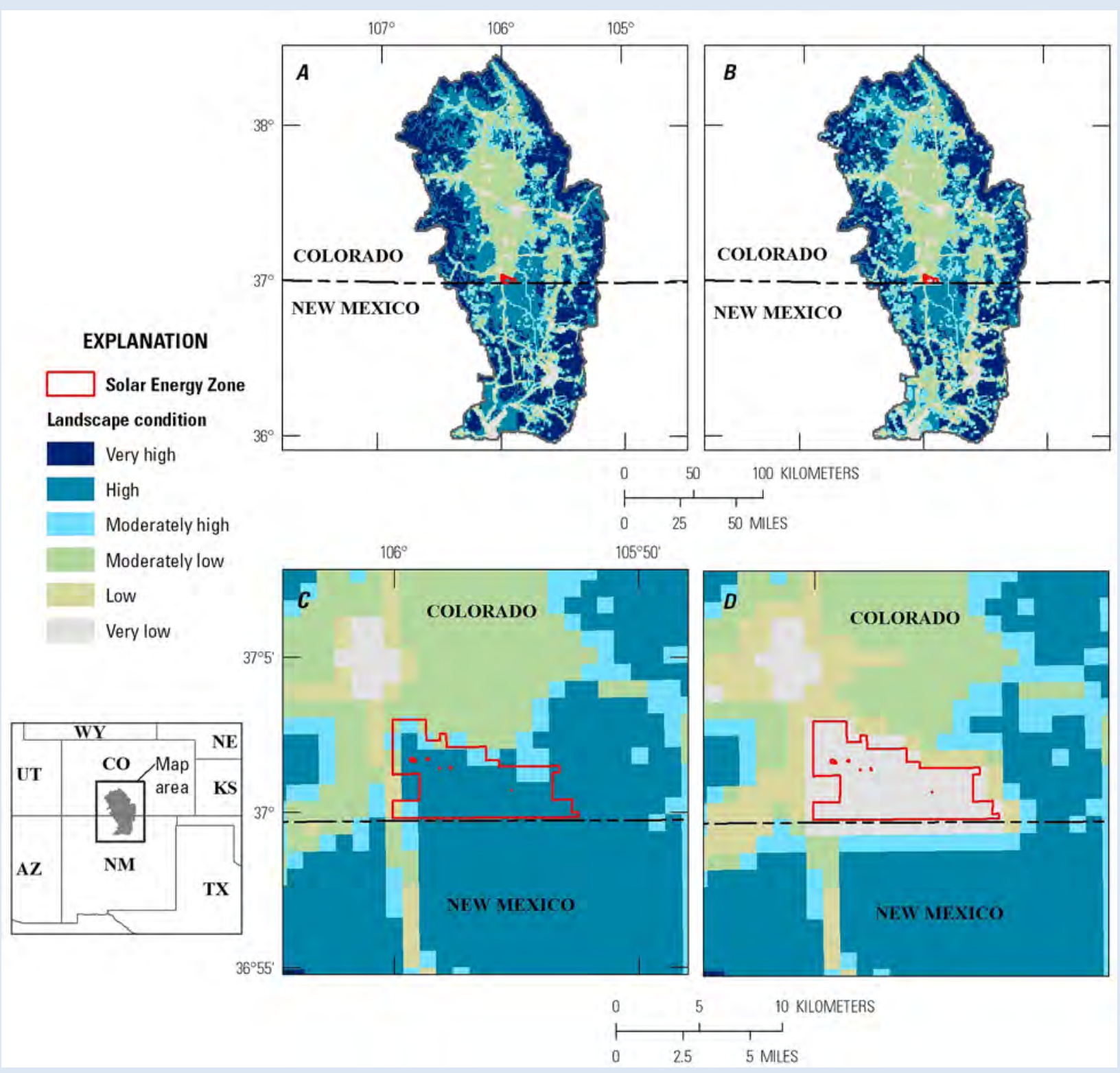

Box 2-Figure 1. $\quad A$ and $C$, Current (2015) and $B$ and $D$, future (2025-2030) landscape condition for the San Luis ValleyTaos Plateau Landscape Assessment (Walston and others, 2016). Results show the expected future change in landscape condition related to solar energy development and were used to inform the Solar Regional Mitigation Strategy for the Colorado Solar Energy Zones (Bureau of Land Management and Argonne National Laboratory, 2016). 


\section{Box 2-Continued}

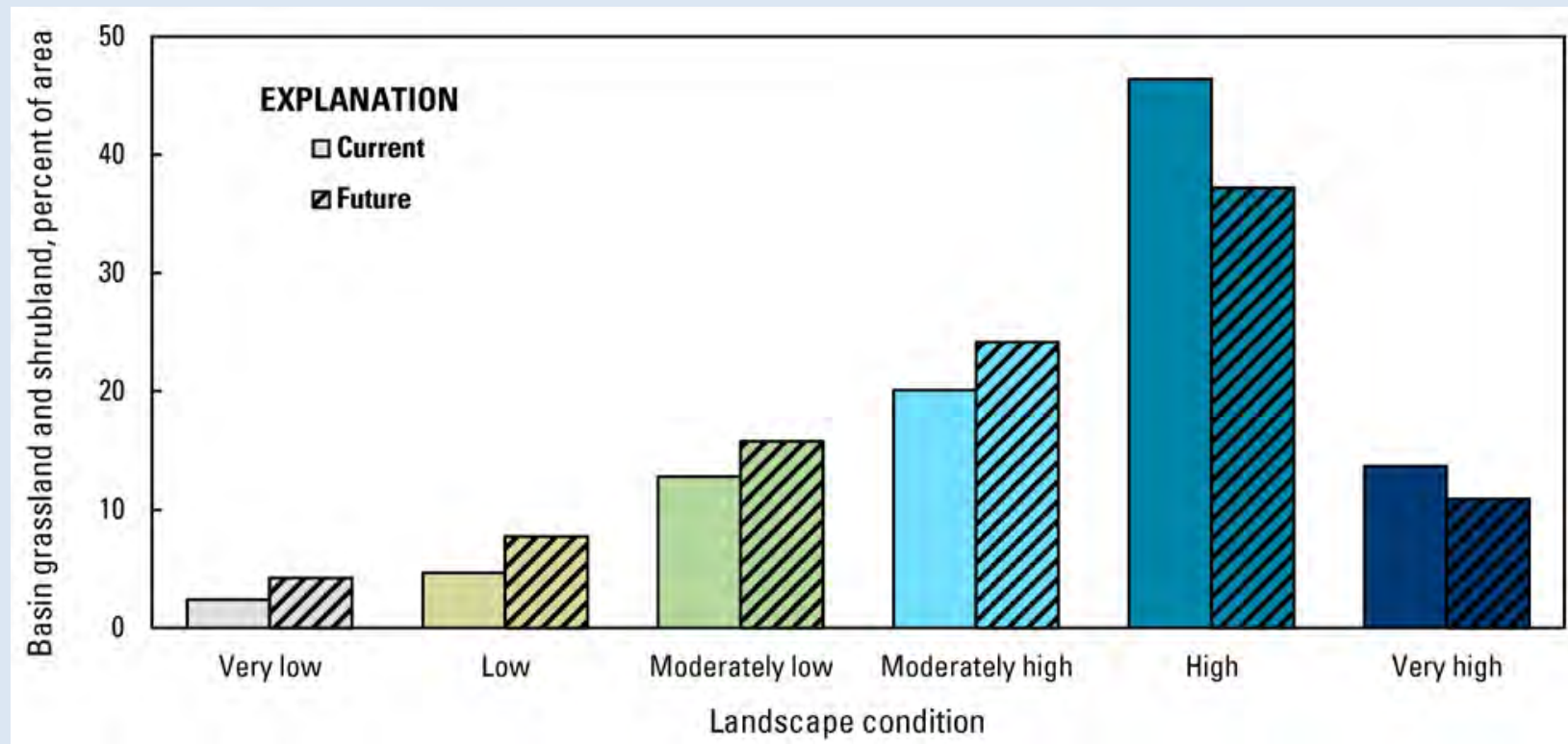

Box 2-Figure 2. Evaluation of current and projected future landscape condition of grasslands and shrublands in the San Luis Valley-Taos Plateau ecoregion (Walston and others, 2016). Results suggest a future decline in the area of shrublands and grasslands with high and very high landscape condition. Grasslands and shrublands dominate the SEZs, suggesting that solar energy development may contribute to declining trends in overall resource condition across the SEZs. Note that anticipated solar development within the SEZs is included in the calculation of future landscape condition.

\section{Conclusion}

While the mandates and missions of natural resource management agencies differ, most are committed to monitoring the status and trend of natural resources on the lands they manage. Developing guidance for assessing broad-scale indicators and using those indicators to inform field monitoring efforts is a first step in providing consistent, multiscale natural resource information across public lands, including on the multiple-use lands of the BLM. Identifying a core set of broad-scale indicators to be measured and standardizing methods for quantifying those indicators would facilitate efficient collection, use, and sharing of multiscale data and information across natural resource programs, entities, and jurisdictions. Standardized methods would also facilitate coordination across boundaries by decreasing the need to allocate staff and resources to understanding differences in methods and analyses between agencies and across boundaries, ultimately allowing greater direction of resources toward management responses to assessment and monitoring findings.

Collecting consistent, multiscale information across broad extents supports implementation of a landscape approach to natural resource management across public lands in numerous ways. Multiscale data are the foundation for understanding and quantifying tradeoffs inherent in meeting different resource objectives across landscapes, a core element of a landscape approach (Sayer and others, 2013). Consistent data across land ownerships and jurisdictions also help to establish a common starting point for conversations between diverse stakeholders about resource values and vulnerabilities. Multiscale monitoring programs supported by multiple entities also build shared understanding and capacity across public lands. Emerging cooperatives at broad, regional scales provide capacity and coordination to support these efforts. For example the Landscape Conservation Cooperatives include collaborative conservation as a goal in their strategic plan, with objectives of removing barriers to cross-agency collaboration and facilitating data sharing (Landscape Conservation Cooperative Network, 2014). The integration of existing, place-based partnerships (such as the Wyoming Landscape Conservation Initiative, the Greater Yellowstone Coordination Committee, and the Crown of the Continent Partnership) with regional conservation cooperatives may help to provide the structure and coordination needed to develop, maintain, and utilize findings from multiscale monitoring programs to improve the effectiveness of management decisions across large, multijurisdictional landscapes. 


\section{References Cited}

Barrett, S.W., Havlina, Doug, Jones, J., Hann, W.J., Frame, C.K., Hamilton, D., Schon, Kathy, Demeo, T., Hutter, L., Menakis, J.P., 2010, Interagency fire regime condition class guidebook, version 3.0: National Interagency Fuels, Fire, and Vegetation Technology Transfer, accessed October 14, 2016, at http:// www.fire.org/niftt/released/FRCC_Guidebook_2010_final.pdf.

Britten, Mike, Schweiger, E.W., Frakes, Brent, Manier, Dan, and Pillmore, David, 2007, Rocky Mountain Network Vital Signs Monitoring Plan: Fort Collins, Colo., National Park Service, Natural Resource Report NPS/ROMN/NRR-2007/010, accessed October 14, 2016, at irmaservices.nps.gov/datastore/ v4/rest/DownloadFile/447063.

Bureau of Land Management, 2013, The National Vegetation Classification and associated mapping standards for Bureau of Land Management planning documents and assignment of state-level vegetation classification data stewards: Bureau of Land Management accessed September 1, 2016, at https:// www.blm.gov/wo/st/en/info/regulations/Instruction_Memos_ and_Bulletins/national_instruction/2013/im_2013-111_the_ national.print.html.

Bureau of Land Management, 2014, Regional mitigation strategy for the Dry Lake Solar Energy Zone: Las Vegas, Nev., Bureau of Land Management, Southern Nevada District Office, Technical Note 444, accessed October 14, 2016, at http://www.blm.gov/style/medialib/blm/wo/blm_library/ tech_notes.Par.29872.File.dat/TN_444.pdf.

Bureau of Land Management, 2015a, AIM National Aquatic Monitoring Framework: Introducing the framework and indicators for lotic systems: Denver, Colo., Bureau of Land Management, National Operations Center, Technical Reference 1735-1, accessed October 14, 2016, at http:/www.blm.gov/style/medialib/blm/wo/blm_library/ tech_refs.Par.86942.File.dat/TR_1735-01.pdf.

Bureau of Land Management, 2015b, Centennial Watershed assessment report: Bureau of Land Management, accessed July 1, 2015, at http:/www.blm.gov/style/medialib/blm/ $\mathrm{mt} /$ field_offices/dillon.Par.70685.File.dat/Centennial\%20 Assessment\%20Report\%202015.pdf.

Bureau of Land Management, 2016, Rapid Ecoregional Assessments: Bureau of Land Management, accessed March 1, 2016, at http:/www.blm.gov/wo/st/en/prog/more/ Landscape_Approach/reas.html.

Bureau of Land Management and Argonne National Laboratory, 2016, Regional mitigation strategy for the Colorado Solar Energy Zones draft report: Argonne, Ill., Argonne National Laboratory Environmental Science Division, accessed October 14, 2016, at http://www.blm.gov/style/medialib/blm/co/ field_offices/slvplc/slv_solar/srms_documents/srms_2016. Par.79732.File.dat/CO\%20SRMS_Draft_1Mar2016\%20 (508\%20Comp).pdf.
Bureau of Land Management and U.S. Department of Energy, 2012, Final Programmatic Environmental Impact Statement (PEIS) for solar energy development in six southwestern states: Washington, D.C., Bureau of Land Management, accessed October 14, 2016, at http://solareis.anl.gov/ Documents/fpeis/index.cfm.

Carr, N.B., and Melcher, C.P., eds., 2015, Wyoming Basin Rapid Ecoregional Assessment: U.S. Geological Survey Open-File Report 2015-1155, 896 p., accessed October 14, 2016, at http://dx.doi.org/10.3133/ofr20151155.

Carroll, Carlos, Noss, R.F., and Paquet, P.C., 2001, Carnivores as focal species for conservation planning in the rocky mountain region: Ecological Applications, v. 11, no. 4, p. 961-980.

Chung-MacCoubrey, A.L., Truitt, R.E., Caudill, C.C., Rodhouse, T.J., Irvine, K.M., Siderius, J.R., and Chang, V.K., 2008, Mojave Desert Network Vital Signs Monitoring Plan: Fort Collins, Colo., National Park Service, NPS/MOJN/NRR2008/057, accessed October 14, 2016, at https://science.nature. nps.gov/im/monitor/plans/MOJN_MonitoringPlan.pdf.

Clement, J.P., Belin, A.d'A., Bean, M.J., Boling, T.A., and Lyons, J.R., 2014, A strategy for improving the mitigation policies and practices of the Department of the Interior: A report to the Secretary of the Interior from the Energy and Climate Change Task Force: Washington, D.C., U.S. Department of the Interior, accessed October 12, 2016, at https://www.doi.gov/sites/doi.gov/files/ migrated/news/upload/Mitigation-Report-to-the-Secretary_ FINAL_04_08_14.pdf.

Comer, Patrick, Crist, Patrick, Reid, Marion, Hak, Jon, Hamilton, Healy, Braun, David, Kittel, Gwen, Varley, Ian, Unnasch, Bob, Auer, Stephanie, Creutzburg, Megan, Theobald, David, and Kutner, Lynn, 2013a, Central Basin and Range Rapid Ecoregional Assessment report: Arlington, Va., NatureServe, prepared for the Bureau of Land Management, $168 \mathrm{p}$.

Comer, Patrick, Crist, Patrick, Reid, Marion, Hak, Jon, Hamilton, Healy, Braun, David, Kittel, Gwen, Varley, Ian, Unnasch, Bob, Auer, Stephanie, Creutzburg, Megan, Theobald, David, and Kutner, Lynn, 2013b, Mojave Basin and Range Rapid Ecoregional Assessment report: Arlington, Va., NatureServe, prepared for the Bureau of Land Management, 173 p.

Cooperrider, A.Y., Boyd, R.J., and Stuart, H.R., eds., 1986, Inventory and monitoring of wildlife habitats: Denver, Colo., Bureau of Land Management Service Center, 858 p.

Crist, Patrick, Reid, Marion, Hamilton, Healy, Kittel, Gwen, Auer, Stephanie, Harkness, M., Braun, David, Bow, J., Scott, C., Misztal, L., and Kutner, Lynn, 2014, Madrean Archipelago Rapid Ecoregional Assessment final report: NatureServe, accessed October 12, 2016, at https://landscape.blm.gov/ REA_General_Docs/MAR_REA_Final_Report_Exec_Sum_ Main_Report.pdf. 
Diffendorfer, J.E., Fleming, G.M., Duggan, J.M., Chapman, R.E., Rahn, M.E., Mitrovich, M.J., and Fisher, R.N., 2007, Developing terrestrial, multi-taxon indices of biological integrity: An example from coastal sage scrub: Biological Conservation, v. 140, p. 130-141.

Fancy, S.G., Gross, J.E., and Carter, S.L., 2009, Monitoring the condition of natural resources in U.S. National Parks: Environmental Monitoring and Assessment, v. 151, p. 161-174.

Frost, Peter, Campbell, Bruce, Medina, Gabriel, and Usongo, Leonard, 2006, Landscape-scale approaches for integrated natural resource management in tropical forest landscapes: Ecology and Society, v. 11, no. 2, article 30, http://www.ecologyandsociety.org/vol11/iss2/art30/.

Gitzen, R.A., Wilson, Marcia, Brumm, Joel, Bynum, Mike, Wrede, John, Millspaugh, J.J., and Paintner, K.J., 2010, Northern Great Plains Network Vital Signs Monitoring Plan: Fort Collins, Colo., National Park Service, Natural Resource Report NPS/NGPN/NRR-2010/186.

Groves, C.R., 2003, Drafting a conservation blueprint: a practitioner's guide to planning for biodiversity: Washington, D.C., Island Press, 404 p.

Gruijter, Jaap de, Brus, D.J., Bierkens, M.F.P., and Knotters, Martin, 2006, Sampling for natural resource monitoring: New York, Springer-Verlag, 334 p.

Inman, R.D., Esque, T.C., Nussear, K.E., Leitner, Philip, Matocq, M.D., Weisberg, P.J., and Dilts, T.E., 2016, Impacts of climate change and renewable energy development on habitat of an endemic squirrel, Xerospermophilus mohavensis, in the Mojave Desert, USA: Biological Conservation, v. 200, p. 112-121.

Karl, M.S, 2015, National terrestrial monitoring: BLM Rangeland Resource Assessment: Society for Range Management, AIM Symposium, February 2015, at http://www.landscapetoolbox.org/society-for-range-management-aim-symposium/.

LANDFIRE, 2010, LANDFIRE Biophysical Settings layer (2010 update): U.S. Geological Survey, accessed October 20, 2015, at http://landfire.cr.usgs.gov/viewer/.

LANDFIRE, 2012, LANDFIRE Vegetation Condition Class layer (2012 update): U.S. Geological Survey, accessed October 20, 2015, at http://landfire.cr.usgs.gov/viewer/.

Landscape Conservation Cooperative Network, 2014, Landscape Conservation Cooperative Network strategic plan: Landscape Conservation Cooperative Network, accessed October 15, 2015, at http://lccnetwork.org/resource/ landscape-conservation-cooperative-network-strategic-plan.
Lindenmayer, David, Pierson, Jennifer, Barton, Phillip, Beger, Maria, Branquinho, Cristina, Calhoun, Aram, Caro, Tim, Greig, Hamish, Gross, John, Heino, Jani, Hunter, Malcolm, Lane, Peter, Longo, Catherine, Martin, Kathy, McDowell, William, H., Mellin, Camille, Salo, Hanna, Tulloch, Ayesha, and Westgate, Martin, 2015, A new framework for selecting environmental surrogates: Science of the Total Environment, v. 538, p. 1029-1038.

Lui, Jianguo, and Taylor, W.W., eds., 2002, Integrating landscape ecology into natural resources management: New York, N.Y., Cambridge University Press, 481 p.

MacKinnon, W.C., Karl, J.W., Toevs, G.R., Taylor, J.J., Karl, Michael, Spurrier, C.S., and Herrick, J.E., 2011, BLM core terrestrial indicators and methods: Denver, Colo., Bureau of Land Management, National Operations Center, Tech Note 440, 14 p.

Manier, D.J., Wood, D.J.A., Bowen, Z.H., Donovan, R.M., Holloran, M.J., Juliusson, L.M., Mayne, K.S., OylerMcCance, S.J., Quamen, F.R., Saher, D.J., and Titolo, A.J., 2013, Summary of science, activities, programs, and policies that influence the rangewide conservation of greater sage-grouse (Centrocercus urophasianus): U.S. Geological Survey Open-File Report 2013-1098, 170 p., accessed March 1, 2016, at http://pubs.usgs.gov/of/2013/1098/.

Miller, D.M., Finn, S.P., Woodward, Andrea, Torregrosa, Alicia, Miller, M.E., Bedford, D.R., and Brasher, A.M., 2010, Conceptual ecological models to guide integrated landscape monitoring of the Great Basin: U.S. Geological Survey Scientific Investigations Report 2010-5133, 134 p., accessed December 8, 2016, at https:/pubs.usgs.gov/sir/2010/5133/ pdf/sir20105133.pdf.

National Park Service, 2012, Guidance for designing an integrated monitoring program: Fort Collins, Colo., National Park Service, Natural Resource Report NPS/NRSS/NRR-545, 49 p.

Noon, B.R., 2003, Conceptual issues in monitoring ecological resources, in Busch, D.E., and Trexler, J.C., eds., Monitoring ecosystems: Interdisciplinary approaches for evaluating ecoregional initiatives: Washington, D.C., Island Press, p. 27-71.

Noss, R.F., 1990, Indicators for monitoring biodiversity: A hierarchical approach: Conservation Biology, v. 4, no. 4, p. 355-364.

Nowacki, Gregory, Spencer, Page, Fleming, Michael, Brock, Terry, and Jorgenson, Torre, 2001, Ecoregions of Alaska: U.S. Geological Survey Open-File Report 2002-297, accessed December 8, 2016, at https://pubs.er.usgs.gov/ publication/ofr2002297.

Office of Management and Budget, 2004, Performance and management assessments, Department of the Interior habitat restoration activities: Office of Management and Budget, accessed October 17, 2016, at https://www.whitehouse.gov/sites/default/ files/omb/budget/fy2004/pma/habitatrestoration.pdf. 
Omernik, J.M., 1987, Ecoregions of the conterminous United States (map scale 1:7,500,000): Annals of the Association of American Geographers, v. 77, no. 1, p. 118-125.

Parrish, J.D., Braun, D.P., and Unnassch, R.S., 2003, Are we conserving what we say we are? Measuring ecological integrity within protected areas: BioScience, v. 53, no. 9, p. 851-860.

Pyke, D.A., Chambers, J.C., Pellant, M., Knick, S.T., Miller, R,F., Beck, J.L., Doescher, P.S., Schupp, E.W., Roundy, B.A., Brunson, M., and McIver, J.D., 2015, Restoration handbook for sagebrush steppe ecosystems with emphasis on greater sage-grouse habitat-Part 1. Concepts for understanding and applying restoration: U.S. Geological Survey Circular 1416, 44 p., accessed December 8, 2016, at http://dx.doi.org/10.3133/cir1416.

Salafsky, Nick, Salzer, Daniel, Stattersfield, A.J., HiltonTaylor, Craig, Neugarten, Rachel, Butchart, S.H.M., Collen, Ben, Cox, Neil, Master, L.L., O'Connor, Sheila and Wilkie, David, 2008, A standard lexicon for biodiversity conservation: Unified classifications of threats and actions: Conservation Biology, v. 22, p. 897-911.

Sayer Jeffrey, Sunderland Terry, Ghazoul Jaboury, Pfund, J.-L., Sheil, Douglas, Meijaard, Erik, Venter, Michelle, Boedhihartono, A.K., Day, Michael, Garcia, Claude, van Oosten, Cora, and Buck, L.E., 2013, Ten principles for a landscape approach to reconciling agriculture, conservation, and other competing land uses: Proceedings of the National Academy of Sciences of the United States of America, v. 110 , no. 21 , p. $8349-8356$.

Science Applications International Corporation, 2012a, Middle Rockies Rapid Ecoregional Assessment-Final memorandum II-3-C: Science Applications International Corporation, accessed July 31, 2015, at http://www.landscape.blm.gov/ REA_General_Docs/MIR_REA-II-3-C_MainReport_ andAppxAandB.pdf.

Science Applications International Corporation, 2012b, Northwestern Plains Rapid Ecoregional Assessment-Final memorandum II-3-C: Science Applications International Corporation, accessed July 31, 2015, at http://www.blm.gov/style/ medialib/blm/wo/Communications_Directorate/public_affairs/ landscape_approach/landscape4.Par.85767.File.dat/ NWP-REA_II-3-C_MainText_App\%20A_Final.pdf.

Ståhl, Göran, Allard, Anna, Esseen, Per-Anders, Glimskär, Anders, Ringvall, Anna, Svensson, Johan, Sundquist, Sture, Christensen, Pernilla, Torell, A.G., Högström, Mats, Lagerqvist, Kjell, Marklund, Liselott, Nilsson, Björn, and Inghe, Ola, 2011, National inventory of landscapes in Sweden (NILS) - Scope, design, and experiences from establishing a multiscale biodiversity monitoring system: Environmental Monitoring and Assessment, v. 173, no. 1-4, p. 579-595.
Stiver, S.J., Rinkes, E.T., Naugle, D.E., Makela, P.D., Nance, D.A., and Karl, J.W., eds., 2015, Sage-grouse habitat assessment framework - A multiscale assessment tool: Denver, Colo., Bureau of Land Management and Western Association of Fish and Wildlife Agencies, Technical Reference 6710-1, 114 p.

Sutherland, W.J., 2013, Review by quality not quantity for better policy, Nature, v. 503, p. 167.

Taylor, J.J., Kachergis, E.J., Toevs, G.R., Karl, J.W., Bobo, M.S., Karl, Michael, Miller, Scott, and Spurrier, C.S., 2014, AIM-Monitoring: A component of the BLM Assessment, Inventory, and Monitoring Strategy: Denver, Colo., Bureau of Land Management, National Operations Center, Technical Note 445, 34 p.

The Heinz Center, 2009, Measuring the results of wildlife conservation activities: Washington, D.C., The Heinz Center, $122 \mathrm{p}$.

The Nature Conservancy, 2006, Conservation by Design: A strategic framework for mission success: Arlington Va., The Nature Conservancy, $17 \mathrm{p}$.

Tierney, G.L., Faber-Langendoen, Don, Mitchell, B.R., Shriver, W.G., and Gibbs, J.P., 2009, Monitoring and evaluating the ecological integrity of forest ecosystems: Frontiers in Ecology and the Environment, v. 7, no. 6, p. 308-316.

Thompson, I.D., Guariguata, M.R., Okabe, Kimiko, Bahamondez, Carlos, Nasi, Robert, Heymell, Victoria, and Sabogal, Cesar, 2013, An operational framework for defining and monitoring forest degradation: Ecology and Society, v. 18, no. 2 , article 20 , at http://www.ecologyandsociety.org/ vol18/iss2/art20/.

Toevs, G.R., Taylor, J.J., Spurrier, C.S., MacKinnon, W.C., and Bobo, M.R., 2011, Bureau of Land Management Assessment, Inventory, and Monitoring Strategy: For integrated renewable resources management: Denver, Colo., Bureau of Land Management, National Operations Center, 34 p.

Unnasch, R.S., Braun, D.P., Comer, P.J., and Eckert, G.E., 2009, The ecological integrity assessment framework: A framework for assessing the ecological integrity of biological and ecological resources of the National Park System: $\mathrm{O}^{2}$ Sound Science, National Park Service, NatureServe, and The Nature Conservancy, A report to the National Park Service, 43 p., accessed March 1, 2015, at http://www.natureserve.org/sites/default/files/ publications/files/nps_ecological_integrity_framework.pdf.

U.S. Department of Agriculture Forest Service, 2011, Forest Service Watershed Condition Framework: Washington, D.C., U.S. Department of Agriculture Forest Service, Watershed, Fish, Wildlife, Air, and Rare Plants Program, 24 p. 
U.S. Department of Agriculture Forest Service, 2012, Summary of the final land management planning rule: U.S. Department of Agriculture Forest Service, accessed March 1, 2016, at: http://www.fs.usda.gov/Internet/FSE_DOCUMENTS/ stelprdb5359652.pdf.

U.S. Fish and Wildlife Service, 2008, Strategic Habitat Conservation handbook-A guide to implementing the technical elements of strategic habitat conservation (version 1.0): Washington, D.C., U.S. Fish and Wildlife Service, a report from the national Technical Assistance Team, accessed March 1, 2016, at https://www.fws.gov/landscape-conservation/pdf/ SHCHandbook.pdf.

Walston, L.J., Hartmann, H.M., Wescott, K.L., Zvolanek, E.A., Rollins, K.E., and Fox, L.R., 2016, San Luis Valley-Taos Plateau Level IV Ecoregion Landscape Assessment final draft report, ANL/EVS-16/5, Prepared for U.S. Department of the Interior, Bureau of Land Management, Colorado State Office and New Mexico State Office: Argonne, Ill., Argonne National Laboratory Environmental Science Division, accessed October 14, 2016, at http://www.blm.gov/style/ medialib/blm/co/field_offices/slvplc/slv_solar/srms documents/srms_2016.Par.49268.File.dat/LA\%20Report\%20 March\%202016\%20\%20(508\%20compliant).pdf.
Western Governors Wildlife Council, 2013, Western Governors Crucial Habitat Assessment Tool (CHAT): Vision, definitions and guidance for state systems and regional viewer: Western Governors Wildlife Council, accessed March 1, 2016, at http://www.westgov.org/component/docman/ doc_download/1746-wgwc-white-paper-2013?Itemid=53.

Wilson, M.J., and Bayley, S.E., 2012, Use of single versus multiple biotic communities as indicators of biological integrity in northern prairie wetlands: Ecological Indicators, v. 20 , p. $187-195$.

World Wildlife Fund International, 2004, Ecoregion action programmes-A guide for practitioners: World Wildlife Fund International, accessed October 1, 2016, at assets.panda.org/downloads/guidebookpart1.pdf.

Wulder, M.A., White, J.C., Gillis, M.D., Walsworth, Nick, Hansen, M.C., and Potapov, Peter, 2010, Multiscale satellite and spatial information and analysis framework in support of a large-area forest monitoring and inventory update: Environmental Monitoring and Assessment, v. 170, p. 417-433. 



\title{
Chapter 4. Assessing Ecological Integrity Using Multiscale Information from Bureau of Land Management Assessment and Monitoring Programs
}

\author{
By Sarah K. Carter, Natasha B. Carr, Curtis H. Flather, Erica Fleishman, Matthias Leu, Barry R. Noon, \\ and David J.A. Wood
}

\section{Abstract}

The Bureau of Land Management manages 246 million surface acres (100 million hectares) across the United States for multiple uses and sustained yield. Ensuring protection of ecological systems in the context of multiple, and often conflicting, resource uses and values is a challenge. Ecological integrity and land health are terms used by the Bureau of Land Management to describe the condition of ecological systems. Ecological integrity refers to the ability of ecological systems to support and maintain a community of organisms that is similar in composition, structure, and function to natural habitats within the region. We present a framework and process for assessing ecological integrity in terrestrial systems that accommodates the multiple-use mission of the Bureau of Land Management and is designed to inform future management actions. The nine steps in the assessment process are specifying the management question, identifying target resources and key stressors, defining spatial and temporal scales of analysis, selecting and evaluating indicators, defining the natural and acceptable range of variation for indicators, collecting and analyzing data, reporting results, using the results to inform and evaluate management actions, and repeating the assessment. We illustrate the process through a conceptual example outlining how the ecological integrity of rangelands across the western United States could be quantified. We propose a suite of six field-based indicators and six complementary broadscale indicators to provide multiscale information on the composition, structure, and function of rangelands. Data on 11 of the 12 proposed indicators are already being collected through the agency's Assessment, Inventory, and Monitoring program. The framework and process presented here can help the BLM quantify ecological integrity to inform future planning and management actions in multiple-use landscapes.

\section{Introduction}

The Bureau of Land Management (BLM) manages 246 million surface acres (100 million hectares) across the United States for multiple use and sustained yield in accordance with the Federal Land Policy and Management Act of 1976 (43 USC §1701). Multiple use refers to a combination of resource uses that take into account both the Nation's present needs and the long-term needs of future generations of the American public (U.S. Department of the Interior, 2001). Resource uses are diverse, and may include livestock grazing, timber harvest, energy production, recreation, and conservation of wildlife, historical, and cultural resources. Sustained yield refers to the ability of lands to achieve and maintain in perpetuity high-level output of various renewable natural resources (U.S. Department of the Interior, 2001). Providing vegetation for livestock and wildlife foraging into the future is one important aspect of sustained yield on lands managed by the BLM. As part of its multiple use and sustained yield mission, the BLM is also charged with protecting the quality of scientific, scenic, historical, ecological, environmental, air, atmospheric, water resource, and archeological values of the public lands it manages (Federal Land Policy and Management Act of 1976 [43 USC §1701]).

Ensuring protection of ecological systems in the context of multiple, and often conflicting, resource uses and values is a challenge. A landscape approach to resource management (hereafter landscape approach) is a strategy that may help to achieve diverse and potentially conflicting resource objectives within and across landscapes (see chapter 2). Key principles of a landscape approach include collecting monitoring information at multiple spatial and temporal scales, focusing on threats and vulnerabilities of key resources, and explicitly acknowledging tradeoffs inherent in meeting different resource objectives within and among landscapes (Sayer and others, 2013). Quantifying the condition of ecological systems across spatial scales and monitoring changes in condition over time in response to different management actions may help managers and stakeholders better understand risks, opportunities, and tradeoffs associated with different resource use decisions.

There are many ways in which the condition or health of ecological systems can be measured. The Fundamentals of Rangeland Health (43 CFR §4180.1), land health standards, and land health evaluations (Bureau of Land Management, 2001) are specific terms used in BLM policy. The BLM seeks to manage lands in a manner consistent with maintaining or making progress toward achieving four Fundamentals of Rangeland Health: (1) properly functioning physical condition of watersheds, (2) ecological processes such as hydrologic and nutrient cycling that support healthy biotic populations and communities, (3) water quality that complies with State standards and 
achieves BLM objectives such as meeting wildlife needs, and (4) restoration or maintenance of habitat for Federal threatened and endangered species, Federal proposed or candidate species, and other special status species (43 CFR §4180.1). Land health standards are ecological goals that conform to the Fundamentals of Rangeland Health and have been established at State or regional levels to reflect the characteristics of rangelands within that area. Land health evaluations establish the degree to which land health standards are being achieved by measuring specific indicators relevant to the land health standards of each State or region (Bureau of Land Management, 2001).

Another term often used to describe the condition or health of ecological systems is ecological integrity (for example, Karr and Dudley, 1981; Parrish and others, 2003). Ecological integrity is defined by the BLM as "the ability of ecological systems to support and maintain a community of organisms that have the species composition, diversity, and functional organization comparable to those of natural habitats within the ecoregion range or area" (p. 30 in Toevs and others, 2011). This definition embodies three components of ecological systems: composition, structure, and function (Noss, 1990). Composition refers to the identity, variety, and diversity of elements in a collection. Structure refers to the physical organization or pattern of a system both horizontally and vertically (for example, the size and proximity of vegetation patches and the height of vegetation in those patches). Function refers to the evolutionary processes (for example, gene flow and adaptation), ecological roles (for example, resource use patterns of species and predator-prey dynamics) and ecosystem processes (for example, nutrient cycling) that are foundational to the system (Petchey and Gaston, 2006). Fire, drought, and interactions within and among species (such as insect outbreaks and disease) are processes relevant to the structuring of many ecological communities. Deviation in or absence of key functions can drive systemic changes. For example, an increase in invasive grasses may shorten the fire return interval of and eliminate shrubs from a community (Chambers and others, 2007).

\begin{tabular}{c}
\hline Ecological integrity is the ability of \\
ecological systems to support and maintain \\
a community of organisms that have a species \\
composition, diversity, and functional \\
organization comparable to those of natural \\
habitats within the ecoregion range or area \\
(Toevs and others, 2011).
\end{tabular}

The National Park Service, U.S. Department of Agriculture Forest Service (Forest Service), and many other agencies and conservation organizations now consider ecological integrity in their management decisions. The mission of the National Park Service is to preserve unimpaired the natural and cultural resources and values of the National Park System for future generations (National Park Service Organic Act of
1916 [16 USC §1]). Recent changes to the regulations governing land management planning by the Forest Service also require the agency to maintain or restore the ecological integrity of ecosystems (U.S. Department of Agriculture Forest Service 2012 Planning Rule [36 CFR §219.9(a)]). These policies and recent efforts to develop consistent indicators of ecological integrity (Vickerman and Kagan, 2014) reflect increasing recognition across resource management agencies and conservation organizations of the need to develop standardized methods for quantifying ecological integrity in terrestrial systems across spatial scales, as has been accomplished in aquatic systems (see for example, Karr and others, 1987; Hawkins and others, 2000; Borja and others, 2008).

In this chapter, we first discuss similarities and differences between ecological integrity and land health. We then describe a framework and process for assessing the condition of terrestrial systems. Our framework is intended to be a simple tool that helps to ensure that a comprehensive suite of indicators are considered, and that the scope and limitations of the assessment are clear. The assessment itself may seek to evaluate land health or ecological integrity depending on the management context, the reference conditions to which current systems are compared, and the suite of indicators considered. The steps in the assessment process are consistent with the BLM Assessment, Inventory, and Monitoring (AIM) process, and are applicable to assessments of both land health and ecological integrity. We apply the framework and process to the conceptual example of assessing the ecological integrity of rangelands across the western United States. We propose that a combination of six core terrestrial indicators used in the westwide landscape monitoring component of the BLM AIM program, five broad-scale indicators identified through the BLM Rapid Ecoregional Assessment (REA) program (see chapter 3), and an additional broad-scale indicator of biomass or productivity can be used to quantify the ecological integrity of rangelands across the western United States.

\section{Relation Between Ecological Integrity and Land Health}

The concepts of land health and ecological integrity both describe the condition of ecological systems. However, the specific reference conditions and indicators used to assess land health and ecological integrity may differ. Reference conditions used for comparison with the current status of the system fall along a continuum of human influence and may reflect natural conditions, societally-desired conditions, or both.

Many definitions of ecological integrity, including the BLM definition, compare the current state of the system to that of natural areas within the region (for example, Karr and Dudley, 1981; Parrish and others, 2003; Toevs and others, 
2011). The most conservative interpretation of natural area is what is often termed true reference conditions: the range of conditions that would be expected for a region in the absence of human perturbation. However, the term natural areas may also refer to ecological systems that have been affected by humans to some degree but are perceived to function largely without anthropogenic influences, especially given that there are few if any places today that remain unaffected by human activity (see chapter 5).

Ecological integrity and land health
both describe the condition of ecological systems,
but may be assessed using different indicators
and reference conditions.

The BLM employs a variety of reference conditions to evaluate land health standards, including lands that are not grazed by domestic livestock (but are grazed by native herbivores), plant communities that are desired by management because they will satisfy multiple uses and sustain production of renewable resources, and well-managed rangelands that are grazed by domestic livestock and have nearly intact hydrologic cycles, nutrient cycling, and energy flow (M. Karl, written commun., 2016). This diversity of potential comparison systems illustrates a continuum ranging from pristine systems to systems with increasing degrees of human modification.

For clarity, we propose that the term ecological integrity be applied to assessments in which the current state of the system is being compared to the state of the system that would be expected in the absence of human perturbations (that is, the natural range of variation). It may be necessary to use historical information (for example, estimated conditions prior to EuroAmerican settlement) or information from systems that have been minimally affected by human use (Stoddard and others, 2006) to estimate the natural range of variation of ecological integrity metrics. However, a natural benchmark is the goal.

A second relevant reference condition for many public lands is the state of the system that considers the goals society has identified for the system. We refer to this as a societally determined reference condition (and associated acceptable range of variation), and we emphasize its importance for interpreting and applying ecological integrity assessments to agency planning and management actions. Most public lands managed by the BLM and the Forest Service have been designated for multiple uses, and thus a benchmark that acknowledges this multidimensional management goal is relevant. Balancing maintenance of vegetation condition and providing adequate vegetation for grazing by both wildlife and domestic livestock is one common management decision that considers socially determined acceptable ranges of variation. Examples of societally determined reference conditions include the best available ecological conditions given the current state of the landscape and the expected ecological condition if the best possible management practices were followed for some time (Stoddard and others, 2006).

In ecological integrity assessments, societally determined reference conditions that differ from natural reference conditions (for example, areas consisting primarily of non-native forage plants) will highlight changes in the composition, structure, or function of systems that have accompanied these new societal goals. In some cases, society has decided that the appropriate benchmark is the natural state of the system in the absence of human influence (for example, designated Wilderness Areas are managed to leave them unimpaired and to preserve their wilderness character [16 USC §1131]). In these cases, the societally determined benchmark and the natural benchmark are the same, and the management goal may be to achieve ecological integrity. A societally determined reference condition may often be appropriate as the primary comparison for land health assessments, provided it is consistent with achieving the Fundamentals of Rangeland Health (43 CFR §4180.1).

After reference conditions have been identified, one must select indicators of ecological integrity or land health. In ecological integrity assessments, indicators ideally are identified on the basis of conceptual models of the system and encompass aspects of the composition, structure, and function of systems or elements at different levels of biological organization (for example, genes, species, ecosystems, and ecoregions). Assessments of land health use established indicators of land health for each state or region (Bureau of Land Management, 2001, 2009). There are 19 sets of land health standards, and more than 100 suggested indicators (M. Karl, unpub. data, 2015). In Colorado, for example, indicators for the health standard for upland soils include canopy and ground cover, litter, soil organic matter, and plant species diversity (Bureau of Land Management, 1997).

The interacting nature of ecological processes operating at different spatial and temporal scales suggests that the most comprehensive assessments of either land health or ecological integrity will use data collected at multiple spatial scales (see chapter 2 for a discussion of ecological patterns and processes across different spatial scales). For example, complementary information about vegetation structure may be gained by measuring both the percent cover of vegetation within a patch and the size and proximity of vegetation patches across a landscape. To date, land health assessments have focused primarily on metrics assessed at local scales (J. Taylor, written commun., 2015), although indicators have been identified at broader scales (M. Karl, unpub. data, 2015). 


\section{A Framework for Assessing Ecological Integrity Across Scales in Terrestrial Systems}

We present a framework for assessing ecological integrity that is a $3 \times 4$ matrix that managers may use to help identify the scope and limitations of ecological integrity assessments and help ensure consideration of (1) all components of integrity (composition, structure, and function) and (2) key levels in the ecological hierarchy (fig. 4-1). Using the organizing framework, it is possible to consider a total of 12 combinations of ecological levels and system components in any given ecological integrity assessment. Considering that within each 'cell' in the matrix, there are likely multiple indicators and potentially different spatial and temporal scales to consider (see next section), it becomes apparent that assessments that consider all possible combinations of system components and ecological levels will rarely be possible. Explicitly identifying which system components and levels in the ecological hierarchy will be considered helps to characterize the scope and limitations of any individual ecological integrity assessment.

The framework may also be used to help identify indicators, data sources, and methods that may be most relevant and feasible for a given ecological integrity assessment. At the ecoregion and ecosystem levels of the hierarchy, remotely sensed imagery is a common data source. Geographic Information Systems technology is often used to assess composition (for example, the diversity of vegetation communities), structure (for example, the proximity or size distribution of natural vegetation patches), and function (for example, fire frequency) within and across ecoregions. At the ecosystem level, field-collected data are often used together with remotely sensed data (Noss, 1990). If, for example, a primary focus of the assessment is the effect of invasive species on the ecological integrity of shortgrass prairie ecosystems, an indicator may be the change in the proportion of non-native plant species sampled at shortgrass prairie sites across a gradient of human modification. If the assessment is focused at the species level (for example, the effect of energy development on migratory behavior of mule deer), data often are collected through targeted research or surveys (for example, detection of movement patterns with radiotelemetry, Sawyer and others, 2009b). Continuing with the mule deer example, indicators might include the change in migration speed or the probability of use of different migratory routes through areas with different development densities (for example, Sawyer and others, 2009a). At the genetic level, new analysis techniques are greatly facilitating addressing questions about the genetic structure of populations and species across landscapes (Waits and Paetkau, 2005; Beja-Pereira and others, 2009; Luikart and others, 2010). Findings from broad-scale

\section{Ecological hierarchy}

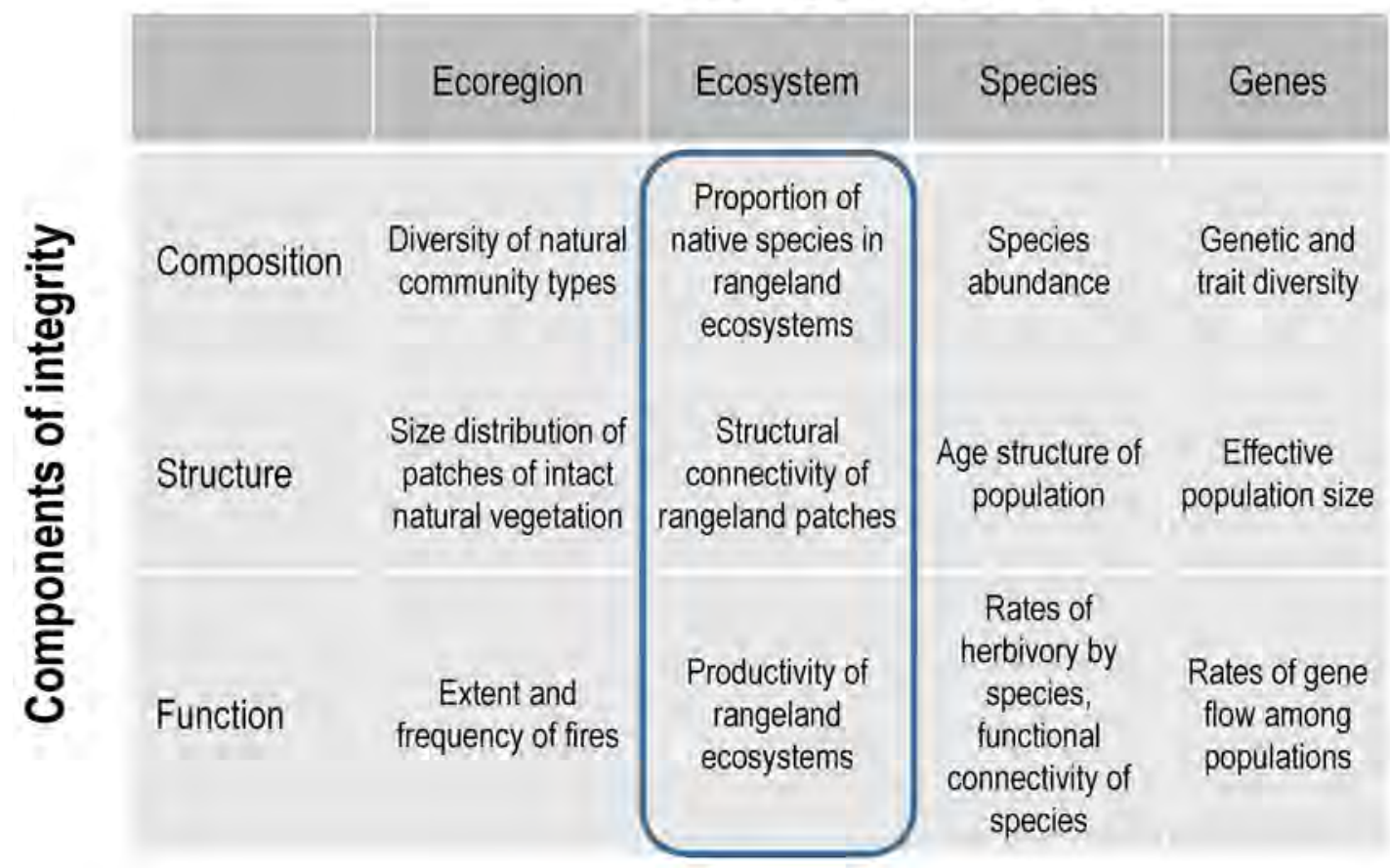

Figure 4-1. Conceptual framework for quantifying ecological integrity, with example ecological attributes for each level in the hierarchy and component of integrity. The blue box indicates the area of focus for the example assessment described in this chapter. 
indicators can be supplemented with local research or monitoring information to more fully assess local effects. For example, managers working on the above mule deer migration example may seek genetic evidence to evaluate the potential for future development to genetically isolate populations, particularly if substantial changes in movement patterns are likely.

\section{Using the Framework to Assess Ecological Integrity on Rangelands Across the Western United States}

The process for assessing the condition of a species or system (fig. 4-2) may be organized into a series of steps within the general BLM AIM process of developing, designing, implementing, and repeating monitoring or assessments (Taylor and others, 2014, see also fig. 3-4). We illustrate the steps for assessing ecological integrity using a conceptual example related to management of rangelands across the western United States. We also note aspects of the process that would vary if the goal of the assessment was to quantify land health instead of ecological integrity.

\section{Specify Management Question}

Developing an assessment of ecological integrity or land health requires first identifying an explicit management question within a more general management and policy context. The management question will reflect the mission and regulatory requirements of the organization, and will differ according to management goals and responsibilities for the area, the size of the area being assessed, and other factors. At the local level, for example, a manager may assess land health as part of the process of renewing an individual grazing permit. At the level of field, district, or State offices, the goal of the assessment may be to evaluate achievement of natural resource objectives in resource management plans. At the national level, the goal may be to quantify the ecological integrity of all lands managed by the BLM to inform national policy and meet agency reporting requirements. Assessments of ecological integrity may complement land health assessments by providing a broader perspective and context, particularly when assessments encompass large areas or lands within a more protective management category (for example, the National Landscape Conservation System). It may also be possible to evaluate land health and ecological integrity simultaneously, with associated economies of time and funds.

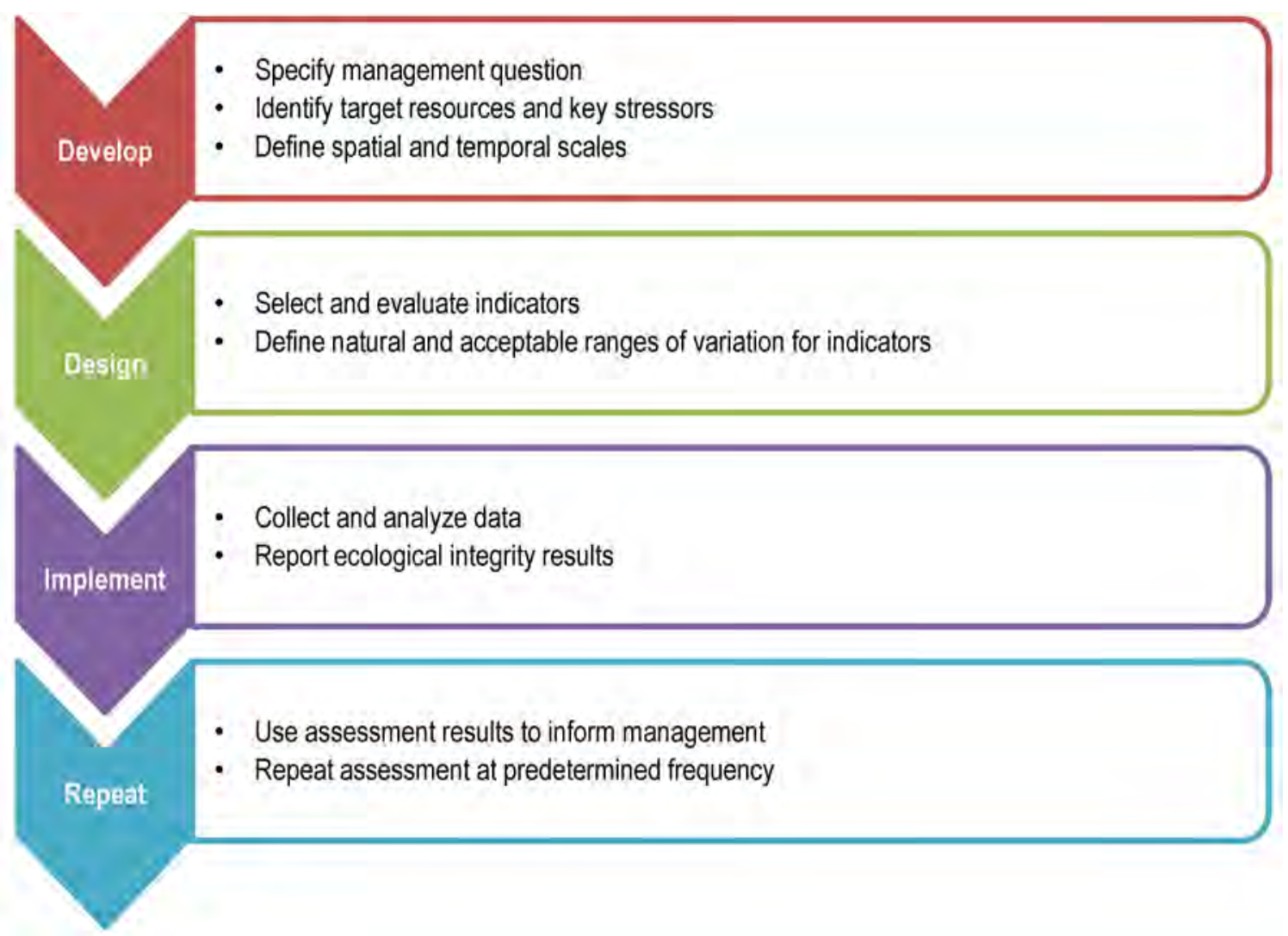

Figure 4-2. Steps for assessing ecological integrity, which are consistent with the broader AIM process (see also chapter 3$)$. 
In our example, the management question is: What is the ecological integrity of rangelands across the western conterminous United States? This question is separate from but related to the requirement of BLM to report periodically on the condition and trend in condition of rangelands that the agency manages (Public Rangelands Improvement Act of 1978 [43 USC §1903]). Consequently, the assessment would focus at the ecosystem level and include indicators of the composition, structure, and function of rangelands (fig. 4-1). Ecosystems considered to be rangeland by the BLM include grasslands, savannas, shrublands, deserts, tundra, alpine plant communities, marshes, wet meadows, and oak and pinyonjuniper woodlands (Karl and others, 2016).

We explore the management question,
What is the ecological integrity of rangelands
across the western conterminous United States?,
to illustrate the steps for assessing
ecological integrity.

\section{Identify Target Resources and Key Stressors}

Management goals and relevant State and Federal laws and policies (for example, BLM land health standards, Federal Endangered Species Act [16 U.S.C. §§ 1531-1544]) will inform selection of target resources. A conceptual model of the system guides identification of the major natural and anthropogenic processes that may affect key resources (Woodley, 2010).

In our example, we focus on soils and terrestrial vegetation. Soils and terrestrial vegetation are two resources now widely monitored across rangeland ecosystems managed by the BLM to measure progress toward attaining land health standards (Taylor and others, 2014). We illustrate a conceptual model developed for one rangeland community type (short grass prairies) in one ecoregion (the Southern Great Plains, Assal and others, 2015). The model identified soils, climate, fire, grazing, development, insects and disease, and invasive species as major factors and processes affecting the flora, fauna, and landscape structure of short grass prairies in the region (fig. 4-3).

Assessments of ecological integrity likely will measure resources sensitive to multiple stressors, and may quantify the stressors themselves as well. Resources sensitive to stressors over which there is management control (for example, livestock grazing) may be the most helpful in informing future management actions intended to improve the ecological status and condition of the lands. However, understanding the influence of unmanaged processes and patterns on target resources is important for accurately assessing the potential effects of management actions.

\section{Define Spatial and Temporal Scales}

The spatial extent of the assessment and the temporal and spatial scales of analysis will be informed by the management question, management jurisdictions (such as field office boundaries), and conceptual models of the system. The boundary of an assessment may be administrative (such as BLM State or district office boundaries) or environmental (such as ecoregional boundaries). The extent of the assessment area and the analysis scale used will reflect scales at which stressors act on elements of ecological systems or scales at which management actions typically are applied. Spatial mapping units may be determined by the resolution of available remotely sensed data (for example, 30- x 30-meter (m) pixels of most nationwide land cover datasets). Relevant temporal scales may be defined by seasonal field sampling, reporting periods (for example, required annual reports), the cycle of key ecological processes, or the timeframe within which resources respond to stressors (for example, the length of time it may take for an area to recover from overgrazing).

In our example, the spatial extent of the assessment is the western United States defined using state boundaries. Both local and broad-scale indicators will be considered (see next step) both because rangeland ecosystems occur in different spatial configurations (for example, small patches compared to vast areas of relatively homogeneous vegetation cover) and because anthropogenic and natural processes affecting rangelands operate at multiple scales. For example, livestock stocking rates may vary by individual grazing allotments, land use allocations occur at the scale of larger areas within BLM resource management plan boundaries, and patterns of development may vary by region.

\section{Select and Evaluate Indicators}

Detailed design of the assessment begins with selecting and evaluating indicators. Indicators should reflect key ecological attributes of a resource - the biological characteristics, ecological processes or physical interactions that define the resource and whose alteration beyond some threshold could lead to degradation or loss of the resource in the near future (Parrish and others, 2003, Unnasch and others, 2009). Examples of key ecological attributes include the extent of a community, reproduction rates of a species, and genetic diversity of a population (fig. 4-1).

In our example, 11 of the 12 indicators are currently measured by the BLM AIM program or were quantified in REAs. The BLM AIM program has identified a core set of indicators for quantifying the status, condition, and trend of renewable resources on lands managed by the BLM (Toevs and others, 2011, Taylor and others, 2014). The core terrestrial indicators are measured on 50-m long transects at all AIM field monitoring sites using standardized methods, and include indicators of system composition, structure, and 


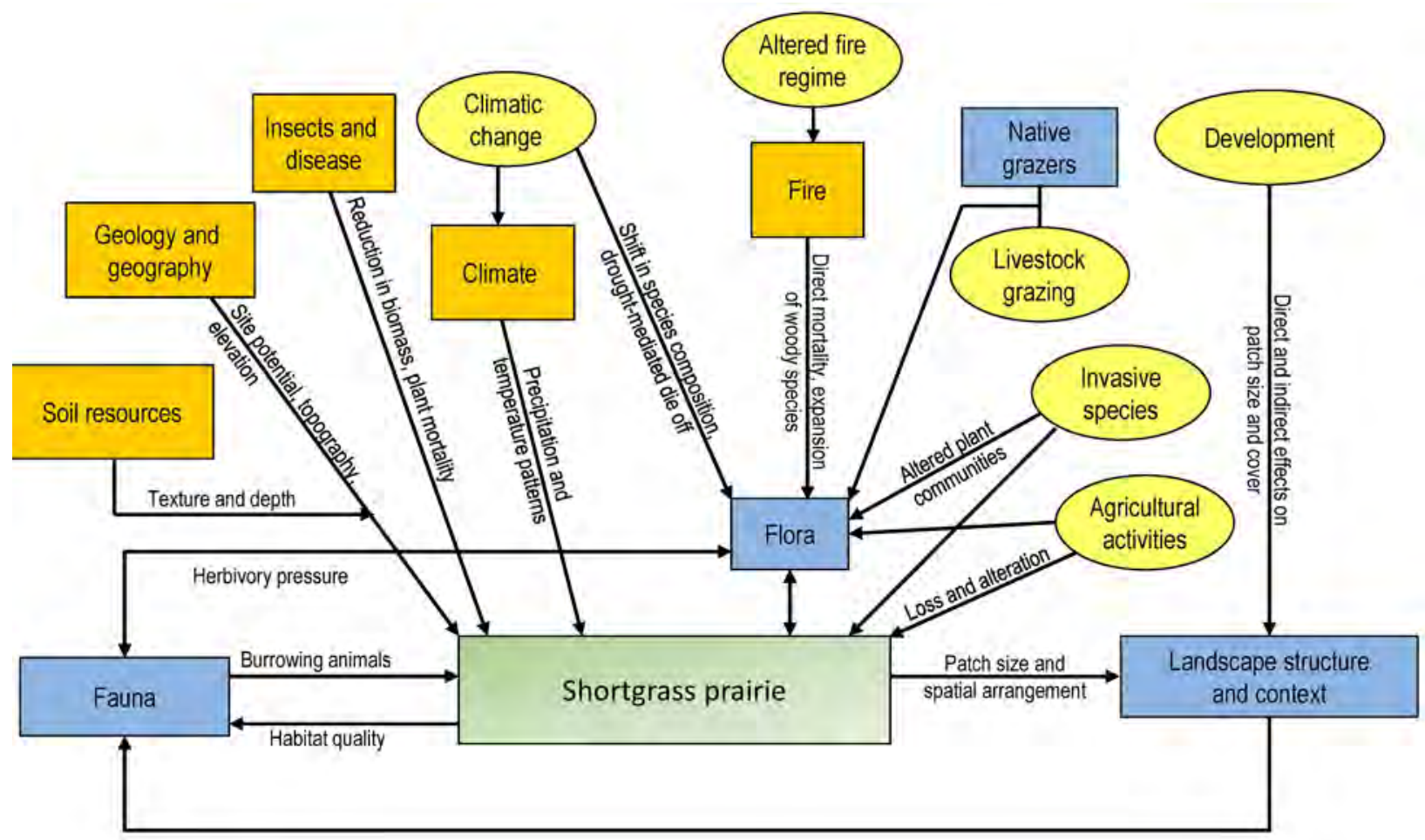

Explanation

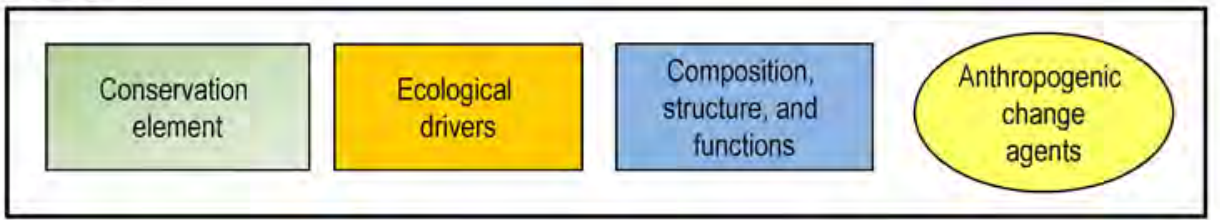

Figure 4-3. Conceptual model highlighting the major ecological drivers and anthropogenic stressors affecting shortgrass prairies in the Southern Great Plains ecoregion (figure modified from the Southern Great Plains Rapid Ecoregional Assessment [Assal and others, 2015]).

function (Herrick and others, 2009; MacKinnon and others, 2011; Taylor and others, 2014). Core indicators have also been identified for streams and rivers, and are in development for lakes and ponds (Miller and others, 2015).

AIM monitoring sites are chosen using a statistically valid sampling design that allows inference to be drawn about values of the terrestrial indicators across larger extents (such as ecological sites or ecoregions), particularly as sampling density increases over time. We note that there will also always be a role for localized, fine-scale monitoring to understand and evaluate effects of specific local decisions. Environmental processes and anthropogenic disturbances operating at broad scales also affect terrestrial and aquatic ecosystems, suggesting a need to consider spatially and temporally extensive indicators of system status and condition as well (see chapters 2 and 3 ).

REAs compile broad-scale data on the status and condition of natural resources at the level of ecoregions, and have been completed or are in progress across much of the western United
States (fig. 4-4). The broad-scale information in REAs complements local data and facilitates resource planning and management by the BLM and other partners across jurisdictional boundaries. Regularly updating REAs or other broad-scale assessments would provide information on resource status and condition into the future (see chapter 3). Our example management question encompasses some areas for which REAs have not yet been completed (fig. 4-4), but other data sources (such as LANDFIRE Existing Vegetation Type) provide continuous vegetation cover across the western United States.

In our example, we propose quantifying the ecological integrity of rangelands across the western United States using six core terrestrial AIM indicators, four broad-scale indicators derived from REAs (chapter 3), and one additional broad-scale indicator of rangeland biomass or productivity (table 4-1). The AIM core terrestrial indicators and the broad-scale indicators derived from REAs originally were selected by researchers, managers, and stakeholders on the basis of their feasibility 


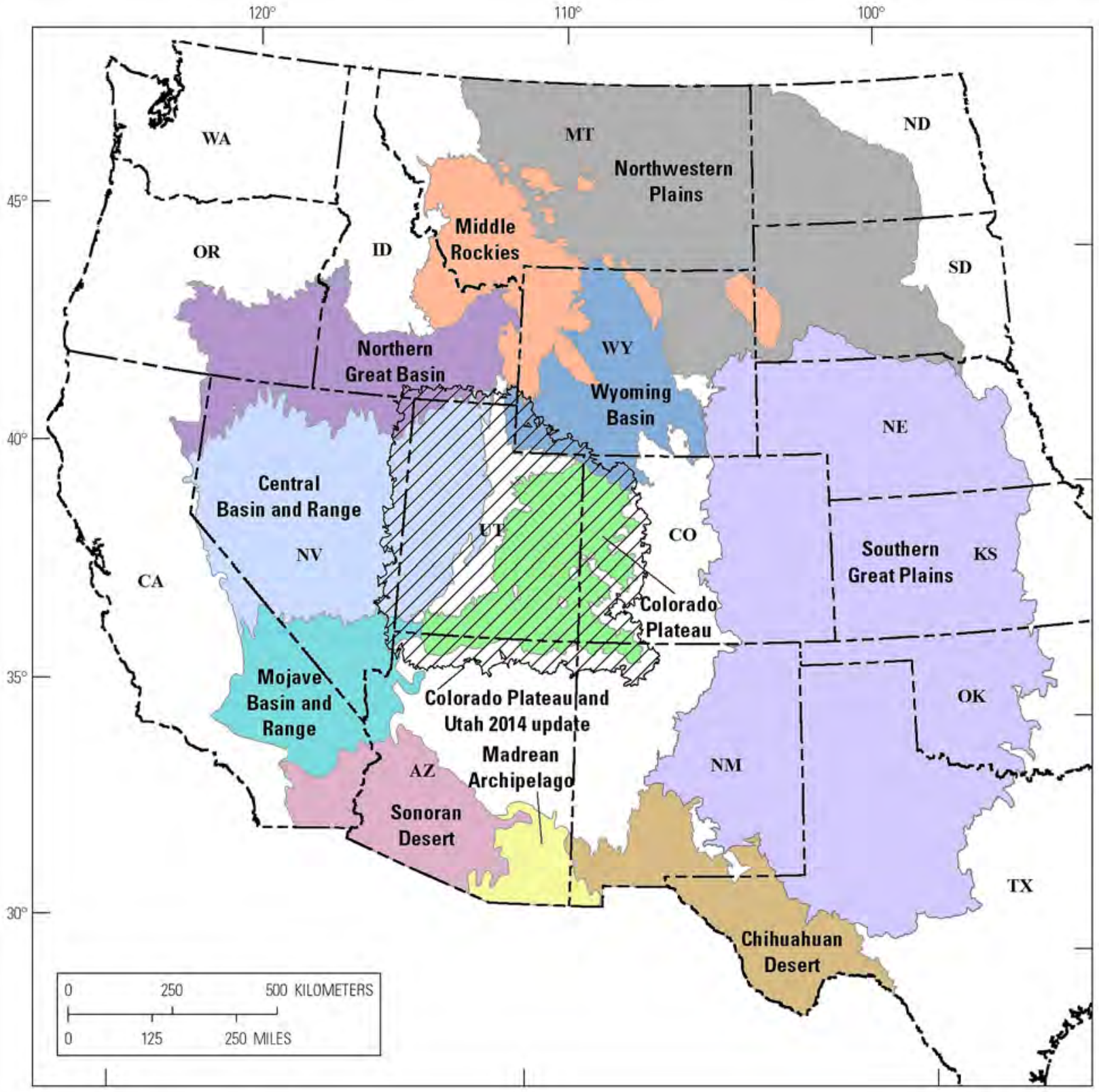

Figure 4-4. Bureau of Land Management Rapid Ecoregional Assessments that are in progress or have been completed across the western conterminous United States (Bureau of Land Management, 2016).

of measurement and utility for informing BLM management. The core terrestrial AIM indicators are measured in the field, and consist of the amount of bare ground, vegetation composition, invasive plants, plants of management concern, vegetation height, and the proportion of the soil surface in large, intercanopy gaps. The broad-scale indicators are derived primarily from satellite imagery and cover broad spatial extents at a spatial resolution of 30- x 30-m pixels to 90- $x$ 90-m pixels. Four broad-scale indicators were identified through REAs: the distribution and amount, patch size, and structural connectivity of communities considered to be rangelands by the BLM, and the amount and distribution of development in and near rangelands. A fifth broad-scale indicator, the normalized difference vegetation index, is one index of rangeland biomass or productivity. The normalized difference vegetation index is available as a standard global product derived from satellite imagery that is strongly and consistently related to aboveground biomass and productivity (Pettorelli and others, 2005).

Standard methods have been established to measure the AIM core terrestrial indicators (MacKinnon and others, 2011). Some guidance for quantifying broad-scale indicators is available from completed REAs (see chapter 3 ). Data on the amount and location of natural community types considered to be rangelands by the BLM are available from REAs and 
Table 4-1. Proposed indicators, the spatial extent at which they are assessed (local or regional), and example reference conditions for quantifying the compositional, structural, and functional components of ecological integrity on rangelands across the western United States. Indicators are listed under the ecological integrity component(s) about which they provide the most information, but many indicators also provide some information about other components of ecological integrity.

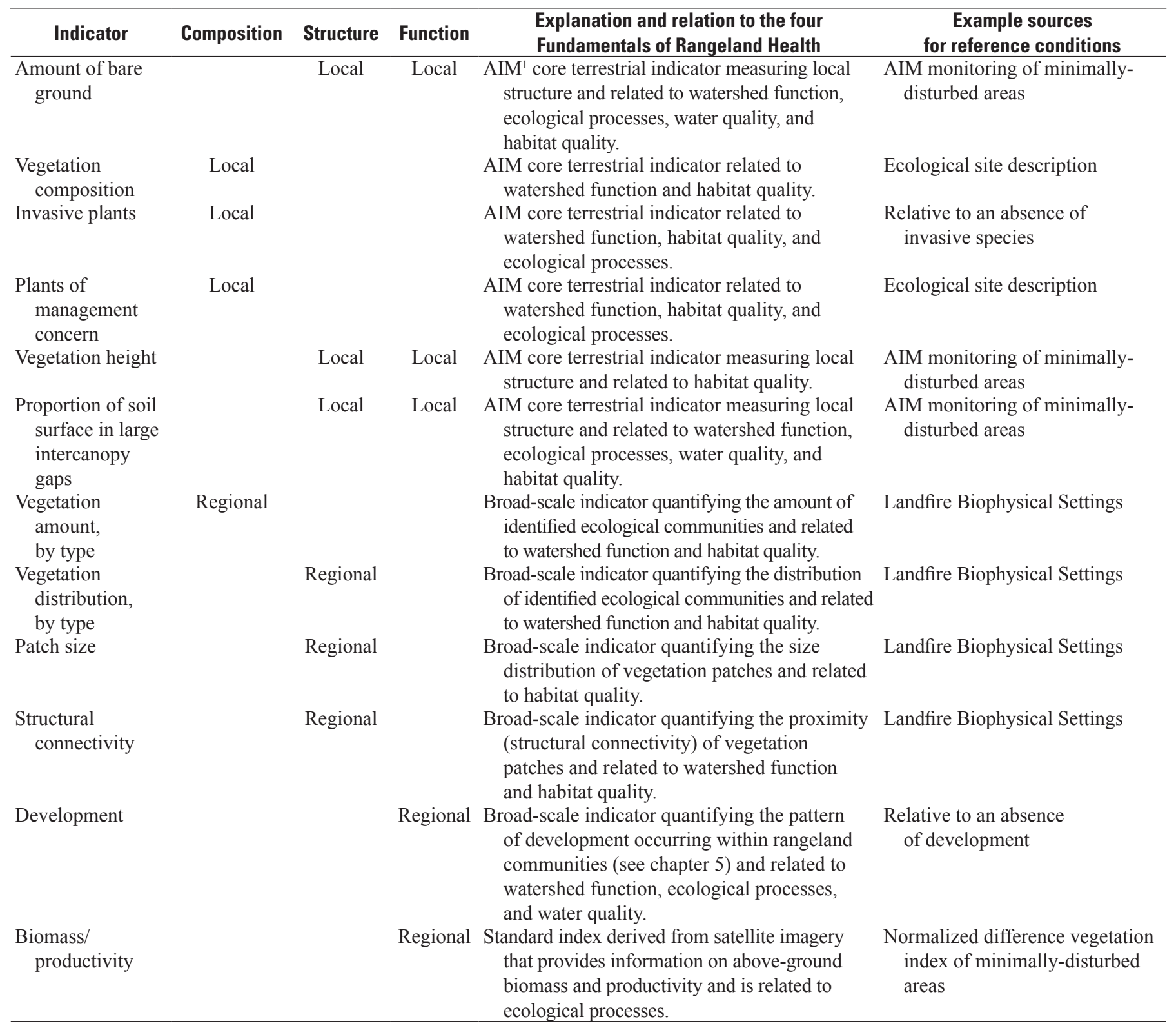

${ }^{1}$ Assessment, Inventory, and Monitoring, a Bureau of Land Management program.

nationwide land cover datasets. A standardized indicator of development is now available across the western United States (see chapter 5). Indicators of patch size and structural connectivity may be calculated using consistent methods applied to REA or nationwide land cover datasets. The BLM and USGS are currently (2017) working to standardize methods and datasets for quantifying these broad-scale indicators.

A final step in choosing indicators is to confirm that they are sensitive to the stressors of interest identified in the conceptual model (see fig. 4-3) at the chosen temporal and spatial scales of interest. Ideally, sensitivity of the indicators to the stressors of interest will have been documented in the peerreviewed literature. For example, grazing intensity by domestic livestock is widely known to affect the species composition and proportion of invasive species present in grasslands (DiTomaso and others, 2000). If sensitivity has not been documented, new analyses relating known changes in the presence and intensity of stressors to changes in the indicators, ideally under experimentally controlled conditions, may be needed to ensure that the results of the ecological integrity assessment are defensible. 


\section{Define Natural and Acceptable Ranges of Variation for Indicators}

Quantifying the condition of a system requires comparison to a reference condition. For an assessment of ecological integrity, the current value of indicators ideally is compared to the natural range of variation for that indicator under true reference conditions (that is, in areas with no human influence). Established alternatives to true reference conditions are minimallydisturbed condition (the condition of systems in the absence of significant human disturbance) and historical condition (the condition of systems at a specified point in their history, often prior to EuroAmerican settlement, Stoddard and others, 2006). Within the BLM, the best source of information on reference conditions is likely to be ecological site descriptions (Bureau of Land Management, U.S. Department of Agriculture [USDA] Forest Service, and USDA Natural Resources Conservation Service, 2010, Taylor and others, 2014). AIM monitoring data collected in minimally-disturbed systems also may provide information on natural variation of the measured indicators. Most REAs have considered minimally-disturbed or estimated historical condition in lieu of true reference conditions, with estimated historical conditions often derived from LANDFIRE Biophysical Settings (BpS) (LANDFIRE, 2010). When estimating natural ranges of variation, it is also important to consider potential future ranges of variation under changing climate conditions (Millar and others, 2007, Keane and others, 2009).

A societally determined acceptable range of variation for system indicators is a second relevant reference against which to compare the current state of systems managed explicitly for multiple uses. This acceptable range of variation takes into account societal goals established for the system through policy (for example, compliance with land health standards and endangered species laws) and the current landscape context of the system. An acceptable range of variation may be defined on the basis of measurements of a system believed to be in the best available or best attainable condition (Stoddard and others, 2006) given the landscape in which the system occurs and the regulatory context within which the system is managed. In the case of ecological integrity assessments, the purpose of this second benchmark is to provide additional context regarding the landscape, planning, and policy context in which the system occurs. For land health assessments, a societally determined acceptable range of variation may be the primary benchmark for the assessment as long as it is consistent with achieving the Fundamentals of Rangeland Health (43 CFR §4180.1).

For ecological integrity assessments, it is also necessary to specify the indicator values below which a system will be considered to lack integrity for that indicator. The values may be the upper or lower bound of the natural range of variation for each indicator, or may reflect indicator values likely to allow persistence of target species or communities into the future (Parrish and others, 2003). The values may also reflect current policy or management guidelines.
In our example, a relevant management goal across sagebrush-dominated shrublands in much of the western United States is conservation of greater sage-grouse (Stiver and others, 2015). Development in or near greater sage-grouse habitat may be detrimental to populations, and detrimental anthropogenic disturbances occurring within 3 kilometers of greater sagegrouse habitat degrade habitat suitability (Knick and others, 2013; Stiver and others, 2015). A target of maintaining anthropogenic disturbances at or below 3 percent of the landscape within priority greater sage-grouse habitat has been suggested (Sage-grouse National Technical Team, 2011), and caps of 3 to 5 percent disturbance have been implemented in an effort to allow persistence of greater sage-grouse populations (for example, State of Wyoming, 2011; Bureau of Land Management, 2015). As a result, in areas that may provide habitat for greater sage-grouse, acceptable ranges of variation for patch size and connectivity indicators might be defined on the basis of sites with less than 3 to 5 percent development. Different ecological, conservation and management issues apply to other community types and locations, suggesting that community types within ecoregions are likely to be the appropriate strata for defining natural and acceptable ranges of variation and associated lower limits of integrity for most indicators.

\section{Collect and Analyze Data}

In our example, the ecological integrity assessment focuses on use of existing (primarily BLM) data rather than collection of new data. AIM westwide monitoring has been operating since 2011, and is beginning to provide the density of samples needed to infer information about the composition, structure, and function of rangelands managed by the BLM across the western United States (Taylor and others, 2014; Karl and others, 2016). Similarly, 11 REAs have been completed or are in progress in the western conterminous United States, providing example approaches and methods needed to quantify the amount, patch size, and connectivity of rangelands across the west (see chapter 3 ). The current effort to quantify terrestrial development across the conterminous western United States (see chapter 5) provides consistent information on development across all western lands. The normalized difference vegetation index, an index of vegetation biomass and productivity, is calculated from open source online satellite imagery at increasingly fine spatial and temporal resolutions (as fine as $10-\times 10-\mathrm{m}$ pixels or as frequently as daily [but not both], depending on the sensor).

\section{Report Ecological Integrity Results}

Presentation of assessment results requires deciding on a format for presenting the condition of individual indicators (for example, Cardoso and others, 2007; Tierney and others, 2009), and, if desired, combining individual indicators into a 
more comprehensive index of ecological integrity (for example, Glennon and Porter, 2005). Presenting results for individual indicators and for comprehensive indices is common in the literature (for example, Karr and others, 1986, Cardoso and others, 2007, Diffendorfer and others, 2007, Tierney and others, 2009). The target audience and context in which the information will be used will help inform the best presentation format.

Ecological integrity results may be presented as the degree of departure from reference conditions (table 4-2). This approach is simple and informative. Presenting ecological integrity results categorically (for example, good, caution, significant concern, Tierney and others, 2009) using breakpoints that are meaningful both biologically and to management is another option that can convey additional information to managers, stakeholders, and the public. Ideally, passing a breakpoint will automatically trigger a management response, which might include additional monitoring, research, or management actions (Mitchell and others, 2014).

In our example, we present hypothetical results using degree of departure from reference conditions at the level of our original management question - the entire western conterminous United States (table 4-2). However, natural and acceptable ranges of variation, breakpoints for indicators, and management actions for addressing identified deficiencies may differ among ecoregions. Thus it may be helpful, particularly for land managers, to report assessment results at ecoregion levels as well (see Mitchell and others, 2014 for an example). Because of the multiple-use mandate of the BLM, it may be helpful to present findings relative to departure from both the natural and acceptable ranges of variation. Given the prominent role of the Fundamentals of Rangeland Health in driving management, monitoring, and reporting activities within the BLM, it also may be appropriate to highlight how each of the ecological integrity indicators relates to the Fundamentals of Rangeland Health (table 4-1).

\section{Use Assessment Results to Inform Management}

Once the assessment has been completed, the final steps include using the assessment results to inform and evaluate management actions and repeating the assessment as needed. The BLM is committed to implementing adaptive management that is informed by the best available science (Clement and others, 2014). The assessment process outlined here is grounded in well-established principles of environmental monitoring and assessment, and is intended to include key resources over which there is management control or concern. As a result, the assessment process is designed to explicitly inform management actions focused on maintaining or improving ecological integrity within the context of the multiple-use mandate of the BLM.
In our example, conceptual models identify known or hypothesized stressors (such as grazing), and thus inform potential management responses to those stressors (such as changing allowed grazing intensities if land health standards are not met). The process of identifying stressors also acknowledges that local managers have a reasonable level of control over some processes (for example, local grazing intensities) but not others (for example, a changing climate). The reporting format explicitly identifies the degree to which current values of each indicator depart from reference conditions, and whether the indicators were measured at local or broad scales. In some cases, it may be helpful to analyze and present results at finer spatial scales (for example, ecoregions or field office boundaries) to guide management responses.

\section{Repeat Assessment at Predetermined Frequency}

An initial ecological integrity assessment will usually identify the degree of departure from reference conditions for each indicator, informing the type and amount of management that may be needed to improve the integrity of the system. Repeated assessments can be used to evaluate the extent to which management actions are correlating with indicator values that are closer to their natural and acceptable ranges of variation. The frequency at which the assessment is repeated will be informed by factors similar to those identified for defining relevant temporal scales, including the ecology of the system and the time frames in which management decisions are made and management responses are likely to be detected.

\section{Using the Ecological Integrity Framework and Assessment Process to Facilitate Implementing a Landscape Approach in the Bureau of Land Management}

The early adoption of ecological integrity as a goal for aquatic systems in the United States through implementation of the Clean Water Act of 1972 (33 USC §1251) and early definition of a standard method for assessing integrity in aquatic systems (Karr and Dudley, 1981; Karr and others, 1986) may have fostered widespread use of ecological (or biotic) integrity assessments for managing aquatic systems. There is a comparable desire and policy foundation for considering ecological integrity in management of terrestrial systems in the United States (Vickerman and Kagan, 2014), including on Federal lands (for example, National Park Service Organic Act of 1916 [16 USC §1], USDA Forest Service 2012 Planning Rule [36 CFR §219]). However, quantitative application of 
Table 4-2. One model for presenting results of an ecological integrity assessment for rangelands across the western United States. Results include the name of the indicator, the component(s) of ecological integrity (composition, structure, or function) described by the indicator, the spatial scale at which each indicator is assessed (local or regional), and the degree to which the current value of each indicator departs from reference conditions for the Western United States. Note: these data are fictional representations of the proportional area of rangelands in each departure category, and are intended for illustration only.

\begin{tabular}{|c|c|c|c|c|}
\hline $\begin{array}{l}\text { 0-10 percent departure } \\
\text { from reference conditions }\end{array}$ & $\begin{array}{r}20-30 \\
\text { dep }\end{array}$ & rent & $\begin{array}{l}\text { 30-40 percent } \\
\text { departure }\end{array}$ & $\begin{array}{c}\text { Greater than } \\
40 \text { percent departure }\end{array}$ \\
\hline Indicator & Composition & Structure & Function & Western United States \\
\hline Amount of bare ground & & Local & Local & \\
\hline Vegetation composition & Local & & & \\
\hline Invasive plants & Local & & & \\
\hline Plants of management concern & Local & & & \\
\hline Vegetation height & & Local & Local & \\
\hline Proportion of soil surface in large intercanopy gaps & & Local & Local & \\
\hline Vegetation amount & Regional & & & \\
\hline Vegetation distribution & & & Regional & \\
\hline Patch size & & Regional & & \\
\hline Structural connectivity & & Regional & & \\
\hline Development & & & Regional & \\
\hline Biomass/productivity & & & Regional & \\
\hline
\end{tabular}

the ecological integrity concept in terrestrial systems has been limited (but see Fraser and others, 2009; Tierney and others, 2009; Mitchell and others, 2014), likely due in part to the difficulty in identifying and measuring representative indicators across what are often larger systems with less defined boundaries compared to freshwater systems. In addition, application of the concept of ecological integrity to multiple-use contexts, in which some resource objectives directly conflict with protection of pristine systems, is not well understood (Wurtzebach and Schultz, 2016).

The BLM is not required by policy or law to consider ecological integrity in its management. Rather, the agency manages on the basis of multiple use and sustained yield (43 USC §1701) and the Fundamentals of Rangeland Health (43 CFR §4180.1). We suggest, however, that evaluating ecological integrity is possible with little additional monitoring effort (11 of 12 proposed indicators are already quantified in REAs or through AIM monitoring). Further, assessing ecological integrity would provide complementary information to land health assessments and contribute to both managers and the public gaining a broader understanding of the condition of ecological systems across all Federal lands. The ecological integrity assessment process outlined here is consistent with the AIM monitoring process, facilitating integration of ecological integrity assessments into the existing monitoring and assessment programs of the BLM. In addition, using results from ecological integrity assessments together with information on current and authorized land uses can help identify tradeoffs resulting from different resource management actions, a key aspect of implementing a landscape approach to resource management on lands managed by the BLM (see chapter 2). 


\section{References Cited}

Allred, B.W., Smith, W.K., Twidwell, Dirac, Haggerty, J.H., Running, S.W., Naugle, D.E., and Fuhlendorf, S.D., 2015, Ecosystem services lost to oil and gas in North America: Science, v. 348, p. 401-402.

Assal, T.J., Melcher, C.P., and Carr, N.B., eds., 2015, Southern Great Plains Rapid Ecoregional AssessmentPre-assessment report: U.S. Geological Survey Open-File Report 2015-1003, 284 p., accessed December 8, 2016, at https://dx.doi.org/10.3133/ofr20151003.

Beja-Pereira, Albano, Oliveira, Rita, Alves, P.C., Schwartz, M.K., and Luikart, Gordon, 2009, Advancing ecological understandings through technological transformations in noninvasive genetics: Molecular Ecology Resources, v. 9, p. 1279-1301.

Bureau of Land Management, 1997, Decision record and finding of no significant impact for adoption of standards for public land health and guidelines for livestock grazing management in Colorado: Bureau of Land Management, accessed June 12, 2016, at https://www.blm.gov/style/ medialib/blm/wo/Information_Resources_Management/ policy/blm_handbook.Par.61484.File.dat/h4180-1.pdf.

Bureau of Land Management, 2001, Bureau of Land Management handbook for rangeland health standards: Bureau of Land Management, accessed January 12, 2017, at http:// www.blm.gov/pgdata/etc/medialib/blm/wo/Information Resources_Management/policy/blm_handbook.Par.61484. File.dat/h4180-1.pdf.

Bureau of Land Management, 2008, Colorado standards for public land health: Bureau of Land Management, accessed October 18, 2015, at http://www.blm.gov/co/st/en/BLM Programs/grazing/rm_stds_guidelines.html.

Bureau of Land Management, 2009, Manual 4180, Land health manual for the Bureau of Land Management: Bureau of Land Management, accessed March 2, 2016, at http://www.blm.gov/style/medialib/blm/wo/Information Resources_Management/policy/blm_manual.Par.23764. File.dat/4180.pdf.

Bureau of Land Management, 2015, Record of decision and approved resource management plan amendments for the Great Basin region, including the greater sage-grouse sub-regions of Idaho and southwestern Montana, Nevada and Northeastern California, Oregon, Utah: Bureau of Land Management, accessed October 20, 2015, at http://www.blm.gov/ wo/st/en/prog/more/sagegrouse.html.

Bureau of Land Management, 2016, Rapid Ecoregional Assessments: Bureau of Land Management, accessed March 7, 2016, at http://www.blm.gov/wo/st/en/prog/more/ Landscape_Approach/reas.html.
Bureau of Land Management, USDA Forest Service, and USDA Natural Resources Conservation Service, 2010, Interagency ecological site handbook: Bureau of Land Management, accessed February 28, 2016, at http:// directives.sc.egov.usda.gov/OpenNonWebContent. aspx? content=33943. wba.

Boone, R.B., Taylor, J.J., Swift, D.M., Evangelista, P.H., and Hollowed, Ed, 2011, Developing a resource management and monitoring protocol for a semiarid landscape with extensive oil and gas development potential: Denver, Colo., Bureau of Land Management, National Operations Center, Technical Note 439, 52 p., accessed September 16, 2015, at http://www.blm.gov/nstc/library/ pdf/TN439.pdf.

Borja, Angel, Bricker, S.B., Dauer, D.M., Demetriades, N.T., Ferreira, J.G., Forbes, A.T., Hutchings, Pat, Jia, Xiaoping, Kenchington, Richard, Marques, J.C., and Zhu, Changbo, 2008, Overview of integrative tools and methods in assessing ecological integrity in estuarine and coastal systems worldwide: Marine Pollution Bulletin, v. 56, p. $1519-1537$.

Cardoso, Pedro, Borges, P.A.V., and Gaspar, Clara, 2007, Biotic integrity of the arthropod communities in the natural forests of Azores: Biodiversity and Conservation, v. 16, p. 2883-2901.

Carr, N.B., Wood, D.J.A., Bowen, Z.H., and Haby, T.S., 2015, Broad-scale assessments of ecological landscapesDeveloping methods and applications: U.S. Geological Survey, Fact Sheet 2015-3007, 4 p., accessed October 19, 2015, http://pubs.usgs.gov/fs/2015/3007/pdf/ fs2015-3007.pdf.

Chambers, J.C., Roundy, B.A., Blank, R.R., Meyer, S.E., and Whittaker, A., 2007, What makes Great Basin sagebrush ecosystems invasible by Bromus tectorum?: Ecological Monographs, v. 77, no. 1, p. 117-145.

Clement, J.P., Belin, A.d'A., Bean, M.J., Boling, T.A., and Lyons, J.R., 2014, A strategy for improving the mitigation policies and practices of the Department of the Interior: Washington, D.C., A report to the Secretary of the Interior from the Energy and Climate Change Task Force, $25 \mathrm{p}$.

Diffendorfer, J.E., Fleming, G.M., Duggan, J.M., Chapman, R.E., Rahn, M.E., Mitrovich, M.J., and Fisher, R.N., 2007, Developing terrestrial, multi-taxon indices of biological integrity: an example from coastal sage scrub: Biological Conservation, v. 140, p. 130-141. 
DiTomaso, J.M., 2000, Invasive weeds in rangelands: Species, impacts, and management: Weed Science, v. 28, p. $255-265$.

Fraser, R.H., Olthof, I., and Pouliot, D., 2009, Monitoring land cover change and ecological integrity in Canada's national parks: Remote Sensing of Environment, v. 113, p. 1397-1409.

Glennon, M.J., and Porter, W.F., 2005, Effects of land use management on biotic integrity: An investigation of bird communities: Biological Conservation, v. 126, p. 499-511.

Hawkins, C.P., Norris, R.H., Hogue, J.N., and Feminella, J.W., 2000, Development and evaluation of predictive models for measuring the biological integrity of streams: Ecological Applications, v. 10, p. 1456-1477.

Herrick, J.E., Van Zee, J.W., Havstad, K.M., Burkett, L.M., and Whitford, W.G., 2009, Monitoring manual for grassland, shrubland and savanna ecosystems: Las Cruces, N. Mex., U.S. Department of Agriculture, Agricultural Research Service, Jornada Experimental Range, accessed June 25, 2015, at http://www.ars.usda.gov/Research/ docs.htm?docid=24068.

Karl, M.G. "Sherm”, Kachergis, Emily, and Karl, J.W., 2016, Bureau of Land Management Rangeland Resource Assessment-2011: U.S. Department of the Interior, Bureau of Land Management, $112 \mathrm{p}$.

Karr, J.R., and Dudley, D.R., 1981, Ecological perspective on water quality goals: Environmental Management, v. 5, p. 55-68.

Karr, J.R., Fausch, K.D., Angermeier, P.L., Yant, P.R., and Schlosser, I.J, 1986, Assessing biological integrity in running waters: a method and its rationale: Illinois Natural History Survey Special Publication 5, 28 p.

Keane, R.E., Hessburg, P.F., Landres, P.B., and Swanson, F.J. 2009, The use of historical range of variability (HRV) in landscape management: Forest Ecology and Management, v. 258 , p. $1025-1037$.

Knick, S.T., Hanser, S.E., and Preston, K.L., 2013, Modeling ecological minimum requirements for distribution of greater sage-grouse leks: Implications for population connectivity across their western range, USA: Ecology and Evolution, v. 3, p. 1539-1551.

LANDFIRE, 2010, LANDFIRE Biophysical Settings layer (2010 update): U.S. Geological Survey, accessed October 20, 2015, at http://landfire.cr.usgs.gov/viewer/.
Luikart, Gordon, Ryman, Nils, Tallmon, D.A., Schwartz, M.K., and Allendorf, F.W., 2010, Estimation of census and effective population sizes: the increasing usefulness of DNA-based approaches: Conservation Genetics, v. 11, p. 355-373.

MacKinnon, W.C., Karl, J.W., Toevs, G.R., Taylor, J.J., Karl, Michael, Spurrier, C.S., and Herrick, J.E., 2011, BLM core terrestrial indicators and methods: Denver, Colo., Bureau of Land Management, National Operations Center, Technical Note 440, accessed June 18, 2015, at http://www.blm.gov/ nstc/library/pdf/TN440.pdf.

Mitchell, B.R., Tierney, G.L., Schweiger, E.W., Miller, K.M., Faber-Langendoen, Don, and Grace, J.B., 2014, Getting the message across: Using ecological integrity to communicate with resource managers, in Guntenspergen, G.R., ed., Application of threshold concepts in natural resource decision making: New York, Springer-Verlag, p. 199-230.

Millar, C.I., Stephenson, N.L., and Stephens, S.L., 2007, Climate change and forests of the future: managing in the face of uncertainty: Ecological Applications, v. 17, p. 2145-2151.

Noss, R.F., 1990, Indicators for monitoring biodiversityA hierarchical approach: Conservation Biology, v. 4, p. 355-364.

Parrish, J.D., Braun, D.P., and Unnasch, R.S., 2003, Are we conserving what we say we are? Measuring ecological integrity within protected areas: Bioscience, v. 53, p. $851-860$.

Pellant, Mike, Shaver, Patrick, Pyke, D.A., and Herrick, J.E., 2005, Interpreting indicators of rangeland health, ver. 4: Denver, Colo., Bureau of Land Management, National Science and Technology Center, Technical Reference 1734-6, BLM/WO/ST-00/001+1734/REV05, 122 p.

Petchey, O.L., and Gaston, K.J., 2006, Functional diversity: back to basics and looking forward: Ecology Letters, v. 9, p. 741-758.

Pettorelli, Nathalie, Vik, J.O., Mysterud, Atle, Gaillard, J.M., Tucker, C.J., and Stenseth, N.C., 2005, Using the satellitederived NDVI to assess ecological responses to environmental change: Trends in Ecology and Evolution, v. 20, p. $503-510$.

Sage-grouse National Technical Team, 2011, A report of national greater sage-grouse conservation measures: Bureau of Land Management, accessed October 20, 2015, at http:// www.blm.gov/style/medialib/blm/co/programs/wildlife. Par.73607.File.dat/GrSG\%20Tech\%20Team\%20Report.pdf.

Sawyer, Hall, Kauffman, M.J., Nielson, R.M., and Horne, J.S., 2009a, Identifying and prioritizing ungulate migration routes for landscape-level conservation: Ecological Applications, v. 19, p. 2016-2025. 
Sawyer, Hall, Kauffman, M.J., Nielson, R.M., and Horne, J.S., 2009b, Influence of well pad activity on the winter habitat selection patterns of mule deer: Journal of Wildlife Management, v. 73, p. 1052-1061.

Sayer, Jeffrey, Sunderland, Terry, Ghazoul, Jaboury, Pfund, J.-L., Sheil, Douglas, Meijaard, Erik, Venter, Michelle, Boedhihartono, A.K., Day, Michael, Garcia, Claude, van Oosten, Cora, and Buck, L.E., 2013, Ten principles for a landscape approach to reconciling agriculture, conservation, and other competing land uses: Proceedings of the National Academy of Sciences of the United States of America, v. 110 , p. $8349-8356$.

State of Wyoming, 2011, Executive Order 2011-5: Greater sage-grouse core area protection: State of Wyoming, accessed October 20, 2015, at http://will.state.wy.us/sis/ wydocs/execorders/EO2011-05.pdf.

Stiver, S.J., Rinkes, E.T., Naugle, D.E., Makela, P.D., Nance, D.A., and Karl, J.W., eds., 2015, Sage-grouse habitat assessment framework: A multiscale assessment tool: Denver, Colo., Bureau of Land Management and Western Association of Fish and Wildlife Agencies, Technical Reference 6710-1, accessed October, 20, 2015, at http:// www.blm.gov/style/medialib/blm/wo/blm_library/tech_refs. Par.34086.File.dat/TR_6710-01.pdf.

Stoddard, J.L., Larsen, D.P., Hawkins, C.P., Johnson, R.K., and Norris, R.H., 2006, Setting expectations for the ecological condition of streams: The concept of reference condition: Ecological Applications, v. 16, p. 1267-1276.

Taylor, Jason, Kachergis, Emily, Toevs, Gordon, Karl, Jason, Bobo, Matthew, Karl, Michael, Miller, Scott, and Spurrier, Carol, 2014, AIM-Monitoring: A component of the BLM Assessment, Inventory, and Monitoring Strategy: Denver, Colo., U.S. Department of the Interior, Bureau of Land Management, National Operations Center, accessed June 18, 2015, at http://www.blm.gov/style/medialib/blm/ wo/blm_library/tech_notes.Par.24137.File.dat/TN_445.pdf.

Tierney, G.L., Faber-Langendoen, Don, Mitchell, B.R., Shriver, W.G., and Gibbs, J.P., 2009, Monitoring and evaluating the ecological integrity of forest ecosystems: Frontiers in Ecology and the Environment, v. 7, p. 308-316.
Toevs, G.R., Taylor, J.J., Spurrier, C.S., MacKinnon, W.C., and Bobo, M.R., 2011, Bureau of Land Management Assessment, Inventory, and Monitoring Strategy: For integrated renewable resources management: Denver, Colo., Bureau of Land Management, National Operations Center, accessed June 15, 2015, at http://www.blm.gov/style/ medialib/blm/wo/Information_Resources_Management/ policy/ib_attachments/2012.Par.53766.File.dat/IB2012080_att1.pdf.

Unnasch, R.S., Braun, D.P., Comer, P.J., Eckert, G.E., 2008, The Ecological Integrity Assessment Framework: A framework for assessing the ecological integrity of biological and ecological resources of the National Park System, Report to the National Park Service: National Park Service, accessed December 7, 2016, at http://www.natureserve.org/biodiversity-science/ publications/ecological-integrity-assessment-frameworkframework-assessing.

U.S. Department of the Interior, Bureau of Land Management, and Office of the Solicitor, eds., 2001, The Federal Land Policy and Management Act, as amended: Washington, D.C., U.S. Department of the Interior, Bureau of Land Management Office of Public Affairs, 69 p., accessed October 18, 2015, at https://www.blm.gov/or/regulations/ files/FLPMA.pdf.

Vickerman, Sara, and Kagan, J.S., 2014. Assessing ecological integrity across jurisdictions and scales: accessed September 3, 2015, at http://www.defenders.org/publication/ eco-integrity-measures-across-jurisdictions-and-scales.

Waits, L.P., and Paetkau, David, 2005, Noninvasive genetic sampling tools for wildlife biologists: A review of applications and recommendations for accurate data collection: Journal of Wildlife Management, v. 69, p. 1419-1433.

Woodley, Stephen, 2010, Ecological integrity: A framework for ecosystem-based management, in Cole, D.N., and Yung, Laurie, eds., Beyond naturalness: rethinking park and wilderness stewardship in an era of rapid change: Washington D.C., Island Press, p.106-124.

Wurtzebach, Zachary and Schultz, Courtney, 2016, Measuring ecological integrity: history, practical applications, and research opportunities: Bioscience, v. 66 , no. 6 , p. 446-457. 



\title{
Chapter 5. A Multiscale Index of Landscape Intactness for Management of Public Lands
}

\author{
By Natasha B. Carr, Ian I.F. Leinwand, and David J.A. Wood
}

\section{Abstract}

Landscape intactness has been defined as a quantifiable estimate of naturalness measured on a gradient of anthropogenic influence across broad landscapes or ecoregions. We developed a multiscale index of landscape intactness for the Bureau of Land Management (BLM) landscape approach, which requires multiple scales of information to quantify the cumulative effects of land use. The index represents a gradient of development as represented by the surface disturbance footprint from development (surface disturbance footprint) at two analysis scales. To create the index, we first mapped the surface disturbance footprint for the western United States by compiling and combining spatial data for transportation, energy and minerals, agriculture, and urban development. We summarized the total surface disturbance footprint using a 2.5-kilometer $(\mathrm{km})$ and $20-\mathrm{km}$ circular moving window and ranked the development levels for each scale of analysis. The classes for both scales were combined to quantify landscape intactness level. The multiscale index of landscape intactness is designed to be flexible, transparent, defensible, and applicable across multiple spatial scales, ecological boundaries, and jurisdictions. We illustrate how the multiscale index of landscape intactness can be applied to management issues across a broad range of spatial extents that span ecological and jurisdictional boundaries. Landscape intactness is a key derived broadscale indicator for quantifying natural resource status and condition, and the standardized index builds on several approaches for quantifying landscape intactness previously developed as a part of the BLM Rapid Ecoregional Assessment program. Information on landscape intactness can be used to develop landscapelevel strategies to avoid, minimize, and compensate for adverse ecological consequences of development on public lands and to incorporate ecological characteristics that promote ecosystem resilience into management strategies.

\section{Broad-Scale Indicators for the Landscape Approach}

Implementing a landscape approach for managing multiple uses of public lands requires information that spans a broad range of scales (Sayer and others, 2014; Freeman and others, 2015). Multiple scales of information are needed to quantify the cumulative effects of land use because the effects can vary with the scale of evaluation (Sayer and others, 2013; Burton and others, 2014; Freeman and others, 2015; see also chapter 2). For example, the fragmenting effects of land use on the size and connectivity of wildlife habitats may be most evident at broad scales of analysis using remotely sensed data (fig. 5-1). In contrast, changes to vegetation composition, such as the presence of non-native species, often requires field surveys conducted at finer spatial scales (fig. 5-1). Although invasive species are increasingly being assessed using remotely sensed data (for example, Wenjie and Wang, 2016), challenges in mapping invasive species remain (Mairota and others, 2015). The continual improvements in quality and accessibility of remotely sensed data and national datasets has expanded the potential for addressing broad-scale effects of land use to better evaluate cumulative effects than was previously possible (Heilman and others, 2002; Potapov and others, 2008).

Integral to the landscape approach, the Assessment, Inventory, and Monitoring (AIM) Strategy of the Bureau of Land Management (BLM) addresses the need for information at local, landscape, and regional scales (see chapter 3). Components of the AIM strategy include AIM monitoring, which provides local-scale information on ecological conditions, and the Rapid Ecoregional Assessments (REA), which provide information representing broader scale conditions. Standardized core indicators of local-scale vegetation and soil conditions have been developed and incorporated into AIM monitoring (table 4-1), whereas standardized broad-scale indicators of the status and condition of habitats, ecological communities, and ecoregions are currently in development (see chapter 3). Collectively, the fine-scale and broad-scale indicators are integral to the multiscale approach to managing landscapes (fig. 5-1).

One initial objective of the REA program was to develop broad-scale indicators of the status and condition of ecological resources, which potentially could be incorporated into the AIM monitoring standards (see chapter 3). Broad-scale indicators of ecosystem composition, structure, and function, including development, can be used to characterize components of ecological integrity (table 3-1; see also chapter 4). Indicators of landscape composition may include the amount and distribution of native ecological communities (such as sagebrush steppe or riparian zones), wildlife habitats, and invasive species. Landscape structure includes the spatial arrangement of patches of ecological communities or wildlife habitats and may include indicators of patch size and 


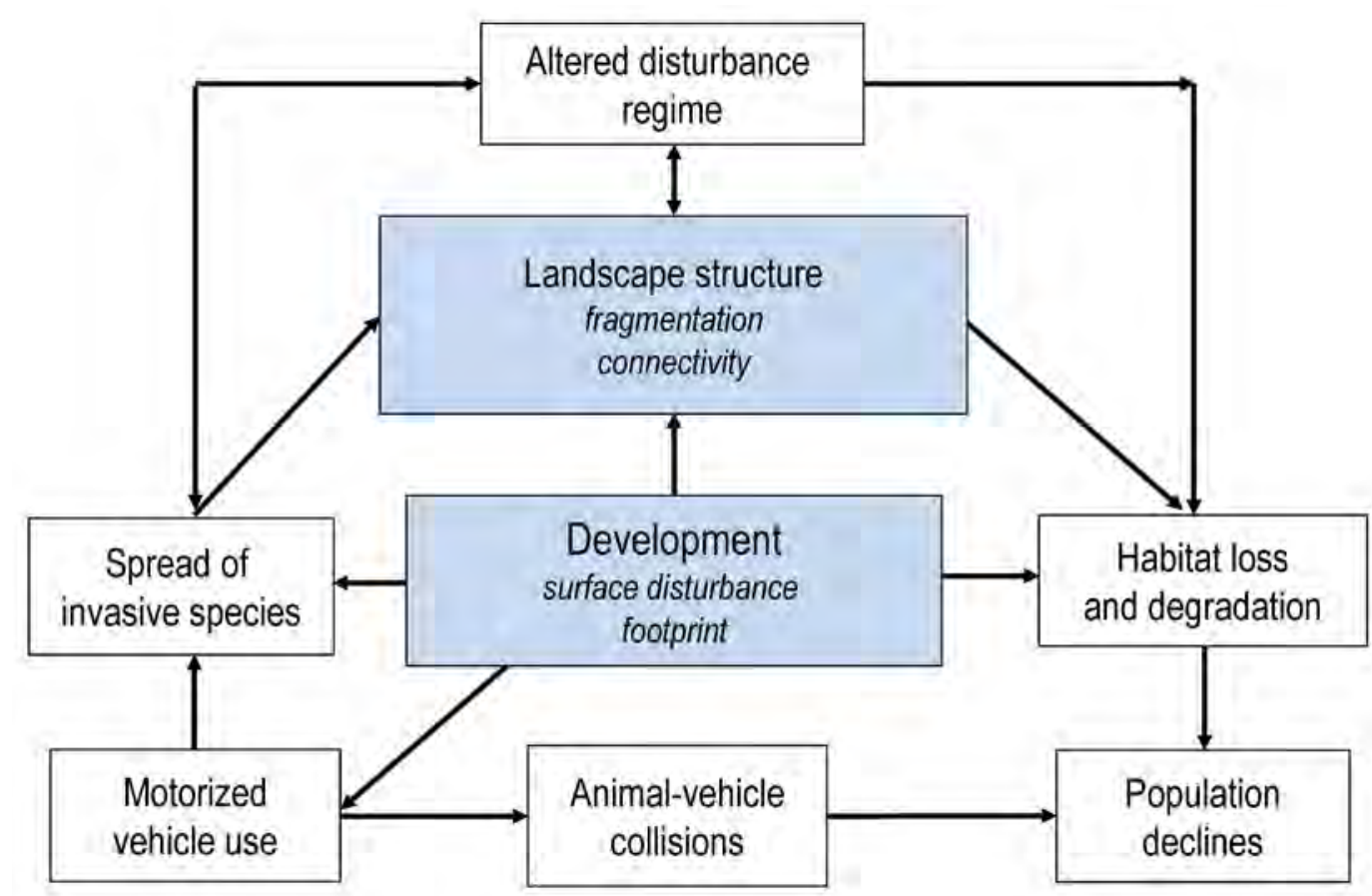

Figure 5-1. Examples of the cumulative direct and indirect ecological effects of development as a function of the surface disturbance footprint resulting from development. Blue boxes highlight some of the broad-scale effects of development on landscape structure and intactness that are addressed by broad-scale indicators compiled in Rapid Ecoregional Assessments. White boxes highlight other direct and indirect effects of development, some of which are addressed by local-scale Assessment, Inventory and Monitoring (AIM) core indicators.

connectivity (see chapter 2). Landscape function includes disturbance regimes and may be represented by indicators such as estimated historical and current fire return intervals. Landscape intactness, as defined by the BLM, is a quantifiable estimate of naturalness measured on a gradient of anthropogenic influence, across large landscapes or ecoregions (see chapter 3 ). Broad-scale indicators of ecological systems are interrelated and not mutually exclusive, but emphasize different ecosystem components across broad scales that cannot readily be represented by a single metric or scale of analysis (chapter 3).

Information on landscape intactness can inform selection of potential areas for conservation actions across a range of scales. At broad spatial extents, such as ecoregions, the goal of identifying large intact areas as potential areas for conservation is based, in part, on the assumption that because these areas have not been greatly altered by human activities (such as development), they are more likely to contain a variety of plant and animal communities and to be resilient and resistant to changes resulting from natural disturbances such as fire, insect outbreaks, and disease (Noss 1990; Peterson and others, 1998). Large intact areas are likely to support viable plant and animal populations and facilitate seasonal movements and dispersal of organisms. In addition, the potential for maintaining ecological processes across a variety of temporal and spatial scales is expected to be greater in larger intact areas. It is therefore also assumed that large intact areas may afford greater potential for ecological communities and wildlife populations to withstand or adapt to additional stress from projected climate change (Opdam and Wascher, 2004).

Small intact areas surrounded by a mosaic of more developed lands in multiple-use landscapes, however, also contribute to ecosystem functions (Tulloch and others, 2016). In the short term, small intact areas may function as dispersal or migration "stepping stones" that facilitate movements across broad areas with high levels of development that may inhibit movements (Minor and Lookingbill, 2010). Small intact areas may also serve as refugia (Tulloch and others, 2015). Over longer time frames, small intact areas could facilitate organism movements in response to changing climates (Minor and Lookingbill, 2010; Tulloch and others, 2015). Thus, small intact areas may contribute to connectivity and support metapopulations, which may enhance ecological resilience to changing climates in multipleuse landscapes (Sayer and others, 2013).

One of the goals of the REAs was to address ecological integrity by developing methods for quantifying landscape intactness (Bryce and others, 2012; Carr and Melcher, 2015), also referred to as landscape condition (Comer and others, 2013). However, differences among REAs in methods for quantifying landscape intactness present challenges in comparing landscape intactness across REA boundaries. Although all REAs 
included development in the methods for quantifying landscape intactness, there were differences in some of the regional datasets used as input variables. In addition, the methods and scales of analysis used to quantify development varied among REAs. Furthermore, some REAs included additional change agents (fire and invasive species) and in one case, incorporated metrics to address landscape structure. Because of these differences, the methods for quantifying landscape intactness developed by the REAs cannot be used to compare intactness across ecoregions. The different approaches, however, were useful for developing standardized methods to quantify intactness.

To address the need for a standardized approach, we developed a multiscale index of landscape intactness and applied it to 17 western states (Arizona, California, Colorado, Idaho, Kansas, Montana, New Mexico, Nebraska, Nevada, North Dakota, Oklahoma, Oregon, South Dakota, Texas, Utah, Washington, and Wyoming). Our overall goal was to develop a multiscale index with a suite of properties that make it useful for management of public lands across broad spatial extents. Specifically, the index was intended to be flexible and general enough for applications across multiple spatial scales, ecological boundaries, and jurisdictional or administrative boundaries. In addition, the index was designed to be transparent and defensible by limiting assumptions and complexity that increase uncertainty and make it more difficult to interpret the index scores. Landscape intactness has been proposed as a broad-scale indicator of natural resource status and condition for the AIM program (see chapter 3).

The purpose of this chapter is to document how the multiscale index of landscape intactness was designed to achieve the desired index properties and to demonstrate potential applications of the index to management issues that are relevant to the landscape approach. We provide the criteria used for selecting the change agents (such as development) and for evaluating source datasets and scales of analysis. We also discuss the basis for the breakpoints used for defining landscape intactness levels and demonstrate how intermediate derived datasets are retained in the dataset to facilitate ease of interpretation. Finally, we illustrate how the multiscale index of landscape intactness can be applied to management issues across a broad range of spatial extents that span ecological and administrative or jurisdictional boundaries.

\section{Creating a Multiscale Index of Landscape Intactness}

\section{Measuring the Gradient of Anthropogenic Influence}

To create a multiscale index of landscape intactness, we evaluated the methods used for quantifying change agents (types of anthropogenic activities) in REAs and other published broad-scale assessments of landscape intactness and related indices. Development (including agricultural, energy, minerals, transportation, and urban) was included as a measure of anthropogenic influence for all broad-scale assessment methods we reviewed, but in several cases this was the only change agent evaluated (Woolmer and others, 2008; Theobald, 2010; Carr and Melcher, 2015). In addition to the surface disturbance footprint from development (surface disturbance footprint), some methods included human population densities, night-time lights, recreation, or traffic volumes (Leu and others, 2008; Dickson and others, 2015; Theobald 2010, 2013; Ventor and others, 2015). Other change agents sometimes evaluated were invasive species (Leu and others, 2008; Comer and others, 2013; Theobald, 2013), fire (Bryce and others, 2012), and potential predators that can increase as a result of human activities (such as corvids, dogs, cats; Leu and others, 2008). In some cases, patch metrics related to fragmentation were included (Leu and others, 2008; Bryce and others, 2012). For the approaches that limited the number of change agents and related indicators addressed, additional types of anthropogenic influence were addressed by overlaying datasets (such as invasive species) or evaluating fragmentation separately (such as Carr and Melcher, 2015).

We focused on quantifying the surface disturbance footprint from development as the best indicator of multiscale landscape intactness for several reasons. First, national datasets quantifying development were readily available for all 17 western states, whereas national datasets for other anthropogenic influences (such as grazing, invasive species, traffic volumes, and altered fire regimes) were either context specific, or were not consistently available (Crall and others, 2010; Veblen and others, 2014). As a result, other change agents were problematic to evaluate using a generalized index that traverses multiple ecoregions and were beyond the scope of this project. Such anthropogenic influences can have profound effects on intactness; however, we suggest that local-level information on context-specific change agents be used to supplement broad-scale indicators of landscape intactness (see chapters 3 and 4). Second, the direct effects of development, specifically the conversion of native vegetation to impervious surfaces, bare ground, or croplands, could be quantified readily with a single metric: the area of vegetation conversion, referred to as the surface disturbance footprint. To maintain the generality of the index, we did not include data on predators (such as corvids or domestic pets) that are only relevant to some taxa, and also are strongly correlated with development infrastructure (such as garbage dumps and houses) addressed indirectly by the index.

\section{Selection of Analysis Methods for Development}

To quantify development levels, we did not use weightings for different types of development (Comer and others, 2013; Theobald, 2010, 2013; Venter and others, 2016) or 
fuzzy logic models (Bryce and others, 2012) that generally require assumptions about the magnitude of the response of a particular species to the change agent and rely on expert opinion, which can introduce bias (Brown and Williams, 2016). Such assumptions limit the generality, flexibility, and transparency of the index. To maintain transparency and facilitate interpretation, we only included the direct effects of development, namely the surface disturbance footprint. One of our assumptions is that for species sensitive to development, decreasing development levels corresponds to an increase in landscape intactness. Because the landscape intactness index is intended to apply generally across ecological systems, we do not establish thresholds for particular species.

We derived an index of development levels by first quantifying the footprints of urban development, agriculture, and infrastructure associated with energy and minerals extraction and transmission and transportation. We used national datasets that provided the most complete data across the entire 17-state assessment area, were used in recent western assessments (Manier and others, 2014), or were readily available (table 5-1). All linear features and points were buffered to create a surface disturbance footprint (table 5-2). Buffered footprints and polygonal data were rasterized (converted to a grid) as outlined in table 5-2. All variables were quantified using a gridded surface (raster) representing the landscape as $15-\times 15$-meter $(\mathrm{m})$ cells (hereafter $225 \mathrm{~m}^{2}$ [square meter] cells) or $30-\mathrm{x} 30$-m cells (hereafter $900 \mathrm{~m}^{2}$ cells) depending on the resolution of the source data (table 5-1). All $225-\mathrm{m}^{2}$ resolution input layers (table 5-1) were summed using a raster calculator. The maximum disturbance value of the composite data layer was set at 100 percent (table 5-2). The composite raster dataset was aggregated to $900 \mathrm{~m}^{2}$ and summed with the other $900 \mathrm{~m}^{2}$ raster datasets (table 5-1). Because the focus of the multiscale index is on broad-scale patterns not fine-scale precision, we aggregated to $8,100 \mathrm{~m}^{2}$ to facilitate analysis of westwide patterns, which is a standard practice for broad-scale assessments (Dickson and others, 2014; Theobald, 2010).

We derived a terrestrial development index (TDI) by summarizing the cumulative effects of the surface disturbance footprint using circular moving windows (Theobald 2010, 2013; Dickson and other, 2014) rather than a fixed rectangular (Bryce and others, 2012) or hexagonal grid (Woolmer and others, 2008). We used the ArcGIS focal neighborhood statistics function (Environmental Systems Research Institute, 2011) to sum the total percent of the surface disturbance footprint for a particular size of moving window (for example, a 2.5-kilometer $[\mathrm{km}]$ radius window). Additional details on data processing and analysis are provided in the metadata associated with the multiscale index of landscape intactness (Carr, Leinwand, and Wood, 2016).

\section{Selection of Scales of Analysis for Quantifying Development and Landscape Intactness}

To identify the size and minimum number of analysis scales necessary to capture cumulative effects of development across multiple scales, we compared 10 moving window sizes with a radius ranging from 1 to 250 kilometers. TDI scores for individual cells were highly correlated across window sizes (Pearson correlation coefficients $>0.8$ ), but there were several distinct spatial patterns evident for several

Table 5-1. Data sources used to quantify the surface disturbance footprint from development.

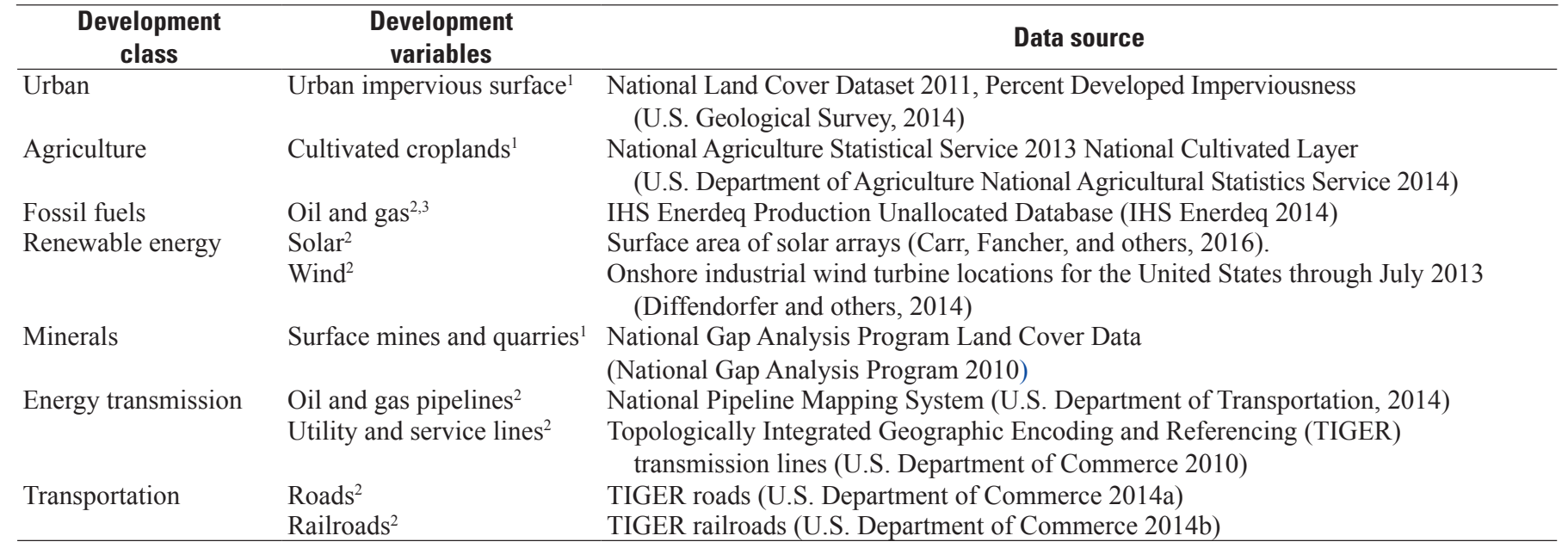

1900 square meter resolution.

${ }^{2} 225$ square meter resolution.

${ }^{3}$ Active wells and wells abandoned less than 30 years ago. 
Table 5-2. Buffer sizes for creating the surface disturbance footprint from development for linear and point features. The corresponding footprint area represented as the percent of disturbance per 15- x 15-meter cell (225 square meters) used to create the raster dataset is provided.

\begin{tabular}{lcc}
\hline Linear or point feature & $\begin{array}{c}\text { Buffer width } \\
\text { (meters) }\end{array}$ & $\begin{array}{c}\text { Percent }^{\mathbf{0}} \\
\text { of cell }^{\mathbf{2}}\end{array}$ \\
\hline Transportation & & \\
Interstate & 45 & 100 \\
Highway & 15 & 100 \\
Secondary road & 10 & 67 \\
Four-wheel drive road & 4 & 27 \\
Railroad & 10 & 67 \\
Oil and gas pipeline & 10 & 67 \\
Transmission line $^{3}$ & 10 & 67 \\
Oil and gas well pad $^{4}$ & 56 & 100 \\
Wind turbine pad $^{4}$ & 72 & 100 \\
\hline
\end{tabular}

${ }^{1}$ Buffer widths correspond to buffer sizes used by Leu and others (2008).

${ }^{2} 100$ percent of $15-\times 15$-meter cell $=225$ square meters $\left(\mathrm{m}^{2}\right)$;

67 percent $=150 \mathrm{~m}^{2} ; 27$ percent $=60 \mathrm{~m}^{2}$.

${ }^{3}$ Buffers represent half widths applied to each side of linear features (roads, railroads, pipelines, transmission lines).

${ }^{4}$ Radius of footprint assigned to each point feature.

ranges of scales that supported their inclusion or exclusion from the index. At the finest analysis scale evaluated (1-km moving window), the TDI scores for most of the assessment area were strongly skewed towards the low end of the development gradient. As a result, this analysis scale provided little discriminating power among development levels (Carr and Melcher, 2015). In addition, the TDI scores at this scale closely corresponded to the surface disturbance footprint, consequently this scale provided little additional information beyond what is already provided by the footprint dataset. At the broadest analysis scales, window sizes greater than $35 \mathrm{~km}$ resulted in highly smoothed TDI scores that had little discriminating power. As a result, we eliminated the $1-\mathrm{km}$ window and window sizes greater than $35-\mathrm{km}$ from consideration for use in the multiscale index.

Previous analysis for the Wyoming Basin ecoregion indicated that a window radius of approximately $2.5-\mathrm{km}$ is optimal for quantifying development levels (Carr and Melcher, 2015). The $2.5-\mathrm{km}$ window fell within a narrow range of scales corresponding to a threshold at which the TDI shifted from reflecting the presence or absence of development to representing average development level. We found the $2.5-\mathrm{km}$ threshold to be consistent for multiple other ecoregions. Therefore, we selected the $2.5-\mathrm{km}$ radius window (equivalent to $19 \mathrm{~km}^{2}$, or 7 sections) for the finest scale of analysis. To provide a broader context, we selected the $20-\mathrm{km}$ moving window (equivalent to $1,256 \mathrm{~km}^{2}$, or 1,357 townships) for a second scale of analysis because this scale had the lowest correlation with the $2.5-\mathrm{km}$ window and provided better discrimination among large undeveloped areas compared to the 10 - or $15-\mathrm{km}$ moving window analyses. However, the results are similar if either a $10-$ or $15-\mathrm{km}$ moving is used, indicating the results are fairly robust to the scale of analysis. Collectively, the TDI scores summarized at $2.5-\mathrm{km}$ and $20-\mathrm{km}$ radius windows capture landscape patterns relevant to a variety of ecological processes such as habitat selection, metapopulation dynamics, and organism dispersal, which are relevant to conservation planning (Opdam and Wascher, 2004) and the landscape approach (Sayer and others, 2013).

TDI scores for each scale of analysis were divided into six classes for visualization purposes (figs. 5-2 and 5-3) (see the Appendix in Carr and Melcher [2015] for additional details on how breakpoints were derived). At $2.5 \mathrm{~km}$, the terrestrial development index scores between 0 and 1 percent represent areas with very low levels of development (such as a few roads or oil and gas wells) (fig. 5-2). Scores between 1 and 3 percent often represent areas with low development including low densities of roads (for example, $3 \mathrm{~km}$ of roads per $\mathrm{km}^{2}$ ) or medium densities of oil and gas wells (for example, 4 wells per section), whereas terrestrial development index scores greater than 3 percent represent medium-to-high levels of development, including relatively high-density large oil and gas fields, surface mines, agricultural fields, centers of urban development, and major highways.

\section{Selection of Breakpoints for Calculating Landscape Intactness Level}

The TDI scores at two analysis scales were combined to quantify landscape intactness level according to the matrix in figure 5-4. To combine the scales, we first defined four levels of development at each scale (fig. 5-4). We focused on TDI scores less than or equal to 3 percent for identifying areas that had moderate or greater levels of intactness (table 5-3) because these development levels represent relatively low levels of development on multiple-use lands managed by the BLM and other land management agencies (fig. 5-2). We used equal breakpoints $(0-1,1-2$, and $2-3$ percent) at each scale to classify intactness levels (fig. 5-4). The highest landscape intactness level corresponds to TDI scores $=0-1$ percent at both scales. Very high landscape intactness corresponds to TDI scores $=0-1$ percent at one scale, and 1-2 percent at the other scale. High landscape intactness corresponds to TDI scores $=1-2$ percent at both scales. Moderate landscape intactness corresponds to TDI scores $=2-3$ percent at one scale and less than 3 percent at the other scale. The lowest landscape intactness levels have TDI scores $=3-100$ percent at either scale. Although other breakpoints could be used to evaluate landscape intactness, the breakpoints we selected help to identify lands with little development at both analysis scales and were useful in discriminating among lands in a multiple-use 

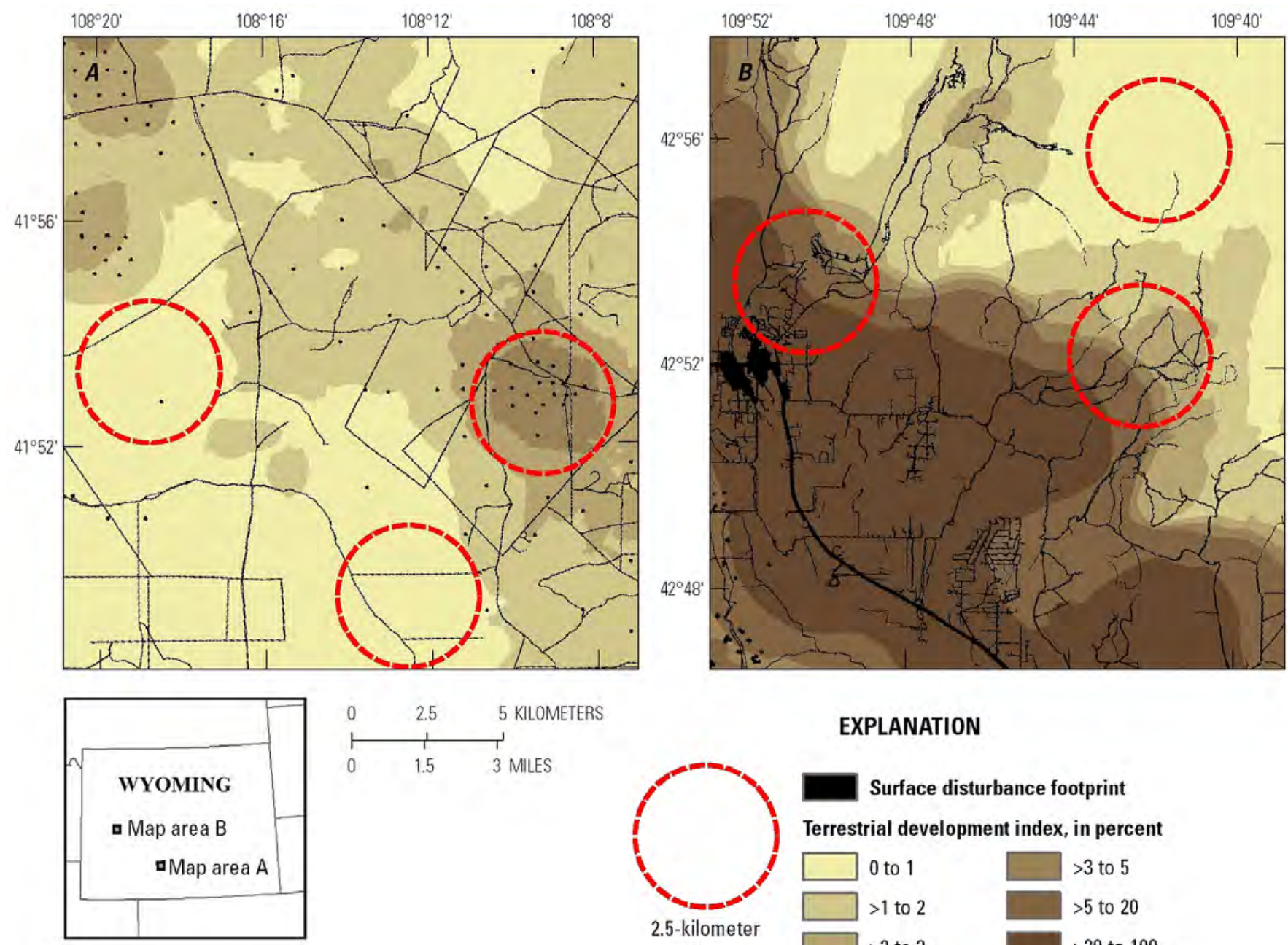

\section{EXPLANATION}

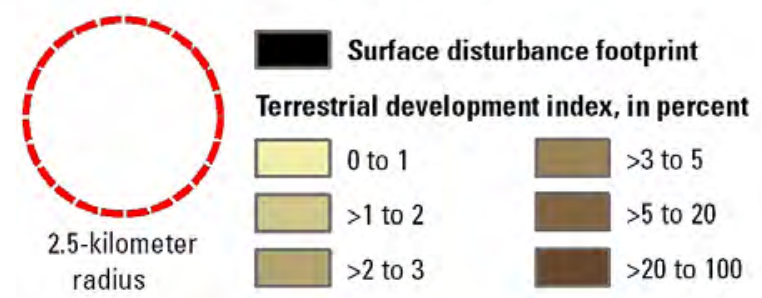

Figure 5-2. Terrestrial development index score and the associated surface disturbance footprint from development for two landscapes in Wyoming. The terrestrial development index, derived from the percent of the surface disturbance footprint within a 2.5-kilometer moving window, is depicted. $A$, an oil and gas field north of Wamsutter in south central Wyoming, and $B$, an agricultural landscape near Pinedale in western Wyoming (each location depicted by a square on inset map). Examples of 2.5-kilometer radius windows are indicated by red dashed circles.

landscape. An overview of the steps used to generate the multiscale index of landscape intactness is provided in figure 5-5 and the resulting map of landscape intactness is provided in figure 5-6.

Collectively, the 2.5- and 20-km windows represented the fine- and broad-scale spatial patterns of development better than a single analysis scale (fig. 5-3, table 5-3). For example, 39.4 percent of BLM lands had a TDI score of $0-1$ percent and would be considered to have the highest level of landscape intactness using only the $2.5-\mathrm{km}$ analysis scale, whereas only 19.2 percent of BLM lands had a TDI score of 0-1 percent at both $2.5 \mathrm{~km}$ and $20 \mathrm{~km}$. Consequently, two moving window sizes $(2.5 \mathrm{~km}$ and $20 \mathrm{~km})$ provided better discrimination among development levels than only one analysis scale (table 5-3). Because of the high correlation among scales, the inclusion of additional analysis scales provided little added information and complicated interpretation of the landscape intactness index.

\section{Transparency and Interpretation of the Multiscale Index of Landscape Intactness}

To meet the goals of transparency and to facilitate the interpretation of landscape intactness levels, the dataset used to create the map of landscape intactness retains the continuous scores for the TDI at each scale (table 5-4 and fig. 5-7). By retaining the contributing information from each step in the process model (fig. 5-5) and in the published datasets (Carr, Leinwand, and Wood, 2016), end users can readily identify the types and levels of development and the contribution of each analysis scale to the level of landscape intactness for a given area of interest (fig. 5-7). In addition, alternative breakpoints can be used for displaying TDI or defining landscape intactness to address different management questions. Fostering transparency and ease of interpretation also will help to ensure that the multiscale index of landscape intactness is defensible when used to inform management decisions. 

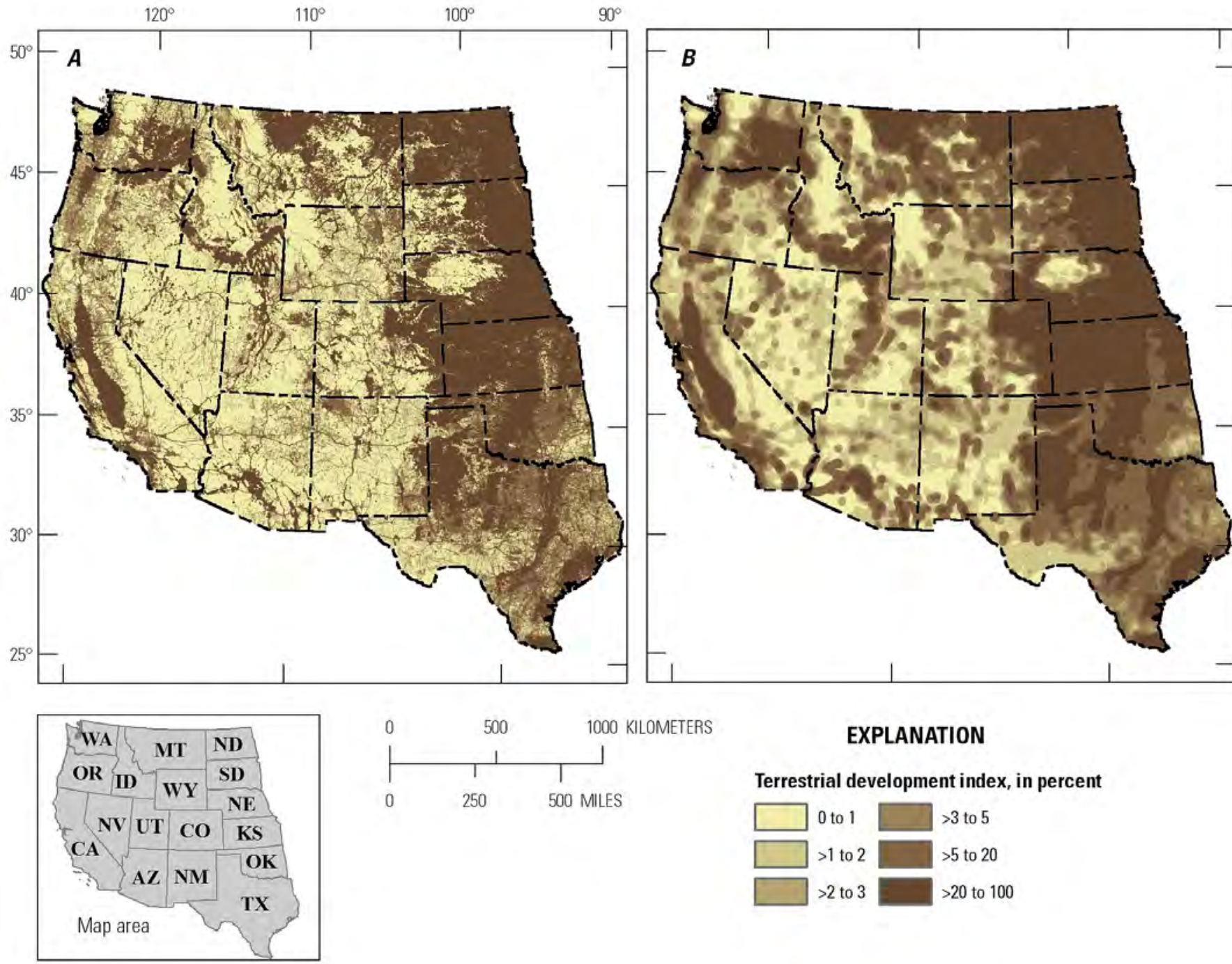

EXPLANATION

Terrestrial development index, in percent

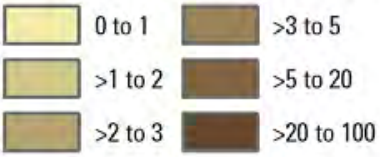

Figure 5-3. The terrestrial development index at two analysis scales. The index is derived from the surface disturbance footprint of agriculture, energy and minerals, transportation, and urban development and summarized for a given size of moving window. $A$, derived from a 2.5-kilometer moving window, and $B$, derived from a 20-kilometer moving window. The two scales of analysis are used for calculating the landscape intactness index.

\section{Use of the Multiscale Index of Landscape Intactness to Address Management Questions}

We used the multiscale index of landscape intactness for the western United States (fig. 5-6) to address five management questions relevant to the BLM and other land management agencies. These questions represent a variety of spatial extents, ecological contexts, land ownership and jurisdictions, and protection status of areas. The management questions and associated maps and graphics were intended to demonstrate the utility of the multiscale index to evaluate intactness of public lands and the flexibility of the index to provide information across a broad range of spatial extents.
1. How does landscape intactness vary across the ecoregions and ecological communities assessed for the REAs?

2. Where are the largest intact areas and which land management agencies have primary responsibility for these areas?

3. How does landscape intactness vary by land ownership or jurisdiction?

4. What is the status of BLM lands on the basis of the multiscale index of landscape intactness and how does this vary among field offices within an ecoregion?

5. Where are the most intact areas managed by the BLM that are not protected as national conservation lands? 


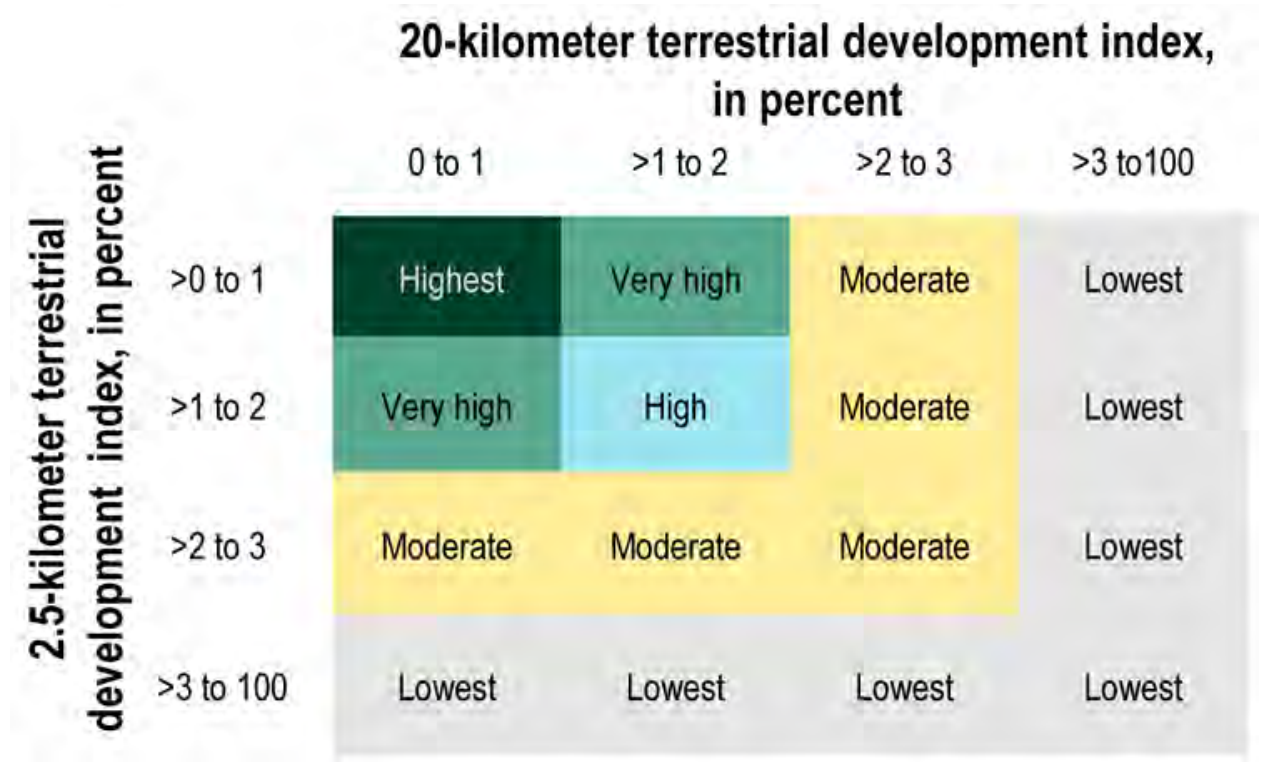

Figure 5-4. The level of landscape intactness as derived from terrestrial development index classes at two scales (2.5- and 20-kilometer radius moving window; see fig. 5-3). Level of landscape intactness is provided in each cell.

Table 5-3. Landscape intactness of Bureau of Land Management (BLM) lands derived from two analysis scales across the western U.S. Landscape intactness level and the corresponding percent of BLM lands are provided in each cell. Terrestrial development index scores greater than 3 percent at either scale have moderate to high development levels and were considered to have the lowest intactness levels (representing 33.3 percent of BLM lands).

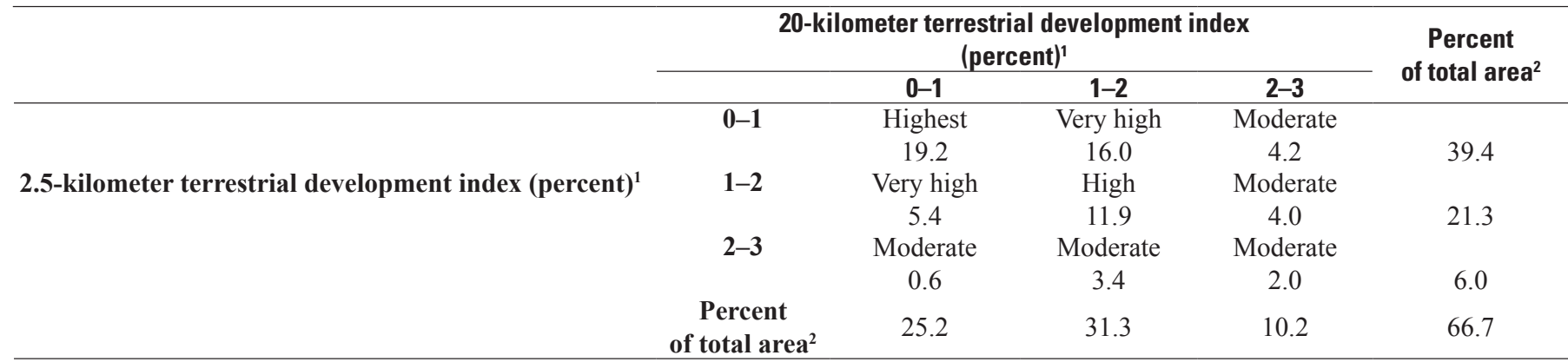

${ }^{1}$ Terrestrial development index (TDI) scores for 2.5-kilometer $(\mathrm{km})$ and 20-km radius moving windows.

219.6 percent of the total area had a TDI score greater than 3 percent for a $2.5-\mathrm{km}$ moving window and less than 3 percent for a $20-\mathrm{km}$ window; 3.76 percent of the total area had a TDI score greater than 3 percent for a $20-\mathrm{km}$ moving window and less than 3 percent for a $2.5-\mathrm{km}$ window, and 9.9 percent of the total area had a TDI score greater than 3 percent for both window sizes.

\section{How does landscape intactness vary across the ecoregions and ecological communities assessed for the REAs?}

Landscape intactness varied considerably across the

11 ecoregions in the contiguous western United States (fig. 5-6) in which REAs are ongoing or have been completed (fig. 5-8; see fig. 4-4 for REA map). More than 20 percent of the Mojave Basin and Range, Central Basin and Range, Middle Rockies, Northern Great Basin, Colorado Plateau, and Sonoran Desert ecoregions was classified at the highest level of landscape intactness (fig. 5-8). Less than 10 percent of the Chihuahuan Desert, Madrean Archipelago, and the Wyoming Basin ecoregions was classified at the highest level of landscape intactness; these ecoregions nevertheless encompass 47-61 percent of the area classified as having moderate to very high levels of landscape intactness. More than 86 percent of the Southern and Northwestern Great Plains ecoregions was classified at the lowest level of intactness reflecting the dominance of agriculture as a land use in these ecoregions.

Landscape intactness levels also varied considerably by ecological communities (NatureServe 2016) for the 17 western states. The ecological communities having greater than 25 percent classified at the highest or very high levels of landscape intactness included high-elevation forests and alpine systems, arid shrublands of intermountain basins, and warm desert systems. In contrast, Pacific coastal shrublands and woodlands and Great Plains grasslands had less than 15 percent in the highest two levels of landscape intactness. 


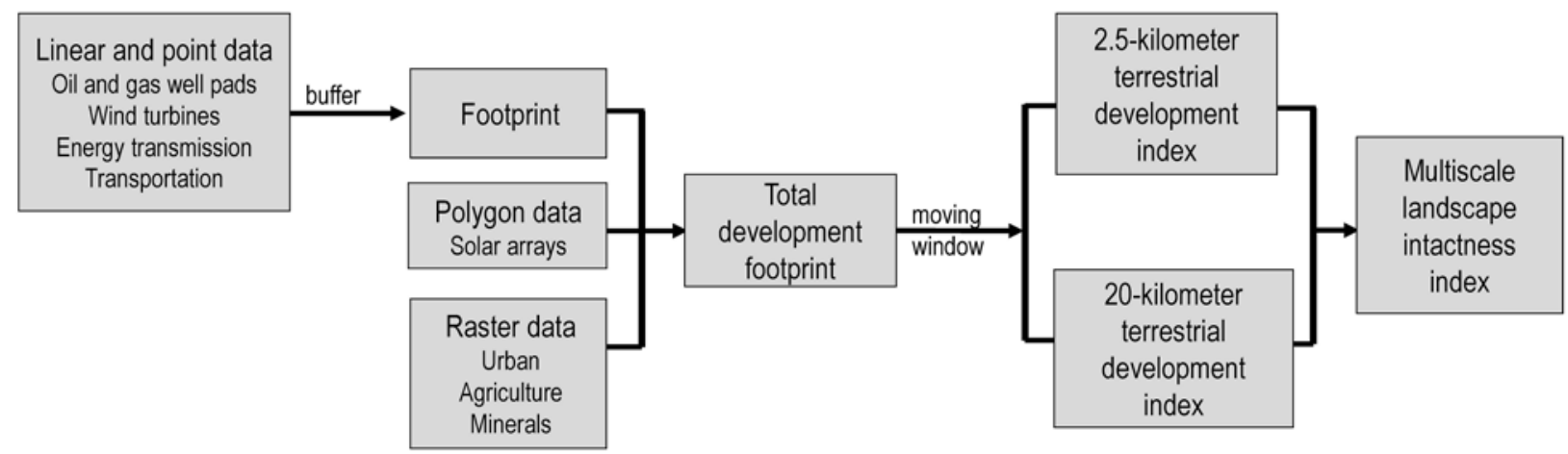

Figure 5-5. Overview of the process model used to create the multiscale index of landscape intactness. See table 5-2 for buffer sizes used to create the surface disturbance footprint for each point (energy and minerals) or linear (transportation and transmission lines) input variables. The terrestrial development index was calculated using a 2.5- and 20-kilometer moving window (fig. 5-3), which were combined (fig. 5-4) to create the multiscale index of landscape intactness (fig. 5-6).

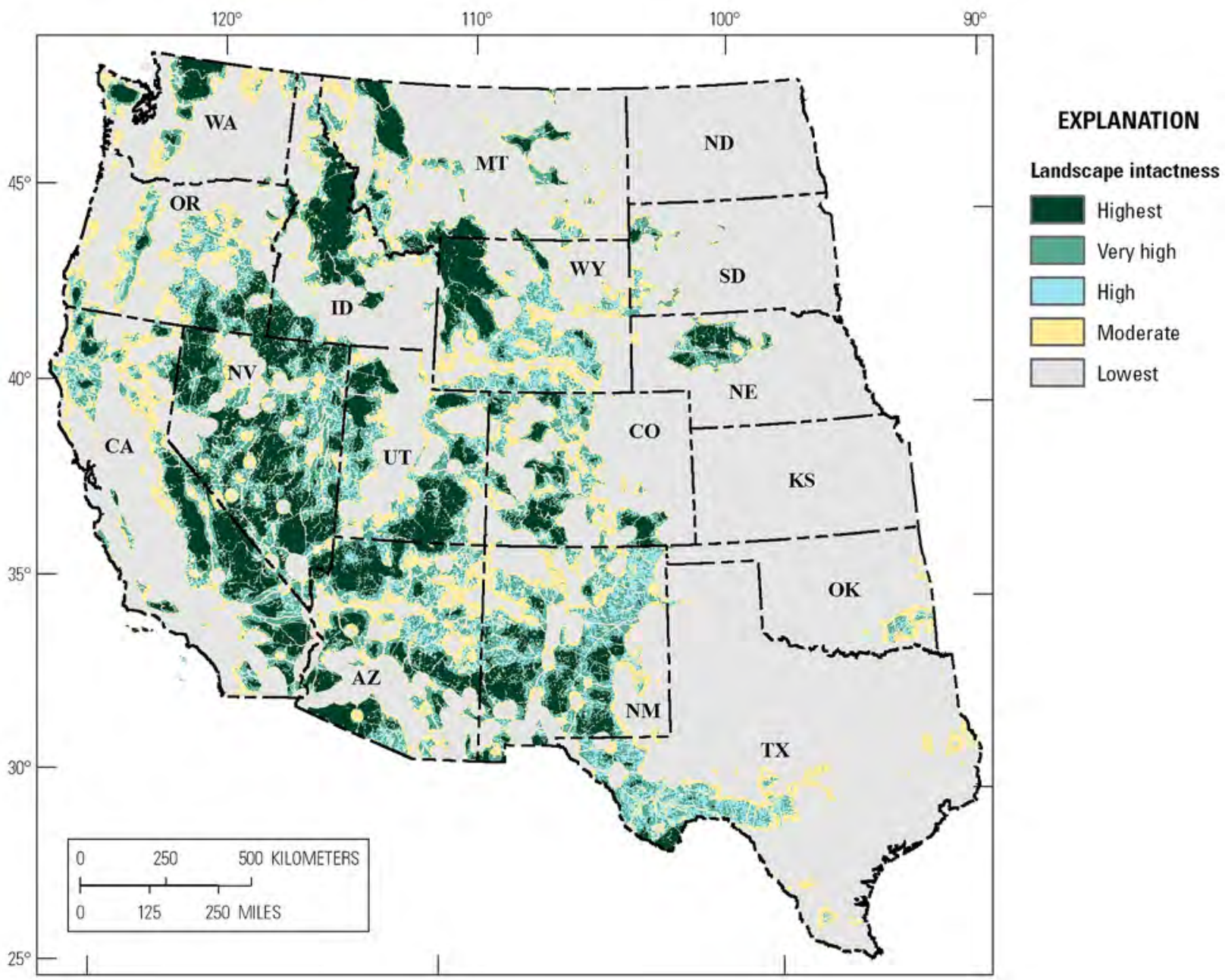

Figure 5-6. Landscape intactness for the western U.S. Intactness levels were derived from terrestrial development index classes using a 2.5- and 20.0-kilometer radius moving window (fig. 5-3). 


\section{Where are the largest intact areas, and which land management agencies have primary responsibility for these areas?}

Except in the Great Plains, large intact areas, as defined by areas with the highest or very high intactness levels, were broadly distributed throughout much of the western United States (fig. 5-9). Most of the largest intact areas (greater than $40,000 \mathrm{~km}^{2}$ ) occurred on public lands at high elevations or in the Great Basin. The BLM (31 percent) and the U.S. Department of Agriculture (USDA) Forest Service (28 percent) are responsible for managing the majority of area with the highest or very high levels of landscape intactness (as depicted in figure 5-9). Privately owned lands (16 percent), national parks ( 8 percent), tribal lands ( 6 percent), military lands ( 3 percent), and national wildlife refuges ( 2 percent) accounted for an additional 35 percent of the most intact lands. The BLM is responsible for managing 46 percent of the largest intact areas (greater than $40,000 \mathrm{~km}^{2}$ ), whereas the USDA Forest Service manages 33 percent and the National Park Service manages 14 percent of these lands (fig. 5-10).

\section{How does intactness level vary by land ownership or jurisdiction?}

Level of landscape intactness closely corresponded to land ownership or jurisdiction and the associated land-use missions (fig. 5-11). More than 50 percent of National Park Service, U.S. Department of Defense, and U.S. Fish and Wildlife Service lands had very high or the highest levels of landscape intactness. Lands under the jurisdiction of multipleuse agencies like the USDA Forest Service and BLM were more evenly distributed among all intactness levels, with approximately 40 percent of lands with very high or the highest level of landscape intactness.

\section{What is the status of BLM lands on the basis of the multiscale index of landscape intactness, and how does this vary among field offices within an ecoregion?}

Approximately 19 percent ( 35 million $\mathrm{km}^{2}$ ) of BLM lands had very high or the highest levels of landscape intactness (fig. 5-11) and approximately 67 percent of all BLM lands had at least moderate levels of landscape intactness (fig. 5-11, table 5-3) compared to 35.8 percent westwide. The largest of the most intact lands managed by the BLM were predominantly arid shrublands in the Great Basin (fig. 5-12). Although landscape intactness was high in the Great Basin, the multiscale index does not include finer-scale information that may be relevant such as the invasive species cheatgrass (Bromus tectorum). Cheatgrass, and associated alterations of fire regime, is much more widespread in arid shrublands of the Great Basin (Chamber and others, 2007) than in areas with lower levels of landscape intactness, such as the Wyoming Basin (Carr and others, 2015). Thus, local information on invasive species occurrence, shrub cover, and altered fire regimes could improve evaluations of ecological integrity (chapter 4).

Levels of intactness at multiple spatial extents (such as westwide, ecoregion, field office) can provide both a multiscale perspective and a basis for comparison. In the Wyoming Basin, for example, lands under the jurisdiction of the BLM Pinedale Field Office were more intact than they were in several other BLM field offices or in the Wyoming Basin overall (figs. 5-13 and 5-14). The mountainous portions of the ecoregion, managed by the National Park Service and the USDA Forest Service, represented the largest intact areas (fig. 5-14A). BLM lands included the largest intact areas in the arid shrublands that dominate the ecoregion (fig. 5-14B), which includes some of the highest densities of greater sage-grouse (Centrocercus urophasianus) within the range of the species (Rowland and Leu, 2011).

Table 5-4. Hierarchy of datasets included in the multiscale index of landscape intactness. All datasets can be accessed for a given area of interest to allow interpretation of landscape intactness levels.

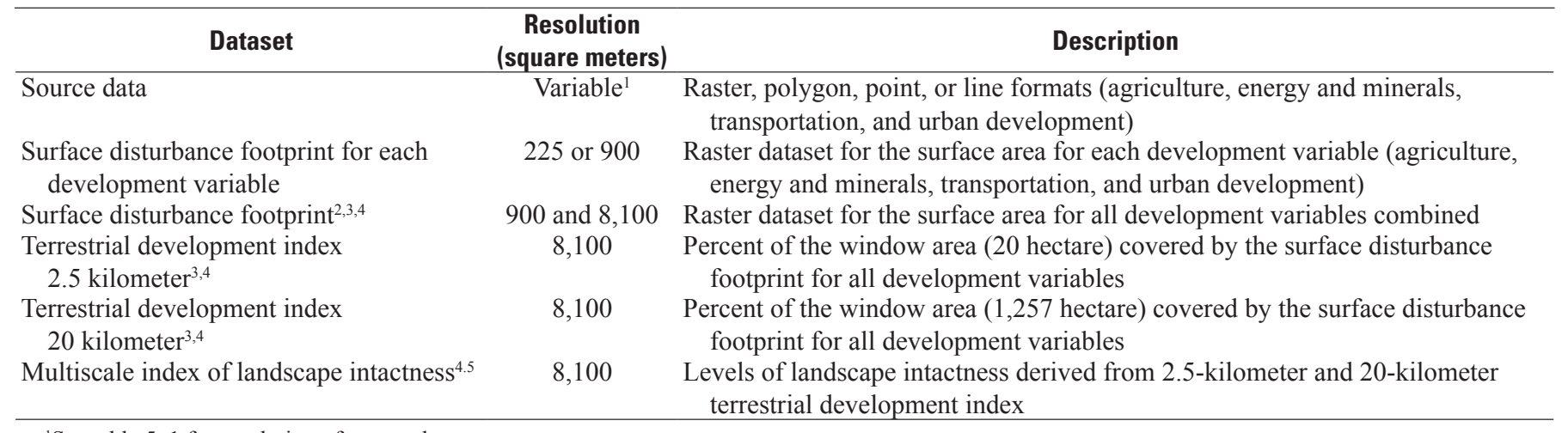

${ }^{1}$ See table $5-1$ for resolution of source data.

${ }^{2}$ See figure 5-2 for map of surface disturbance footprint and associated terrestrial development index.

${ }^{3}$ See figure 5-3 for individual scales of terrestrial development index.

${ }^{4}$ Included as a dataset in Carr, Leinwand, and Wood (2016).

${ }^{5}$ See figure 5-4 for a description of landscape intactness rank. See figure 5-6 for landscape intactness level. 

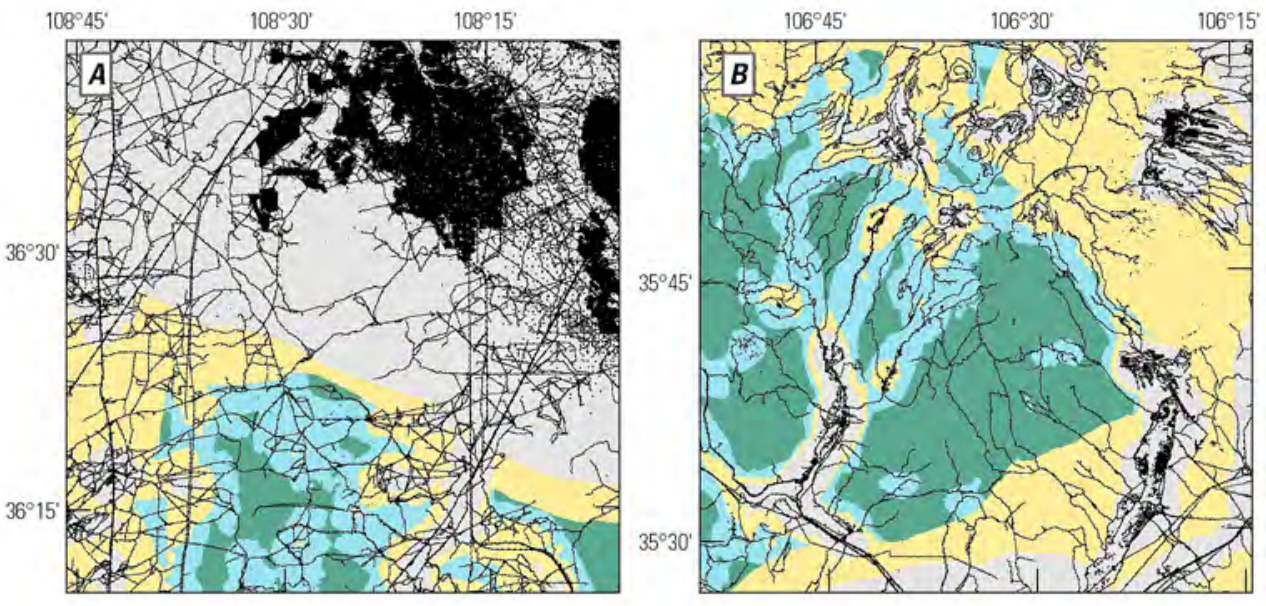

\section{EXPLANATION}

Development footprint Landscape intactness

Highest

$\square$ Very high

$\square$ High

$\square$ Moderate

$\square$ Lowest
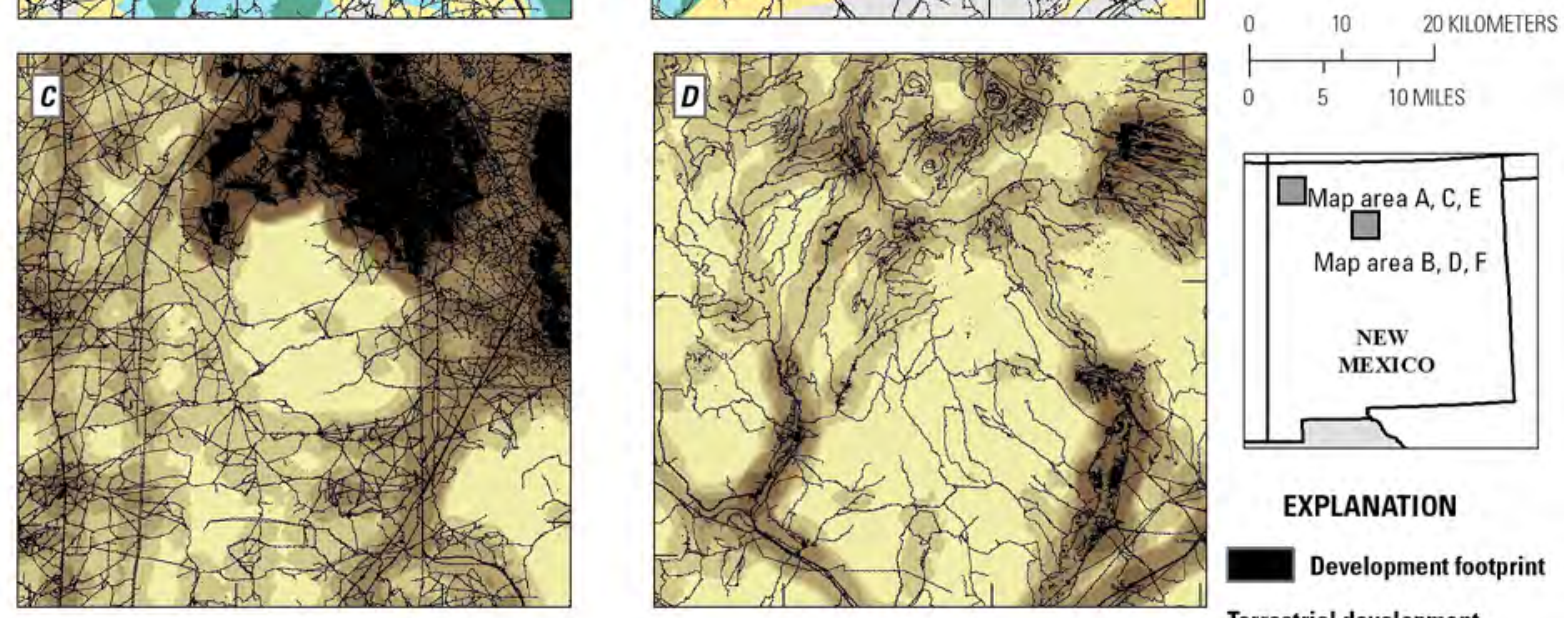

\section{EXPLANATION}

Development footprint Terrestrial development
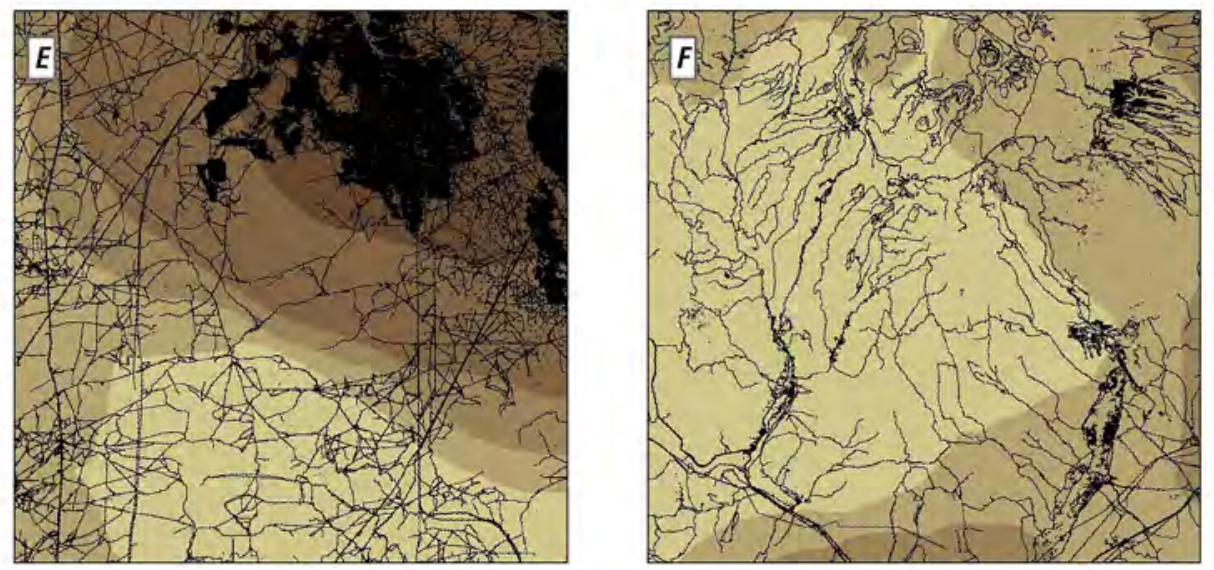
index, in percent

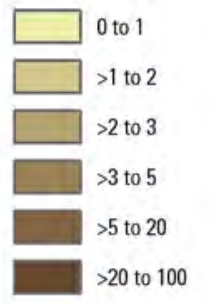

Figure 5-7. Multiscale index of landscape intactness and associated terrestrial development index for two landscapes in New Mexico. Left column Agricultural landscape near Farmington, N. Mex. Right column Oil and gas field near Cuba, N. Mex. Top row depicts the landscape intactness index derived from the surface disturbance footprint using a 2.5-kilometer ( $\mathrm{km}$ ) moving window (middle row), and a 20-km moving window (bottom row). 


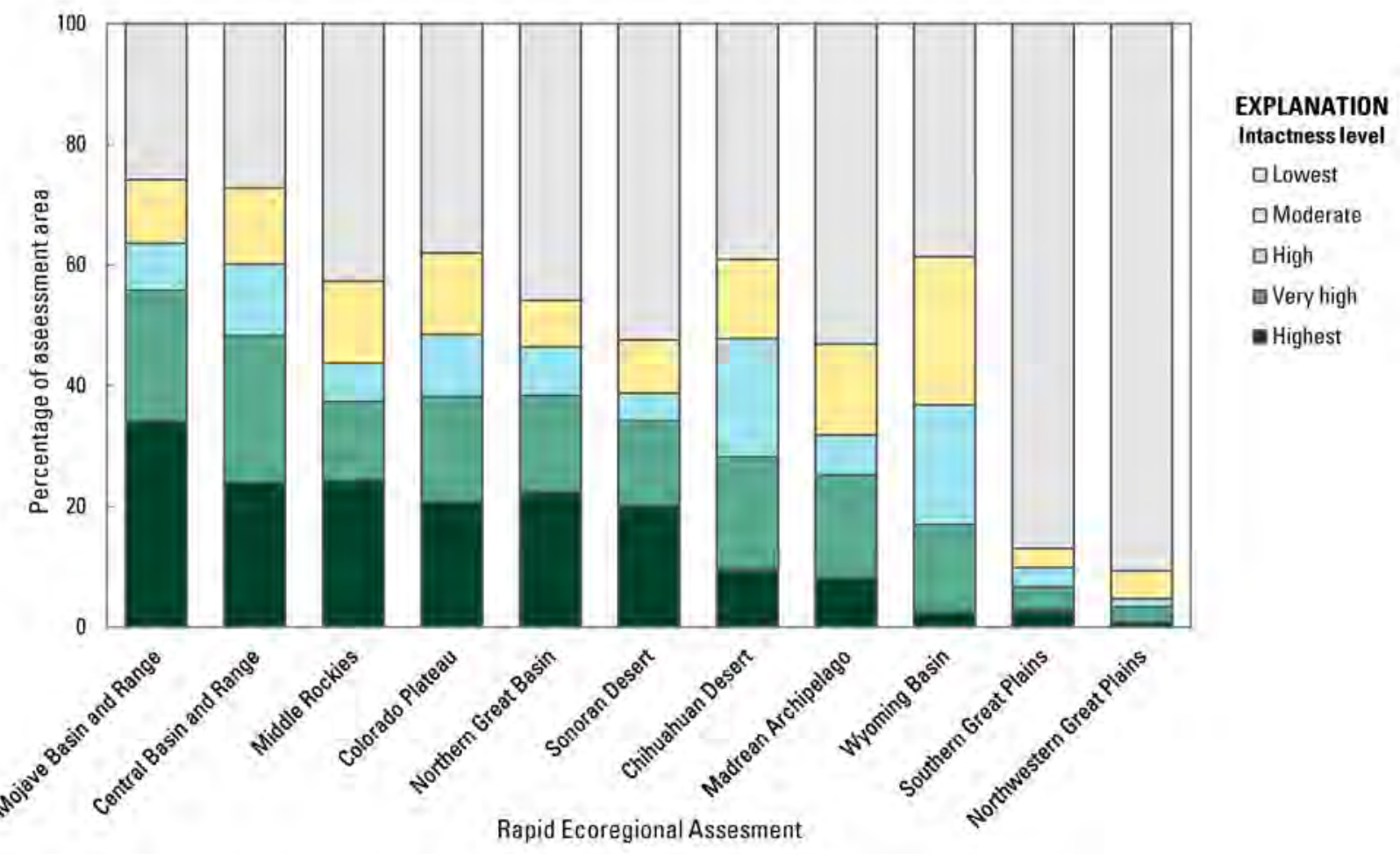

Figure 5-8. Levels of landscape intactness by ecoregion, assessed as a part of the Rapid Ecoregional Assessment program for the western U.S. Intactness levels were derived from the terrestrial development index for 2.5- and 20.0-kilometer radius moving windows (fig. 5-3).

\section{Where are the most intact areas managed by the BLM that are not protected as national conservation lands?}

Special management designations have been established by the BLM to protect resources by restricting certain land uses, such as development, and thus, are useful for evaluating the protected status of the most intact BLM lands. Designation as national conservation lands provides the most restrictions on development of BLM lands and provides Federal protection of more than $105,218 \mathrm{~km}^{2}$ of ecologically and culturally significant areas including national monuments, national conservation areas, wild and scenic rivers, national scenic and historic trails, and wilderness areas. National conservation lands accounted for 26.7 percent of BLM lands with the highest or very high levels of landscape intactness (fig. 5-15).

National conservation lands are designated by congressional or presidential authority, whereas protection of other BLM lands is primarily determined administratively as defined by BLM policies. Other BLM designations limit development to some degree and can contribute to the protection of BLM lands with the highest or very high levels of landscape intactness. For example, areas of critical environmental concern and greater-sage grouse priority habitat management areas, are BLM designations that may include restrictions or stipulations on development activities to reduce potential negative effects on species or communities of management concern.

\section{Discussion}

The multiscale index of landscape intactness addresses broad-scale cumulative effects of development by quantifying the surface disturbance footprint from development at two analysis scales (2.5- and $20-\mathrm{km}$ radius moving windows). The index is designed to be flexible, transparent, defensible, and relevant to a broad range of spatial scales and across ecoregional, land ownership, or jurisdictional boundaries. It also provides a standardized basis for comparing how development affects landscape structure (such as the size and connectivity of intact areas; fig. 5-9) of communities, ecosystems, and ecoregions (see table 3-1). The index may also serve as an indicator for the AIM monitoring program, providing broadscale information on resource condition that complements the local-scale information currently measured using field sampling (chapter 3). Collectively, the index of landscape intactness and local-level monitoring provide a comprehensive set of indicators that span multiple analysis scales and thereby help to inform a landscape approach to resource management (chapter 2).

The multiscale index of landscape intactness can be used in conjunction with other information such as habitat designations, rangeland condition, and AIM monitoring data, to identify potential areas for conservation, restoration, or development activities. Information on landscape intactness can be used to develop landscape-level strategies to avoid, 


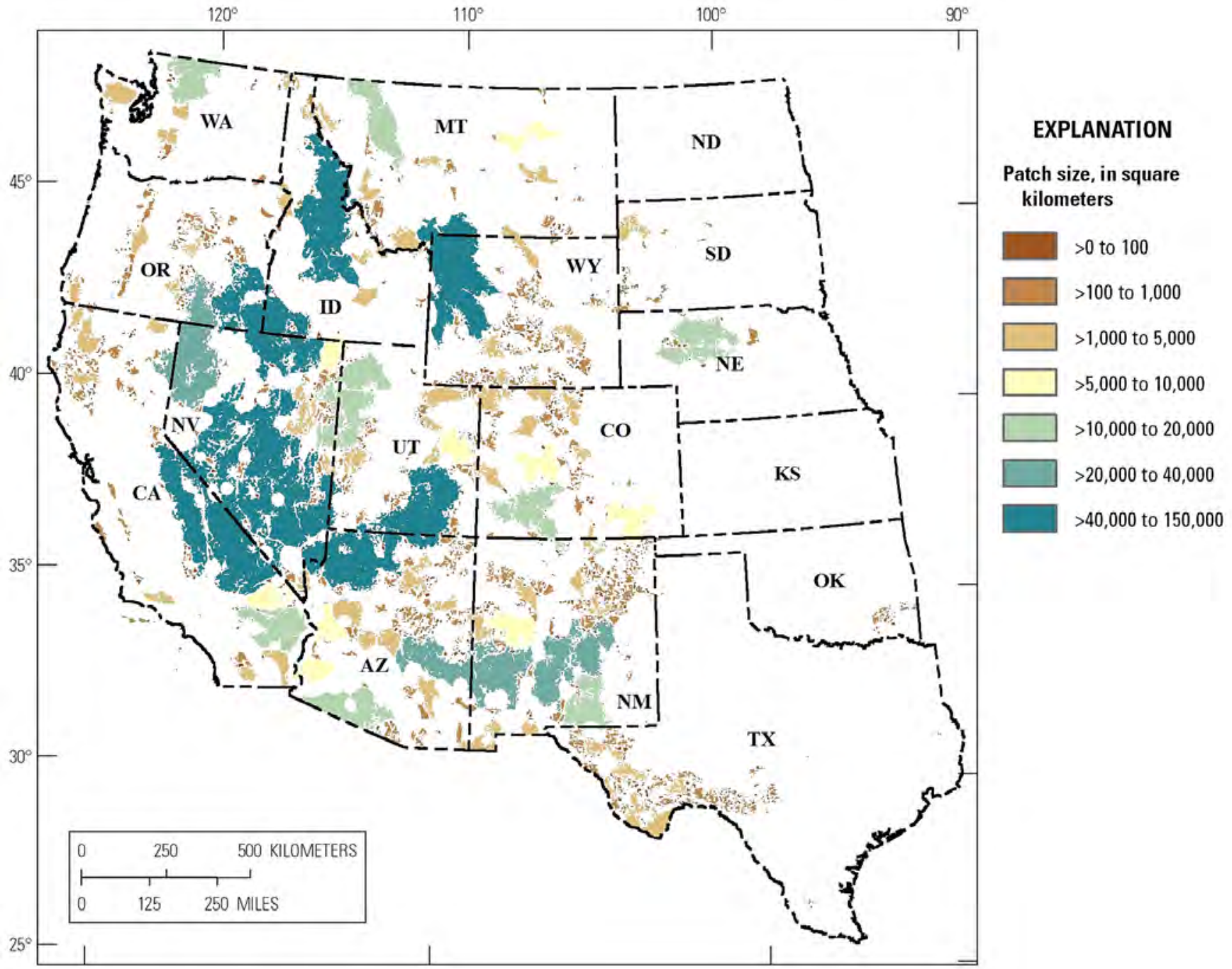

Figure 5-9. Size of patches with the highest and very high levels of landscape intactness for the western United States. Patches are defined by areas with the highest or very high intactness levels (fig. 5-6).

minimize, and compensate for adverse effects from major development activities; develop metrics and benchmarks for use in monitoring changes in the condition of landscapes; and address some of the ecological characteristics that can promote ecosystem resilience, which are all elements of the landscape approach (Sayer and others, 2013, Freeman and others, 2014). The management questions addressed in this chapter demonstrated the utility of the multiscale index of landscape intactness to identify the most intact areas across a range of broad spatial extents, ecological communities and ecoregions, and administrative boundaries. Indeed, comparisons of lands managed by Federal agencies highlight the crucial role of the BLM in managing some of the largest and most intact areas of the western United States. Because many intact areas are managed by multiple agencies, and for multiple uses, coordination and interagency collaboration will be crucial for managing the remaining large intact areas in the western United States (Aycrigg and others, 2016; Sayer and others, 2014).
Multiscale information is necessary because no single scale of analysis is sufficient for assessing the various ecological processes and stressors that can affect ecological integrity (Sayer and others, 2013, Jackson and Fahrig, 2014). At broad spatial extents, the multiscale index of landscape intactness provides the ecological context for finer scale assessments, but additional regional- or local-level datasets are necessary for evaluating stressors that cannot currently be evaluated across the entire western United States, such as invasive species occurrence (Wurtzebach and Schultz, 2016). In addition, there are tradeoffs between the resolution and extent of spatial datasets. Multiple scales of information (for example, REAs and AIM monitoring programs) can be used to address the inherent limitations among datasets with different spatial resolution and extent. National datasets (such as roads from TIGER; table 5-1) typically lack the accuracy or details that are provided by datasets at much smaller spatial extents, such as a digitized road layer developed at the state level (for example, Wyoming roads; O'Donnell and 


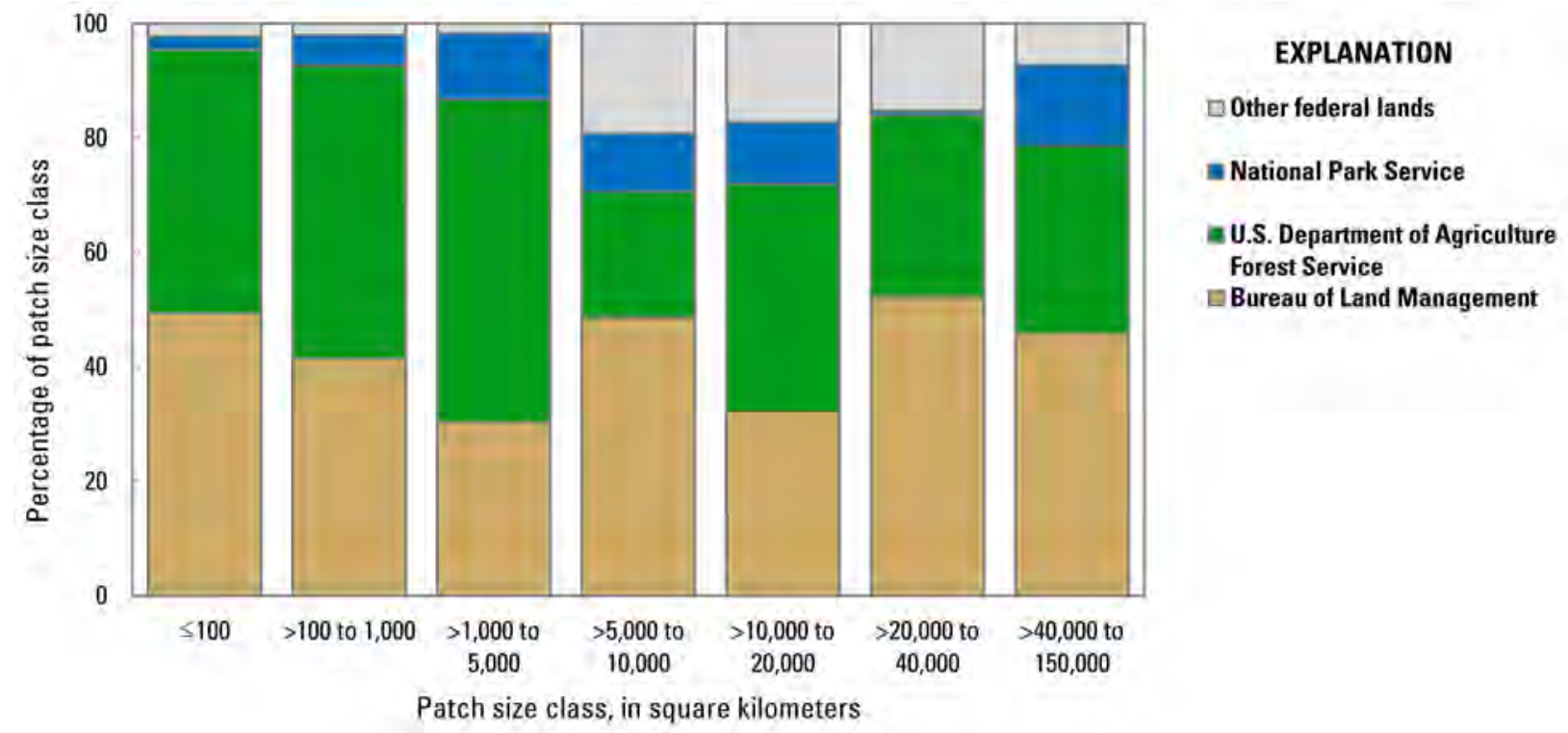

Figure 5-10. Size classes of patches on federal lands with the highest or very high landscape intactness levels, summarized by agency. Patches are defined by areas with the highest or very high landscape intactness (see fig. 5-9 for the map of the most intact patches by size class). Only agencies with responsibility for managing greater than 8 percent of the most intact lands are listed individually. Other federal lands include the U.S. Fish and Wildlife Service and U.S. Department of Defense (see fig. 5-11 for landscape intactness levels by jurisdiction).

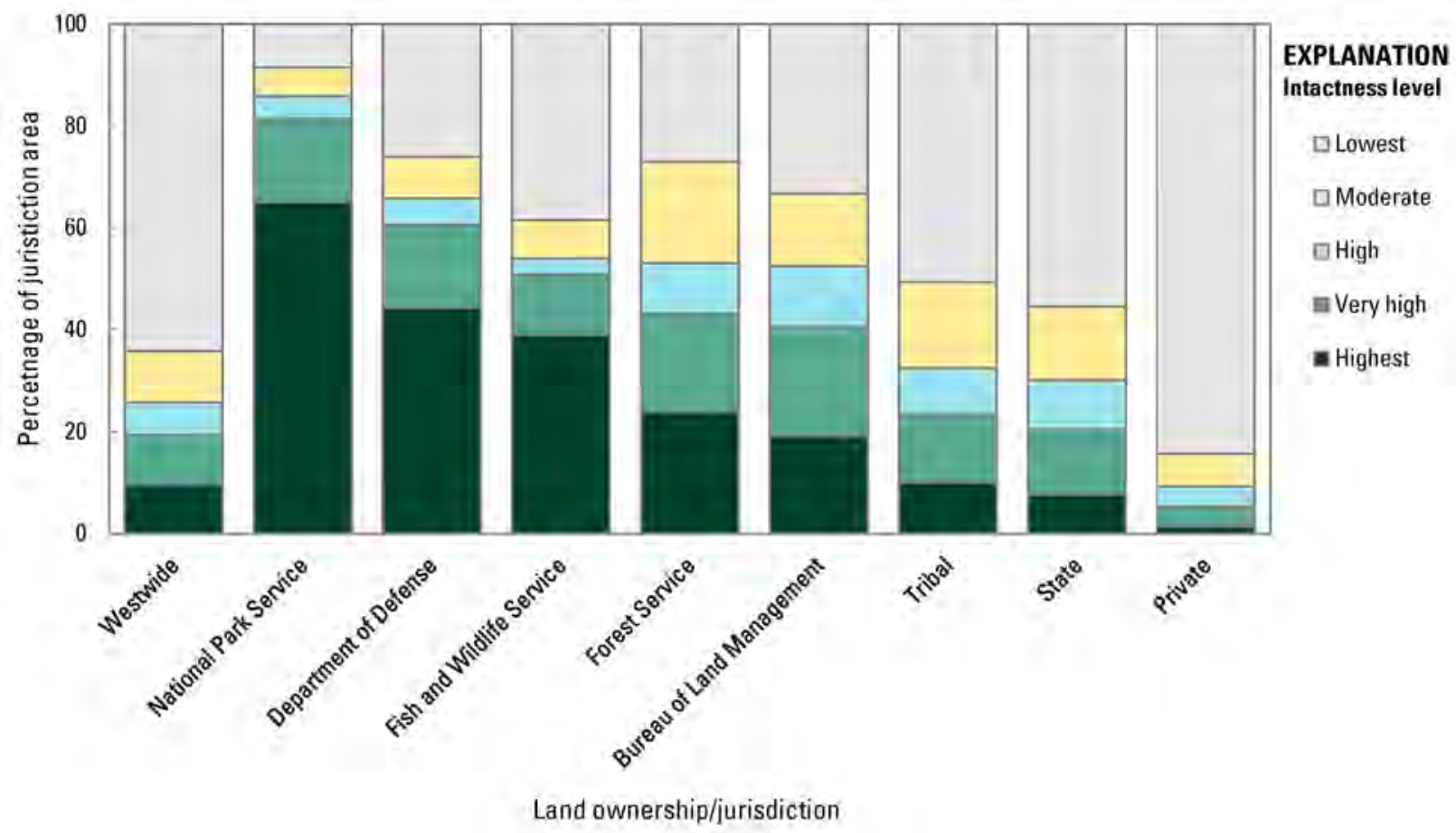

Figure 5-11. Levels of landscape intactness by land ownership or jurisdiction for the entire western United States. Intactness levels were derived from the terrestrial development index for 2.5- and 20.0-kilometer radius moving windows (fig. 5-3). 


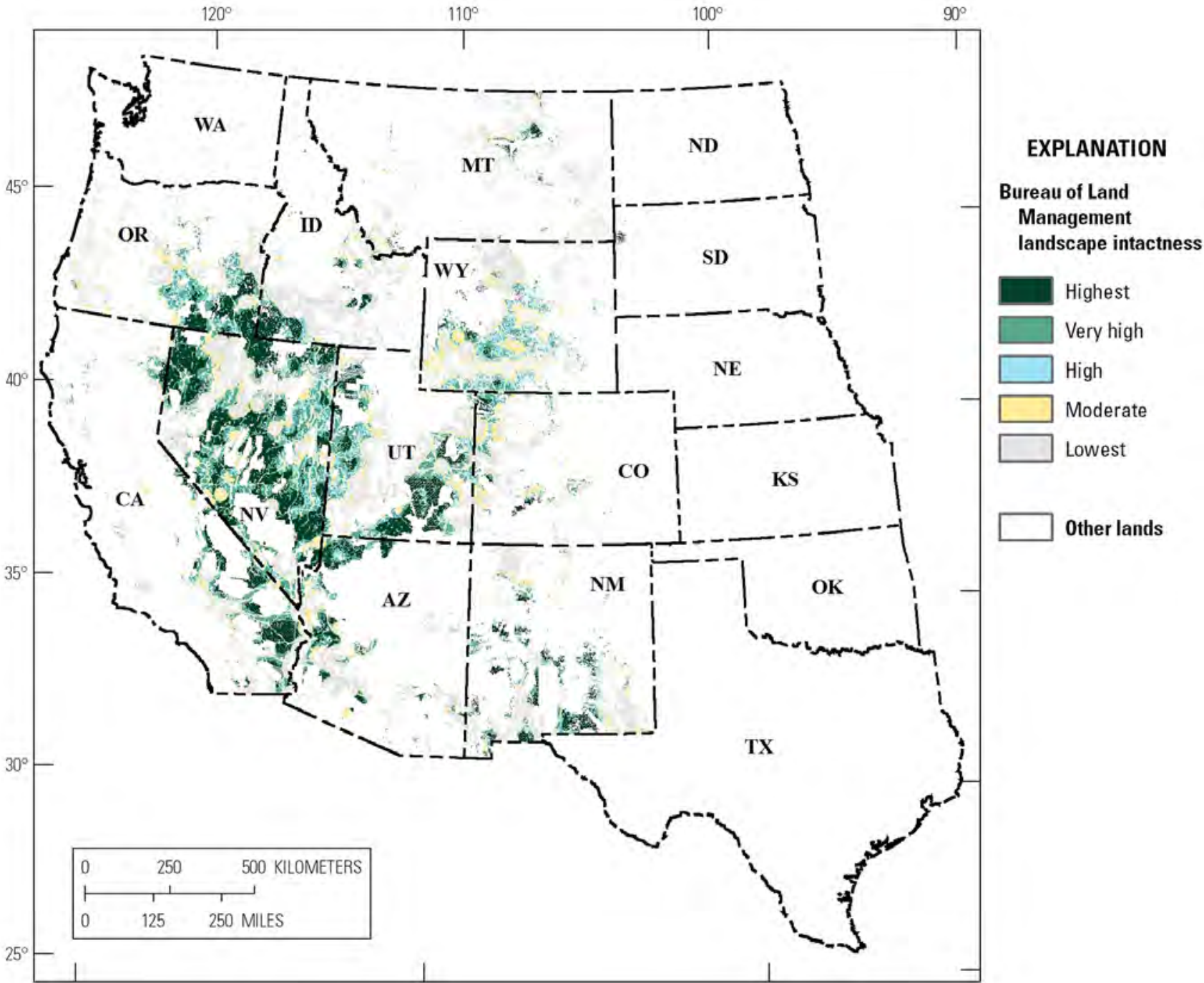

Figure 5-12. Levels of landscape Intactness for lands managed by the Bureau of Land Management. Intactness levels were derived from the terrestrial development index for 2.5- and 20.0-kilometer radius moving windows (fig. 5-3).

others, 2014). In addition, local datasets may be updated more frequently than the planned $2-5$ year scheduled updates for the multiscale landscape intactness index. At broad spatial extents, however, an index that is derived from moving windows can minimize the effects of local inaccuracies by averaging the area of the surface disturbance footprint over larger scales (Theobald, 2007), particularly for comparisons of landscape intactness level across BLM field offices or ecoregions. The use of multiscale data requires an understanding of the limitations and assumptions inherent to each analysis scale.

The criteria for identifying the most intact areas may vary by land-use context and spatial extent. In protected areas, like national parks, large intact areas with limited human activities may be of sufficient size to support viable populations of the native biota, ecological processes, and associated complex interactions (Potapov and others, 2008). In multiple-use landscapes, however, highly intact areas may form a mosaic with more developed landscapes that have lower intactness and consequently have greater fragmentation than protected areas. Nevertheless, smaller but highly intact areas in multiple-use landscapes may contribute to landscape intactness at broader scales and could be targeted for conservation (Minor and others, 2010; Tulloch and others, 2013). Information on landscape intactness at broad scales can be useful for identifying potential areas of restoration that could expand or connect highly intact areas. On the other hand, areas with low landscape intactness may include areas where additional development is less likely to diminish broader scale landscape intactness. Thus, the multiscale index of landscape intactness can be used in developing conservation, restoration, and development strategies when evaluated across a range of spatial scales.

The multiscale index of landscape intactness can be used to address management questions in landscapes managed for multiple uses or for multiple agencies. For example, the size and structural connectivity of areas with the highest or very 


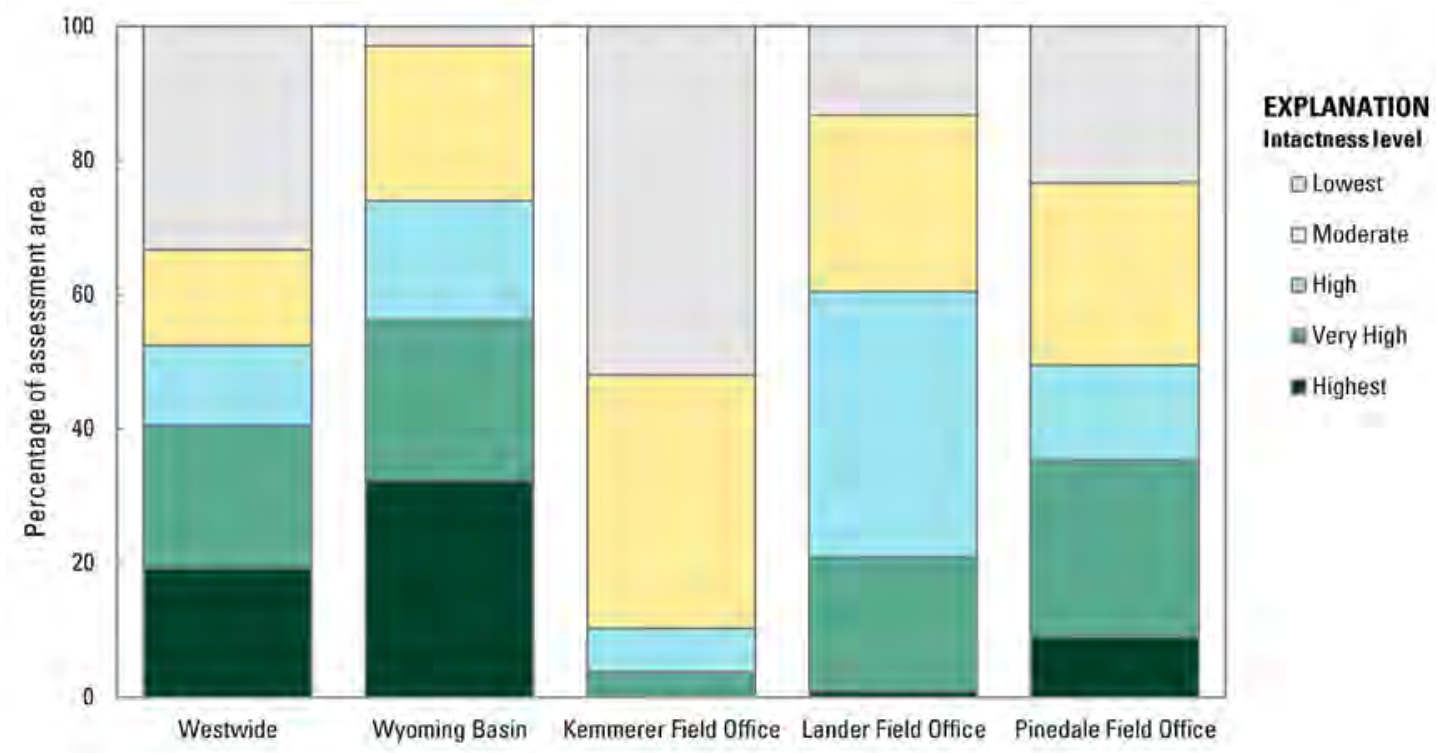

Assessment area

Figure 5-13. Levels of landscape intactness for lands managed by the Bureau of Land Management in the Wyoming Basin. Intactness levels were derived from the terrestrial development index for 2.5- and 20.0-kilometer radius moving windows (fig. 5-3).
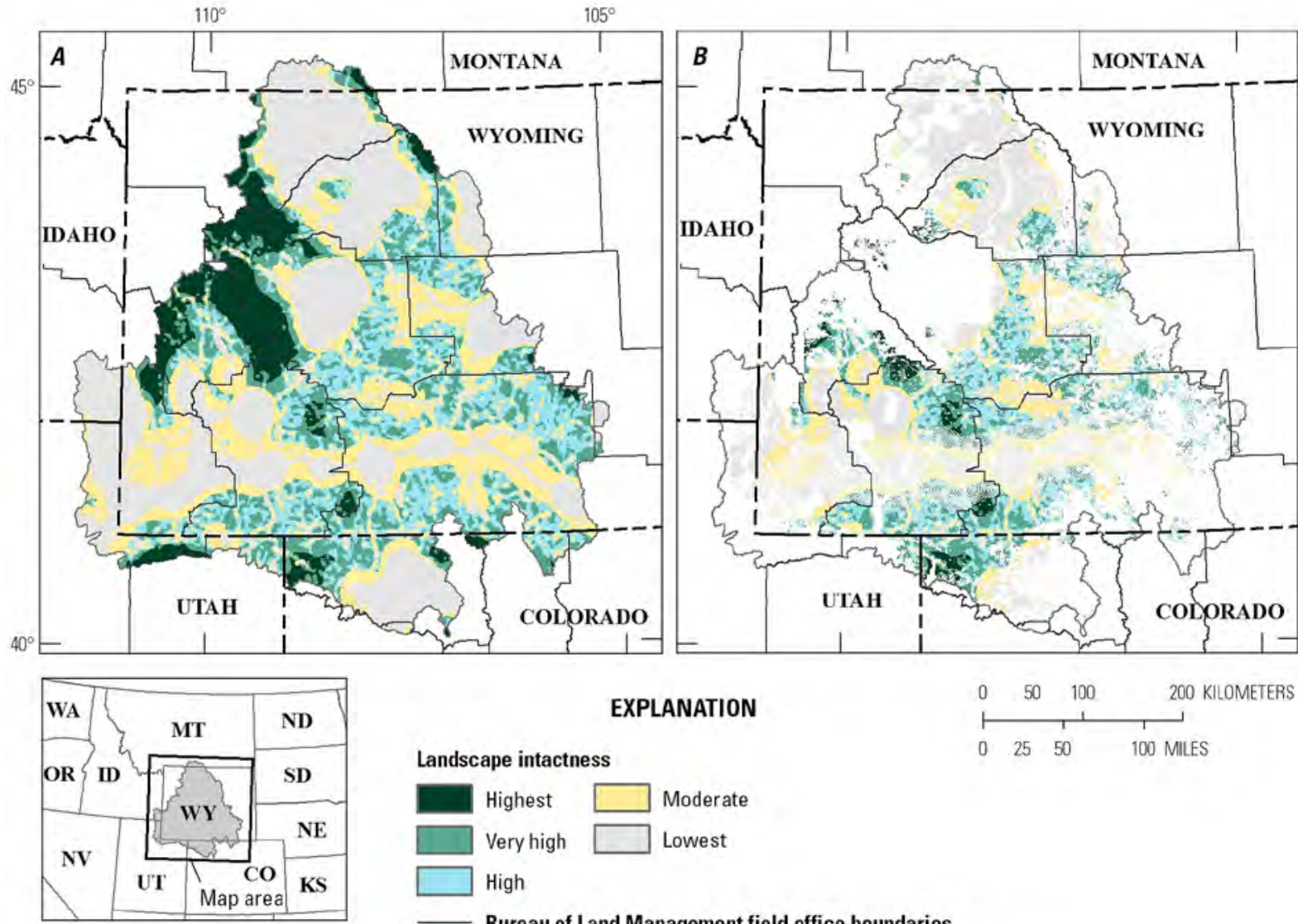

EXPLANATION

Landscape intactness
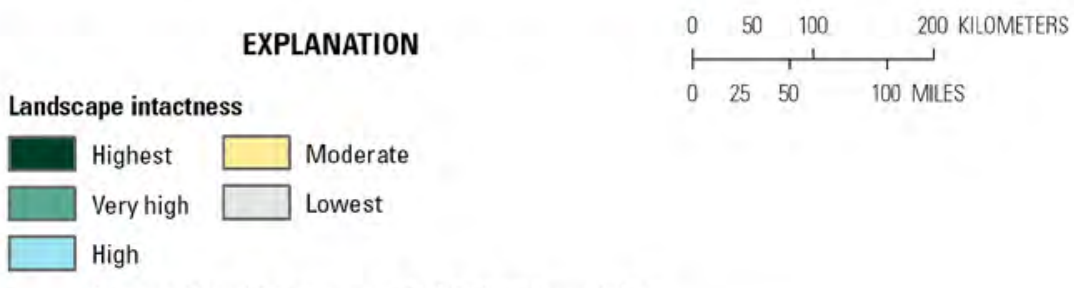

Bureau of Land Management field office boundaries

Figure 5-14. Levels of landscape intactness for lands that fall within the jurisdiction of the Bureau of Land Management (BLM) field office boundaries in the Wyoming Basin Ecoregion. The ecoregion boundary was defined by the Wyoming Basin Rapid Ecoregional Assessment (Carr and Melcher, 2015; fig. 4-4). A, All lands, and B, BLM lands. Intactness levels were derived from the terrestrial development index for 2.5- and 20.0-kilometer radius moving windows (fig. 5-3). 


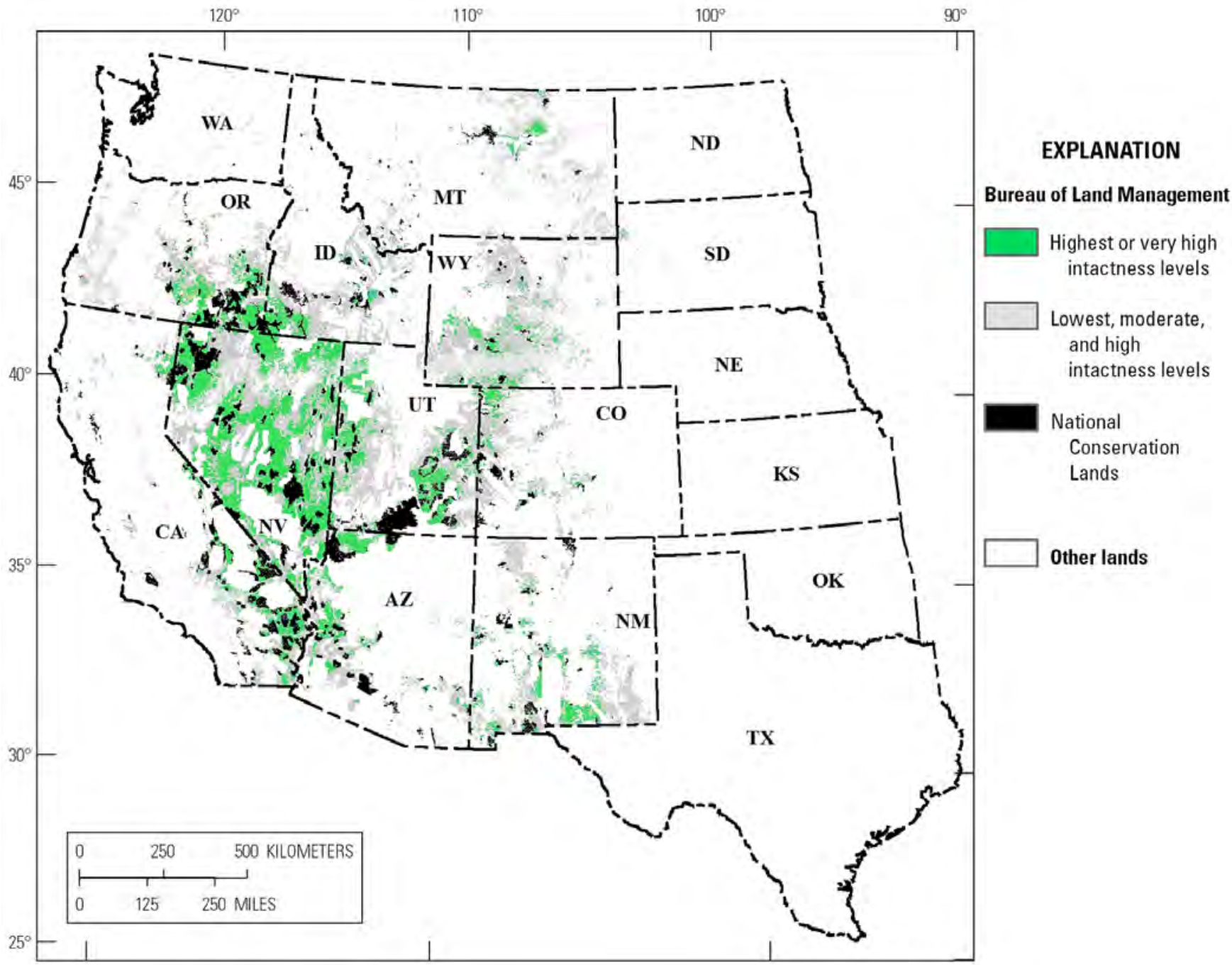

Figure 5-15. Lands managed by the Bureau of Land Management with the highest levels of landscape intactness that are not protected as national conservation lands. Intactness levels were derived from the terrestrial development index for 2.5- and 20.0-kilometer radius moving windows (fig. 5-3).

high landscape intactness could be used as a basis for enhancing the connectedness of intact lands in multiple-use landscapes and across jurisdictional boundaries (see chapter 29 in Carr and Melcher, 2015). For example, small relatively intact areas may serve as refugia or dispersal stepping stones across more developed areas, and land-use managers could target these areas for management actions (such as limiting development or restoring after development) to promote landscape connectivity in multiple use landscapes.

The multiscale index of landscape intactness and its role in the BLM landscape approach supports the U.S. Department of the Interior (DOI) "A Strategy for Improving the Mitigation Policies and Practices of The Department of the Interior," (Clement and others, 2014) also referred to as the LandscapeScale Mitigation Strategy (Landscape Strategy). A primary objective of the DOI Landscape Strategy is to shift from project-level to broad-scale, science-based management that helps to avoid, minimize, and compensate for adverse effects to natural resources. Specifically, by transcending administrative boundaries and addressing broad-scale cumulative effects of development, the multiscale index of landscape intactness addresses the following key components outlined by the DOI Landscape Strategy: develop assessment methods that promote consistency in management decisions, identify ecological characteristics that promote ecosystem resilience under rapidly changing environmental conditions, and foster collaboration among land management agencies (Clement and others, 2014). The BLM Landscape Approach and the DOI Landscape Strategy recognize the need for methods and tools to quantify landscape-level effects across a range of spatial scales. The multiscale index of landscape intactness addresses the consequences of human activities on the spatial patterning and dynamics of ecological communities and wildlife habitats at broad spatial extents. 


\section{References Cited}

Aycrigg, J.L., Groves, Craig, Hilty, J.A., Scott, Michael, Beirer, Paul, Boyce D.A., Jr., Figg, Dennis, Hamilton, Healy, Machlis, Gary, Muller, Kit, Rosenburg, K.V., Sauvajot, R.M., Shaffer, Mark, and Wentworth, Rand, 2016, Completing the system: opportunities and challenges for a National Habitat Conservation System: BioScience, 11 p., doi: 10.1093/biosci/biw090.

Brown, E.D., and Williams, B.K., 2016, Ecological integrity assessment as a metric of biodiversity: are we measuring what we say we are?: Biodiversity and Conservation, v. 25, p. 1011-1035, doi 10.1007/s10531-016-1111-0.

Burton, A.C, Huggard, D. Bayne, E., Schieck, J., Solymos, P., Muhly, T., Farr, D., Boutin, S., 2014, A framework for adaptive monitoring of the cumulative effects of human footprint on biodiversity: Environmental Monitoring and Assessment v. 186, p. 3605-3617.

Bryce, S.A., Strittholt, J.R. Ward, B.C. and Bachelet, D.M., 2012, Colorado Plateau Rapid Ecoregional Assessment Report: Prepared for the U.S. Department of the Interior, Bureau of Land Management, Denver, Colo., available online at http://www.blm.gov/wo/st/en/prog/more/Landscape Approach/reas/coloplateau.html

Carr, N.B., Fancher, Tammy, Freeman, A.T., and Battles Manley, Heather, 2016, Surface area of solar arrays in the conterminous United States: U.S. Geological Survey data release, accessed December 8, 2016, at http://dx.doi.org/10.5066/ F79S1P57.

Carr, N.B., Leinwand, I.I.F, and Wood, D.A.J. 2016. A multiscale index of landscape intactness for the western United States: U.S. Geological Survey data release, accessed December 8, 2016, at https://dx.doi.org/10.5066/ F75H7DCW.

Carr, N.B., and Melcher, C.P., eds., 2015, Wyoming Basin Rapid Ecoregional Assessment: U.S. Geological Survey Open-File Report 2015-1155, 896 p., accessed December 8, 2016, at http://dx.doi.org/10.3133/ofr20151155.

Chambers, J.C., Roundy, B.A., Blank, R.R., Meyer, S.E., and Whittaker, A., 2007, What makes Great Basin sagebrush ecosystems invasible by Bromus tectorum?: Ecological Monographs, v. 77 , no. 1, p. 117-145.
Clement, J.P., Belin, A.d'A., Bean, M.J., Boling, T.A., and Lyons, J.R., 2014, A strategy for improving the mitigation policies and practices of the Department of the InteriorA report to the Secretary of the Interior from the Energy and Climate Change Task Force: Washington, D.C., U.S. Department of the Interior, Energy and Climate Change Task Force, accessed October 12, 2016, at https://www.doi.gov/ sites/doi.gov/files/migrated/news/upload/Mitigation-Reportto-the-Secretary_FINAL_04_08_14.pdf.

Comer, Patrick., Crist, Patrick, Reid, Marion, Hak, Jon, Hamilton, Healy, Braun, David, Kittel, Gwen, Varley, Ian, Unnasch, Bob, Auer, Stephanie, Creutzburg, Megan, Theobald, David, and Kutner, Lynn, 2013, Central Basin and Range Rapid Ecoregional Assessment Report: Prepared for the U.S. Department of the Interior, Bureau of Land Management, 168 p, accessed January 17, 2017, at http:// www.blm.gov/wo/st/en/prog/more/Landscape_Approach/ reas/cbasinrange.html

Crall, A.W., Newman, G.J., Jarnevich, C.S., Stohlgren, T.J., Waller, D.M., and Graham, Jim, 2010, Improving and integrating data on invasive species collected by citizen scientists: Biological Invasions, v. 12, no. 10, p. 3419-3428, DOI: $10.1007 / 210530-01009740-9$.

Dickson, B.D., Zachmann, L.J., and Albano, C.M., 2014, Systematic identification of potential conservation priority areas on roadless Bureau of Land Management lands in the western United States: Biological Conservation, v. 178, p.117-127.

Diffendorfer, J.E., Compton, Roger, Kramer, Louisa, Ancona, Zach, and Norton, Donna, 2014, Onshore industrial wind turbine locations for the United States through July 2013 (ver.1.1, May 2015): U.S. Geological Survey Data Series 817, accessed November 25, 2014, at http://dx.doi.org/10.3133/ds817.

Freeman, O.E., Duguma, L.A., Minang, P.A., 2015, Operationalizing the integrated landscape approach in practice: Ecology and Society, v. 20, no. 1, p. 24, http://dx.doi.org/10.5751/ ES-07175-200124.

Heilman, G.E., Jr., Strittholt, J.R., Slosser, N.C., 2002, Forest fragmentation of the conterminous United States: assessing forest intactness thorough road density and spatial characteristics, 2002: American Institute of Biological Sciences, v, 52, no. 5 , p. 411-422.

IHS Enerdeq, 2014, IHS Enerdeq Production Unallocated Database: IHS, Englewood, Colo., accessed January 16, 2015, at https://www.ihs.com/products/oil-gas-toolsenerdeq-browser.html. 
Jackson, N.D., and Fahrig, Lenore, 2014, Landscape context affects genetic diversity at a much larger spatial extent than population abundance: Ecology v., 95, no. 4, p 871-881.

Leu, Matthias, Hanser, S.E., and Knick, S.T., 2008, The human footprint in the West-A large-scale analysis of anthropogenic impacts: Ecological Applications, v. 18, no. 5 , p. 1119-1139.

Manier, D., Bowen, Z.H., Brooks, M.L., Casazza, M.L., Coates, P.S., Deibert, P.A., Hanser, S.E., and Johnson, D.H., 2014, Conservation buffer distance estimates for greater sage-grouse-A review: U.S. Geological Survey Open-File Report 2014-1239, 14 p., accessed December 8, 2016, at http://pubs.usgs.gov/of/2014/1239/.

Mairota, Paola, Cafarelli, Barbara, Didham, R.K., Lovergine, F.P., Lucas, R.M., Nagendra, Hairini, Rocchini Duccio, and Tarantino, Christina, 2015, Challenges and opportunities in harnessing satellite remote-sensing for biodiversity monitoring: Ecological Informatics, v. 30, p. 207-214.

Minor, E.S., and Lookingbill, T.D., 2010, A multiscale network analysis of protected-area connectivity for mammals in the United States: Conservation Biology v., 24, no. 6, p. $1549-1558$.

National Gap Analysis Program, 2010, Land Cover Data: National Gap Analysis Program, Moscow, ID, accessed February 5, 2016, at http://gapanalysis.usgs.gov/gaplandcover/ data/download/.

NatureServe, 2014, Terrestrial Ecological Systems of the United States: NatureServe, accessed January 21, 2016, at http://www.natureserve.org/conservation-tools/terrestrialecological-systems-united-states.

Noss, R.F., 1990, Indicators for monitoring biodiversity: A hierarchical approach: Conservation Biology, v. 4, no. 5, p. 355-364.

O’Donnell, M.S., Fancher, T.S., Freeman, A.T., Ziegler, A.E., Bowen, Z.H., and Aldridge, C.L., 2014, Large scale Wyoming transportation data-A resource planning tool: U.S. Geological Survey Data Series 821, 21 p., accessed December 8, 2016, at http://dx.doi.org/10.3133/ ds821.

Opdam, Paul, and Wascher, Dirk, 2004, Climate change meets habitat fragmentation: linking landscape and biogeographical scale levels in research and conservation: Biological Conservation, v. 11, p. 285-297.
Peterson, G., Allen, C.R., Holling, C.S., 1998, Ecological resilience, biodiversity, and scale: Ecosystems v. 1, no. 1, p. 6-18.

Potapov, Peter, Yaroshenko, Aleksey, Turubanova, Svetlana, Dubinin, Maxim, Laestadius, Lars, Thies, Christoph, Aksenov, Dmitry, Egorov, Aleksey, Yesipova, Yelena, Glushkov, Igor, Karppachevskiy, Mikhail, Kostikova, Anna, Manisha, Alexander, Tsybikova, Ekaterina and Zhuravleva, Ilona, 2008, Mapping the world's intact forest landscapes by remote sensing: Ecology and Society, v. 13, no. 2, p. 51.

Sayer, Jeffery, Sunderland, Terry, Ghazoul, Jaboury, Pfund, Jean-Laurent, Sheil, Douglas, Meijaard, Erik, Venter, Michelle, Boedhihartono, A.K., Day, Michael, Garcia, Claud, van Oosten, Cora, and Buck, L.E., 2013, Ten principles for a landscape approach to reconciling agriculture, conservation, and other competing land uses: Proceedings of the National Academy of Sciences of the United States of America, v. 110, p. 8349-8356.

Theobald, D.M., 2013, A general model to quantify ecological integrity for landscape assessments and U.S. application: Landscape Ecology, v. 28, p. 1859-1874.

Theobald, D.M., 2010, Estimating natural landscape changes from 1992 to 2030 in the conterminous U.S.: Landscape Ecology, v. 25, p. 999-1011.

Theobald, D.M., 2007, GIS concepts and ArcGIS methods: Fort Collins, Colo., Conservation Planning Technologies, $429 \mathrm{p}$.

Tulloch, A.I.T., Barnes, M.D., Ringma, Jeremy, Fuller, R.A., and Watson, J.E.M., 2016, Understanding the importance of small patches of habitat for conservation: Journal of Applied Ecology, v. 53, p. $418-429$.

U.S. Department of Agriculture National Agricultural Statistics Service, 2014, National Agricultural Statistics Service 2013 National Cultivated Layer: U.S. Department of Agriculture National Agricultural Statistics Service, Sioux Falls, SD, accessed January 24, 2014, at https://www.nass.usda.gov/ Research_and_Science/Cropland/Release/index.php.

U.S. Department of Commerce, 2010, TIGER/Line shapefile: U.S. Department of Commerce, U.S. Census Bureau, Geography Division, Washington D.C., accessed February 5, 2016, at https://www.census.gov/geo/maps-data/data/tiger.html.

U.S. Department of Commerce, 2014a, TIGER roads: U.S. Department of Commerce, U.S. Census Bureau, Geography Division, Washington D.C., accessed February 5, 2016, at https://www.census.gov/geo/maps-data/data/tiger.html. 
U.S. Department of Commerce, 2014b, TIGER railroads: U.S. Department of Commerce, U.S. Census Bureau, Geography Division, Washington D.C., accessed February 5, 2016, at https://www.census.gov/geo/maps-data/ data/tiger.html.

U.S. Department of Transportation, 2004, National Pipeline Mapping System: U.S. Department of Transportation - Pipeline and Hazardous Materials Safety, Washington, D.C., accessed November 7, 2014, at https://www.npms. phmsa.dot.gov/.

U.S. Geological Survey, 2014, NLCD 2006 Percent Developed Imperviousness (2011 edition, amended 2014): U.S. Geological Survey, Sioux Falls, SD, accessed February 5, 2016, at http://www.mrlc.gov/nlcd06_data.php.

Veblen, K.E., Pyke, D.A., Aldridge, C.L., Casazza, Michael, Assal, T.J., and Farinha, M.A., 2014, Monitoring of livestock grazing effects on Bureau of Land Management land: Rangeland Ecology and Management, v. 67, no. 1, p. $68-77$.
Venter, Oscar, Sanderson, E.W., Magrach, Ainhoa, Allan, J.R., Beher, Jutta, Jones, K.R., Possingham, H.P., Luarance, W.F., Wood, Peter, Balázs, M.F., Levy, M.A., and Watson, J.E.M., 2016, Sixteen years of change in the global terrestrial human footprint and implications for biodiversity conservation: Nature Communications, v. 7, article 12558, doi:10.1038/ncomms12558.

Wenjie, Ji and Wang, Le, 2016, Phenology-guided saltcedar (Tamarix spp.) mapping using Landsat TM images in western U.S.: Remote Sensing of Environment v. 173, p. 29-38.

Woolmer, G., Trombulak, S.C., Ray, J.C., Doran, P.J., Anderson, M.G., Baldwin, R.F., Morgan, A., Sanderson, E.W., 2008, Rescaling the human footprint: a tool for conservation planning at an ecoregional scale: Landscape and Urban Planning, v. 87, p. 42-53.

Wurtzebach, Zachary, and Schultz, Courtney, 2016, Measuring ecological integrity: history, practical applications, and research opportunities: BioScience v. 66, no. 6, p. 446-457. 


\section{Glossary}

Terms are defined here as they are used in this report, and citations are included to facilitate further inquiry. Where possible and appropriate, we have used definitions specified by the Bureau of Land Management (BLM).

\section{C}

Change agent A term used in Bureau of Land Management Rapid Ecoregional Assessments to describe natural or anthropogenically caused disturbances that may influence the health of species or communities of conservation concern (Bureau of Land Management 2016).

Composition One of three main characteristics of an ecosystem that refers primarily to the array of plant and animal species present in the system (Franklin and others, 1981) and often includes measures of species or genetic diversity (Noss, 1990).

Condition The status of a renewable resource in comparison with a specific reference value (Bureau of Land Management, 2016).

Connectivity The degree to which a landscape facilitates or impedes movement of organisms among resource patches (Taylor and others, 1993). Two components of connectivity are generally considered. Structural (or physical) connectivity is the spatial arrangement of different elements or habitat types across a landscape (Crooks and Sanjayan, 2006). Functional (or behavioral) connectivity describes the behavioral response of individuals, species, or ecological processes to the physical structure of the landscape (Crooks and Sanjayan, 2006).

Conservation element A term used in BLM Rapid Ecoregional Assessments to describe resources of conservation concern (Bureau of Land Management 2016).

\section{E}

Ecological integrity Ecological integrity is defined by the BLM as "the ability of ecological systems to support and maintain a community of organisms that have the species composition, diversity, and functional organization comparable to those of natural habitats within the ecoregion range or area" (Toevs and others, 2011). A commonly cited definition in the peer-reviewed scientific literature is that of Parrish and others (2003): “An ecological system or species has integrity or is viable when its dominant ecological characteristics (for example, elements of composition, structure, function, and ecological processes) occur within their natural ranges of variation and can withstand and recover from most perturbations imposed by natural environmental dynamics or human disruptions."

Ecoregion Ecoregions are large areas that are described "based on perceived patterns of a combination of causal and integrative factors including land use, land surface form, potential natural vegetation, and soils" (Omernik, 1987).

\section{$\mathbf{F}$}

Function One of the three characteristics of an ecosystem that describes the ecological (for example, production of organic matter and cycling of nutrients) and evolutionary processes that are inherent in the system, how they are accomplished, and the rates at which they occur (Franklin and others, 1981, Noss, 1990).

Fundamentals of Rangeland Health The Fundamentals of Rangeland Health describe conditions relating to the health and functionality of watersheds, ecological processes, water quality, and threatened and endangered species habitat. The four Fundamentals of Rangeland Health are as follows: (a) Watersheds are in, or are making significant progress toward, properly functioning physical condition, including their upland, riparian-wetland, and aquatic components; soil and plant conditions support infiltration, soil moisture storage, and the release of water that are in balance with climate and landform and maintain or improve water quality, water quantity, and timing and duration of flow. (b) Ecological processes, including the hydrologic cycle, nutrient cycle, and energy flow, are maintained, or there is significant progress toward their attainment, in order to support healthy biotic populations and communities. (c) Water quality complies with State water quality standards and achieves, or is making significant progress toward achieving, established BLM management objectives such as meeting 
wildlife needs. (d) Habitats are, or are making significant progress toward being, restored or maintained for Federal threatened and endangered species, Federal proposed or candidate threatened and endangered species, and other special status species (60 FR 9969, Feb. 22, 1995, as amended at 71 FR 39508, July 12, 2006; codified as 43 CFR 4180.1 ${ }^{1}$ ). State or regional land health standards and guidelines must provide for conformance with the Fundamentals of Rangeland Health (43 CFR § 4180.2(b), Bureau of Land Management, 2009).

\section{I}

Indicators "Components of a system whose characteristics (for example, presence or absence, quantity, distribution) are used as an index of an attribute (for example, rangeland health) that is too difficult, inconvenient, or expensive to measure" (Pellant and others, 2005).

\section{L}

Land health The degree to which the integrity of the soil and the ecological processes of ecosystems are sustained (Bureau of Land Management, 2001).

Land health evaluation A process to establish whether land health standards are being achieved. Land health evaluations may refer to either the specific case pertaining to rangeland health standards, or the more general case pertaining to land health standards developed by all programs (rangeland management; forestry; fish and wildlife; soil, water, and air; riparian; wildfire management; cultural resources and paleontology; and use authorization programs; Bureau of Land Management, 2009).

Land health guideline A practice, method or technique determined to be appropriate to ensure that standards of land health or rangeland health can be met or that significant progress can be made toward meeting the standard. Guidelines such as grazing systems, vegetative treatments, or improvement projects help managers and permittees achieve standards. Guidelines may be adapted or modified when monitoring or other information indicates the guideline is not effective, or a better means of achieving the applicable standard becomes appropriate (Bureau of Land Management, 2001).

${ }^{1}$ The 2006 amendment was enjoined by a decision of the Idaho Federal District Court (see BLM Instruction Memorandum 2009-109) which reverted the regulations to those that existed before the amendment.
Land health standard Standards of land health are expressions of levels of physical and biological condition or degree of function required for healthy lands and sustainable uses, and define minimum resource conditions that must be achieved and maintained (Bureau of Land Management, 2001).

Landscape Landscapes have been defined in a number of ways, often focusing primarily on ecological processes. In this report, we use the following definition: an area encompassing an interacting mosaic of ecosystems and human systems that is characterized by a set of common management concerns. A landscape is not defined by the size of the area, but rather by the interacting elements that are relevant and meaningful to management (U.S. Department of the Interior, 2015; Clement and others, 2014). The term landscape is not exclusive of areas described in terms of aquatic conditions, such as watersheds, which may represent the appropriate spatial scale at which to consider landscapes.

Landscape approach A landscape approach to resource management is a set of concepts and principles used to guide resource management when multiple stakeholders are involved and goals include diverse and sustainable social, economic, and environmental outcomes within and across landscapes (Sayer, 2009; Sayer and others, 2013; Freeman and others, 2015). In implementing a landscape approach, the BLM uses broad ecological assessments to discern ecological values, patterns of environmental change, and management opportunities that may not be evident when considering smaller areas, and to inform long-term conservation, restoration, and development efforts (Bureau of Land Management, 2012).

Landscape condition Landscape condition describes output from a landscape condition model that uses regionally available spatial data to transparently express user knowledge regarding the relative effects of land uses on natural ecosystems and habitats. Expert knowledge often forms the basis of stressor selection and relative weightings, with model parameters generally drawn from the published literature. The landscape condition model developed by NatureServe was used in multiple Rapid Ecoregional Assessments (for example, Comer and others, 2013).

Landscape intactness Landscape intactness is akin to the landscape modification gradient (Forman and Godron, 1986), and is defined 
by the BLM Rapid Ecological Assessment program as a quantifiable estimate of naturalness measured along a gradient of anthropogenic influence.

\section{M}

Mitigation Mitigation is defined by the National Environmental Policy Act as measures taken to: (1) avoid an impact altogether, (2) minimize the degree or magnitude of the impact, (3) reduce the impact over time, (4) rectify the impact, or (5) compensate for the impact (40 CFR 1508.20).

\section{$\mathbf{N}$}

National Conservation Lands (also known as the National Landscape Conservation System) Lands with exceptional scientific, cultural, ecological, historical, and recreational values that are designated by Congress or the President to conserve, protect, enhance, and manage public lands for the benefit and enjoyment of present and future generations (Omnibus Public Land Management Act of 2009: Public Law 111-11, Sec. 2002, codified as 16 US Code Chap. 91, Sec. 7202(a)). National Conservation Lands include national monuments, national conservation areas, wilderness study areas, national scenic trails, national historic trails, wild and scenic rivers, and wilderness areas administered by the BLM.

\section{P}

Patch In ecology, a patch is an area of relatively homogeneous environmental conditions that differs from its surroundings (Forman, 1995). In this report we refer to patches defined by the presence of vegetation communities and wildlife habitats, or by landscape intactness level.

\section{$\mathbf{R}$}

Rangeland health The degree to which the integrity of the soil, vegetation, water, and air, as well as the ecological processes of the rangeland ecosystem, are balanced and sustained. Integrity is defined as maintenance of the structure and functional attributes characteristic of a locale, including normal variability (Society for Range Management, 1998). Rangelands are considered healthy when ecological processes are functioning properly to maintain the structure, organization and activity of the system over time (Bureau of Land Management, 1994).
Rangeland health evaluation A rangeland health evaluation is conducted to arrive at two outcomes: (1) an analysis and interpretation of the findings resulting from the assessment, relative to land health standards, to evaluate the degree of achievement of land health standards, and (2) an analysis and interpretation of information-be it observations or data from inventories and monitoring-on the causal factors for not achieving a land health standard (Bureau of Land Management 2001).

\section{Rangeland health standards and guide-}

lines See Land health standard and Land health guideline.

Resilience The capacity of an ecosystem to tolerate disturbance without switching to a qualitatively different state that is controlled by a different set of processes (Holling, 1973).

Resource management plan A blueprint explaining how the Bureau of Land Management will manage areas of public land over a period of time (generally $10-15$ years). BLM field offices or district offices prepare resource management plans (RMPs) for the lands within their boundaries. RMPs contain decisions that guide future management actions and subsequent site-specific implementation decisions. RMPs establish goals and objectives for resource management (desired outcomes) and the measures needed to achieve these goals and objectives (management actions and allowable uses, Bureau of Land Management, 2014).

\section{S}

Scale In ecology, the concept of scale refers to the spatial or temporal dimension of an object or process. Scale is characterized by both extent and grain. Spatial extent is the total area considered, while grain is the size of the individual units of observation (for example, pixels) within the overall extent (Turner and others, 2001; Forman, 1995).

Status The amount of a renewable resource (for example, a vegetation community) present at a single point in time (Karl and others, 2016).

Structure One of three main characteristics of an ecosystem that describes the physical organization or pattern of a system both horizontally and vertically over multiple scales (Noss, 1990).

\section{T}

Trend A change in the condition of a resource over time. 


\section{References Cited in the Glossary}

Bureau of Land Management, 1994, Rangeland Reform '94 Final Environmental Impact Statement: Washington, D.C., Department of the Interior Bureau of Land Management in cooperation with the Department of Agriculture Forest Service, accessed October 12, 2016, at https://archive.org/ details/rangelandreform 25 unit.

Bureau of Land Management, 2001, H-4180-1 Rangeland health standards: Department of the Interior Bureau of Land Management, Washington, D.C., accessed October 12, 2016, at http:/www.blm.gov/style/medialib/blm/wo/ Information_Resources_Management/policy/blm handbook.Par.61484.File.dat/h4180-1.pdf.

Bureau of Land Management, 2009, Manual 4180-Land health manual for the Bureau of Land Management: Washington, D.C., Department of the Interior Bureau of Land Management, accessed October 12, 2016, at http://www.blm.gov/ style/medialib/blm/wo/Information_Resources_Management/ policy/blm_manual.Par.23764.File.dat/4180.pdf.

Bureau of Land Management, 2012, The BLM's landscape approach for managing the public lands: Bureau of Land Management, Information Bulletin 2012-058, accessed June 13, 2016, at http://www.blm.gov/wo/st/en/info/regulations/ Instruction_Memos and Bulletins/national_information/2012/ IB 2012-058.html.

Bureau of Land Management, 2014, Land use planning: Bureau of Land Management, accessed March 7, 2016, at http://www.blm.gov/wo/st/en/prog/planning/planning overview/frequently_asked_questions.html\%20-\%203.

Bureau of Land Management, 2016, Rapid Ecoregional Assessments: Bureau of Land Management, accessed March 7, 2016, at http://www.blm.gov/wo/st/en/prog/more/ Landscape_Approach/reas.html.

Clement, J.P., Belin, A.d'A., Bean, M.J., Boling, T.A., and Lyons, J.R., 2014, A strategy for improving the mitigation policies and practices of the Department of the Interior: Washington, D.C., Energy and Climate Change Task Force, accessed October 12, 2016, at https:/www.doi.gov/sites/ doi.gov/files/migrated/news/upload/Mitigation-Report-tothe-Secretary_FINAL_04_08_14.pdf.

Comer, Patrick, Crist, Patrick, Reid, Marion, Hak, Jon, Hamilton, Healy, Braun, David, Kittel, Gwen, Varley, Ian, Unnasch, Bob, Auer, Stephanie, Creutzburg, Megan, Theobald, David, and Kutner, Lynn, 2013, Mojave Basin and Range Rapid Ecoregional Assessment: Arlington, Va., NatureServe, for the Bureau of Land Management, 173 p.
Crooks, K.R., and Sanjayan, M.A., 2006, Connectivity conservation: New York, Cambridge University Press, 732 p.

Forman, R. T. T., 1995. Land mosaics: The ecology of landscapes and regions: New York, Cambridge University Press, $632 \mathrm{p}$.

Forman, R.T.T., and Godron, M., 1986, Landscape ecology: New York, John Wiley \& Sons, 620 p.

Franklin, J. F., Cromack, Kermit Jr., Denison, William, McKee, Arthur, Master, Chris, Sedell, James, Swanson, Fred, Juday, Glen, 1981, Ecological characteristics of oldgrowth douglas-fir forests: Portland, Oregon, U.S. Department of Agriculture Forest Service, General Technical Report PNW-GTR-118, accessed October 12, 2016, at http://www.fs.fed.us/pnw/pubs/pnw_gtr118.pdf?.

Freeman, O.E., Duguma, L.A., and Minang, P.A., 2015, Operationalizing the integrated landscape approach in practice: Ecology and Society, v. 20, no. 1, article 24.

Holling, C.S., 1973. Resilience and stability of ecological systems: Annual Review of Ecology and Systematics, v. 4, p. 1-23.

Karl, M.G. "Sherm," Kachergis, Emily, and Karl, J.W., 2016, Bureau of Land Management Rangeland Resource Assessment - 2011: Bureau of Land Management, National Operations Center, Denver, Colo., 112 p.

Noss, R.F., 1990, Indicators for monitoring biodiversity: A hierarchical approach: Conservation Biology, v. 4, no. 4, p. 355-364.

Omernik, J.M., 1987, Map supplement-Ecoregions of the conterminous United States: Annals of the Association of American Geographers, v. 77, no. 1, p. 118-125.

Parrish, J.D., Braun, D.P., and Unnasch, R.S., 2003, Are we conserving what we say we are? Measuring ecological integrity within protected areas: BioScience, v. 53, no. 9, p. $851-860$.

Pellant, Mike, Shaver, Patrick, Pyke, D.A., and Herrick, J.E., 2005, Interpreting indicators of rangeland health, version 4, Technical Reference 1734-6: Denver, Colo., Bureau of Land Management National Science and Technology Center, accessed October 12, 2016, at http://jornada.nmsu.edu/files/ IIRHv4.pdf.

Sayer, Jeffrey, 2009, Reconciling conservation and development: Are landscapes the answer?: Biotropica, v. 41, p. 649-652. 
Sayer, Jeffrey, Sunderland, Terry, Ghazoul, Jabouary, Pfund, Jean-Laurent, Sheil, Douglas, Meijaard, Erik, Venter, Michelle, Boedhihartono, A.K., Day, Michael, Garcia, Claude, van Oosten, Cora, and Buck, L.E., 2013, Ten principles for a landscape approach to reconciling agriculture, conservation, and other competing land uses: Proceedings of the National Academy of Sciences of the United States of America, v. 110, p. 8349-8356.

Society for Range Management, 1998, Glossary of terms used in range management (4th ed., edited by the Glossary Update Task Group, T.E. Bedell, Chairman): Society for Range Management, $32 \mathrm{p}$.

Taylor, P.D., Fahrig, Lenore, Henein, Kringen, and Merriam, Gray, 1993, Connectivity is a vital element of landscape structure: Oikos, v. 68, p. 571-573.
Toevs, G.R., Taylor, J.J., Spurrier, C.S., MacKinnon, W.C., and Bobo, M.R., 2011, Bureau of Land Management Assessment, Inventory, and Monitoring Srategy: For integrated renewable resources management: Bureau of Land Management, National Operations Center, accessed June 15, 2015, at http:// www.blm.gov/style/medialib/blm/wo/Information_Resources Management/policy/ib_attachments/2012.Par.53766.File.dat/ IB2012-080_att1.pdf.

Turner, M.G., Gardner, R.H., and O’Neill, R.V., 2001, Landscape ecology in theory and practice: pattern and process: New York, Springer, $403 \mathrm{p}$.

U.S. Department of the Interior, 2015, Implementing mitigation at the landscape-scale, Departmental manual part 600, chapter 6: Washington, D.C., Department of the Interior, accessed October 12, 2016, at https://www.doi.gov/sites/doi.gov/files/ uploads/TRS\%20and\%20Chapter\%20FINAL.pdf.

Publishing support provided by:

Denver Publishing Service Center, Denver, Colorado

For more information concerning this publication, contact:

Center Director, USGS Fort Collins Science Center

2150 Centre Ave., Bldg. C

Fort Collins, CO 80526-8118

(907) 226-9398

Or visit the Fort Collins Science Center Web site at: http://www.fort.usgs.gov/

This publication is available online at: https://doi.org/10.3133/ofr20161207 




\section{$\frac{\mathbb{3}}{3}$}

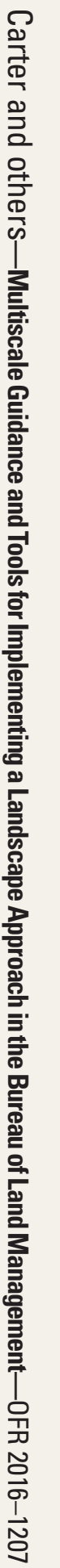

